Universidade de Brasília

Instituto de Ciências Biológicas

Departamento de Fitopatologia

Programa de Pós-Graduação em Fitopatologia

\title{
ASCOMICETOS ASSOCIADOS A PLANTAS DA RESERVA NATURAL DA EMBRAPA CERRADOS, DISTRITO FEDERAL
}

BRUNO CÉZAR PEREIRA DE SOUZA

Brasília - DF 


\title{
ASCOMICETOS ASSOCIADOS A PLANTAS DA RESERVA NATURAL DA EMBRAPA CERRADOS, DISTRITO FEDERAL
}

\author{
Dissertação apresentada à Universidade de \\ Brasília como requisito parcial para \\ obtenção de grau de Mestre em \\ Fitopatologia pelo programa de Pós- \\ graduação em Fitopatologia.
}

Orientador: Prof. José Carmine Dianese, PhD

Brasília - DF

2017 


\section{FICHA CATALOGRÁFICA}

Souza, Bruno Cézar Pereira de

Ascomicetos associados a plantas da reserva natural da Embrapa Cerrados, Distrito Federal / Bruno Cézar Pereira de Souza.

Brasília, 2017.

Número de páginas 148 p., il.

Dissertação de Mestrado. Programa de Pós-graduação em Fitopatologia, Universidade de Brasília, Brasília.

1. Micobiota, Cerrado, Taxonomia

I. Universidade de Brasília. PPG/FIT.

II. Ascomicetos associados a plantas da reserva natural da Embrapa Cerrados, Distrito Federal 


\section{AGRADECIMENTOS}

A Deus, que me permite o dom da vida e tem guiado meus passos com sua infinita misericórdia, que é de sempre! A Ele toda honra e toda glória!

A minha família, minha mãe Elza e meu pai Geraldo, pelo apoio incondicional, pelo amor, pela paciência e por serem pais maravilhosos. A meus irmãos, Sávio e Victor, companheiros de todas as horas, pelas alegrias e tristezas compartilhadas, juntamente com minhas queridas cunhadas Ariane e Viviane, que se tornaram irmãs, e as quais agradeço o carinho e apoio. A meus sobrinhos, Júlia, Pedro e ainda o que está na barriga da Vivi, por alegrarem a vida do tio. A minha avó Ceci, que me inspira a ser simples e feliz. A todos meus tios e tias, primos e primas, que convivendo comigo fraternalmente, me ajudam e animam.

A meus irmãos e irmãs da quinta comunidade da paróquia Imaculada Conceição de Sobradinho, pela força, oração e experiências que me colocaram pra frente desde o início do nosso convívio. Dentre eles agradeço especialmente a minha querida namorada, Pollyanna, por estar ao meu lado, me dando suporte e animando em tantos momentos difíceis.

A meus amigos, sempre presentes quando necessário, pelas conversas, desabafos, risadas, pescarias, reuniões, brassagens, e tudo mais que passamos juntos. Agradeço aos amigos que não estão mais presentes aqui na terra, mas certamente, desde o céu rogam por mim, em especial agradeço ao meu grande amigo César, que Deus o tenha.

A meus inicialmente colegas do grupo de micologia da UnB: Zuleide Chavez, Érica Souza, Leandro Agra, Débora Guterres, Sérgio Zambrano, Danilo Pinho, Denise Dornello, William Soares, Bianca Samay e Camilinha. Obrigado por tantos momentos vividos, pela experiência de trabalhar com vocês, pelo aprendizado, pelas coletas e pela grande ajuda neste e em tantos trabalhos. Vocês são uma equipe fantástica.

A meus colegas do departamento de fitopatologia: Daniela, Carina, Pollyane, Justino, Karina, Thaís, Tadeu, Camila, Cristiano, João, Pimentel, Kamila, Fernanda, Patrícia, Marcelo, 
Moana, Jamile, Sofya, Cléia, Elenice. Obrigado pelos momentos de alegria, nas aulas e nos momentos de diversão.

Aos professores do departamento de fitopatologia com quem pude conviver, primeiramente agradeço o meu orientador, José Carmine Dianese, pelo serviço prestado. Aos professores Danilo Pinho, Adalberto Café, Juvenil Cares, Cláudio Lúcio Costa, Helson Vale, Cléber Furlanetto, Carlos Uesugi e ás professoras Marisa Ferreira, Rita Carvalho e Alice Nagata. Obrigado pelo aprendizado.

Aos funcionários do departamento de fitopatologia: José César, Kamila Araújo, Ribamar Frazão, Arlindo, dona Donária, Marisa Sanchéz (in memoriam), pela ajuda e colaboração em vários serviços.

Ao doutor Alexei de Campos Dianese, pesquisador da Embrapa Cerrados, pela colaboração nos trabalhos, possibilitando as coletas realizadas na reserva da Embrapa Cerrados e dando todo apoio necessário. A diretoria da Embrapa Cerrados, por disponibilizar a reserva para a coleta.

A CAPES por financiar o presente projeto de pesquisa. A Universidade de Brasília pela oportunidade do mestrado, pela área e equipamentos cedidos á pesquisa.

A todos, que de alguma maneira me ajudaram na realização deste passo, meus sinceros agradecimentos. 
"Beati pauperes spiritu, quoniam ipsorum est regnum caelorum. Beati, qui lugent, quoniam ipsi consolabuntur. Beati mites, quoniam ipsi possidebunt terram. Beati, qui esuriunt et sitiunt iustitiam, quoniam ipsi saturabuntur. Beati misericordes, quia ipsi misericordiam consequentur. Beati mundo corde, quoniam ipsi Deum videbunt. Beati pacifici, quoniam filii Dei vocabuntur. Beati, qui persecutionem patiuntur propter iustitiam, quoniam ipsorum est regnum caelorum." 
Trabalho realizado junto ao Programa de Pós-graduação em Fitopatologia, Instituto de Ciências Biológicas, Universidade de Brasília, sob orientação do Prof. José Carmine Dianese, com apoio financeiro concedido pela CAPES.

ASCOMICETOS ASSOCIADOS A PLANTAS DA RESERVA NATURAL DA EMBRAPA CERRADOS, DISTRITO FEDERAL

\section{BRUNO CÉZAR PEREIRA DE SOUZA}

DISSERTAÇÃO APROVADA em 21/02/2017 por:

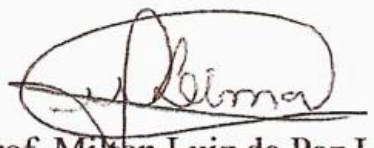

Prof. Miton Luiz da Paz Limass

Examinador externo

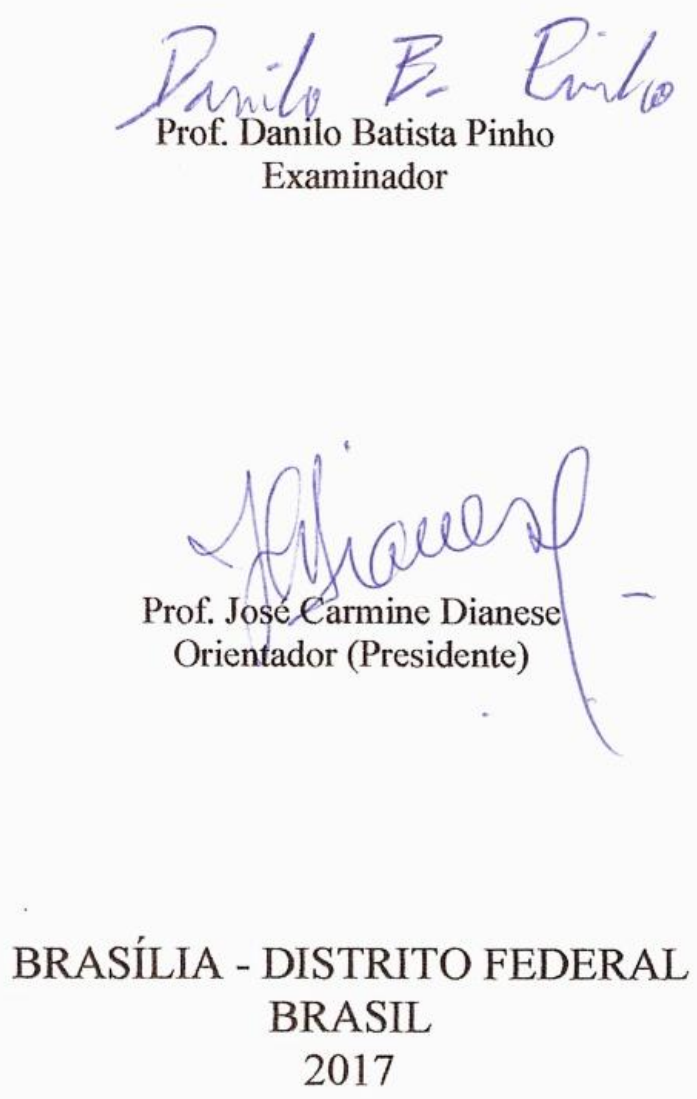




\section{SUMÁRIO}

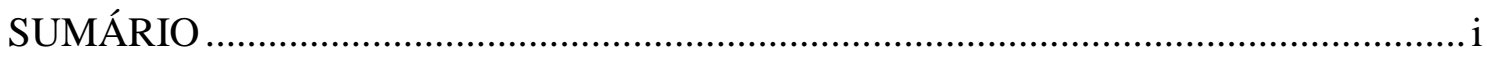

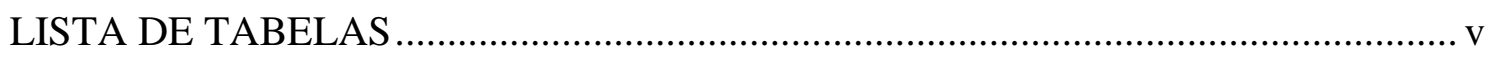

LISTA DE FIGURAS .................................................................................. vii

RESUMO

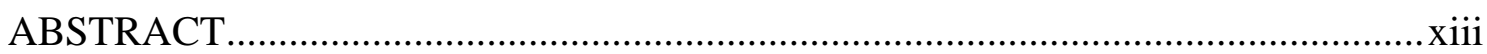

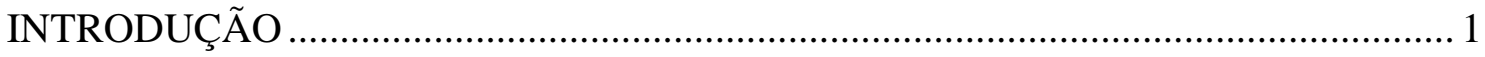

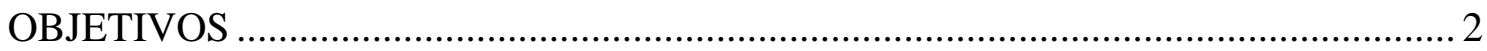

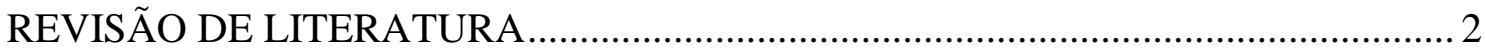

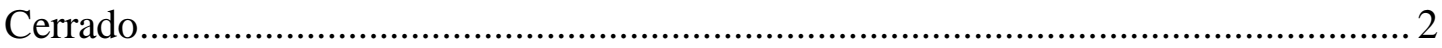

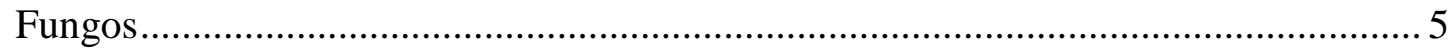

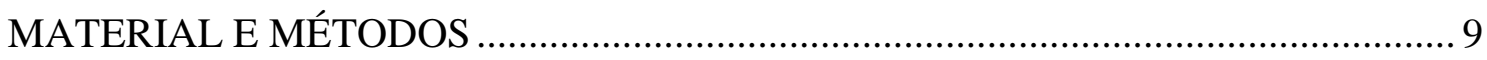

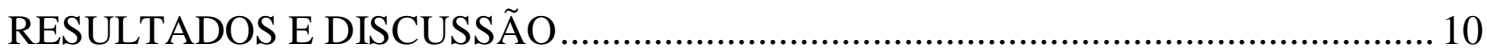

1. ASCOMICETOS FORMADORES DE PICNÍDIO E ESTROMA ........................... 10

1.1. Harknessia qualeae Furlan. \& Dianese, Mycol. Res. 102(1): 27 (1998) Figura 3 $(\mathrm{A}-\mathrm{D})$ 10

1.2. Lasmeniella machaerii (Henn.) Petr. \& Syd., Feddes Repert. Spec. Nov. Regni Veg., Beih. 42: 309 (1927). Figura 4 (A-F) 14

1.3. Phomopsis mangiferae S. Ahmad, Sydowia 8(1-6): 183 (1954). (Nova hospedeira $\left.\mathrm{n}^{\mathrm{o}} 1\right)$. Figura $5(\mathrm{~A}-\mathrm{E})$ 
2. ASCOMICETOS FORMADORES DE CONIDIÓFOROS LIVRES, ESPORODÓQUIO E SINÊMIO

2.1. Pseudocercospora rigidae Meir. Silva \& O.L. Pereira, Mycotaxon 102: 261 (2007). Figura $6(A-G)$

2.2. Trichomatoclava cerradensis G.F. Sepúlveda, Pereira-Carv. \& Dianese, Mycol. Res. 113(2): 262 (2009). Figura 7 (A-F)

2.3. Zasmidium (provável espécie nova $\mathrm{n}^{\circ}$ 1). Figura $8(\mathrm{~A}-\mathrm{G})$ 28

3. ASCOMICETOS SEXUADOS 32

3.1. Genera Incertae sedis. 32

3.1.1. Dothidasteromella (provável espécie nova nº 2). Figura 9 (A-I) 32

3.1.2. Ophiociliomyces (provável espécie nova $\mathrm{n}^{\mathrm{o}} 3$ ). Figura $10(\mathrm{~A}-\mathrm{F})$ 36

3.2. Membros da família Asterinaceae 39

3.2.1. Asterina salaciae Allesch. Hedwigia 36(4): 235 (1897). Figura 11 (A-G) ..... 39

3.2.3. Lembosia (provável espécie nova $\mathrm{n}^{\circ}$ 4). Figura 12 (A-G). 43

3.2.4. Uleothyrium amazonicum Petrak. Annls mycol. 27(5/6): 388 (1929). Figura 13 $(\mathrm{A}-\mathrm{G})$ .47

3.2.4.1. Forma conidial picnotírica: Septothyrella Höhn. Sber. Akad. Wiss. Wien, Math.-naturw. Kl., Abt. 1 120: 393 [15 repr.] (1911)

3.3. Membros da família Erysiphaceae 50

3.3.1. Erysiphe heringeriana (U. Braun ex Dianese \& A.C. Dianese) U. Braun \& S. Takam., Schlechtendalia 4: 20 (2000). Figura 14 (A-F) .50

3.4. Membros da família Micropeltidaceae 52 
3.5.1. Dothidasteroma psidii Inácio, Pereira-Carv., E.S.C. Souza \& Dianese, Mycotaxon 116: 28 (2011). Figura 17 (A-G) 60

3.5.2. Parmularia styracis Lév., Annls Sci. Nat., Bot., sér. 3 5: 286 (1846). Figura 18 (A-F) 64

3.6. Membros da família Phyllachoraceae 67

3.6.1. Apiosphaeria guaranitica (Speg.) Höhn., Sber. Akad. Wiss. Wien, Math.naturw. Kl., Abt. 1 118: 1218 [62 repr.] (1909). Figura 19 (A-E) 67

3.6.2. Phaeochorella parinari (Henn.) Theiss. \& Syd. , Annls mycol. 13(3/4): 405 (1915) Figura $20(\mathrm{~A}-\mathrm{I})$ 69

3.6.3. Phyllachora (provável espécie nova $\mathrm{n}^{\circ}$ 7). Figura $21(\mathrm{~A}-\mathrm{G})$ .72

3.6.4. Phyllachora (provável espécie nova $\mathrm{n}^{\circ}$ 8). Figura $22(\mathrm{~A}-\mathrm{G})$ .75

3.6.5. Phyllachora (provável espécie nova $\mathrm{n}^{\circ}$ 9). Figura 23 (A-F) .78

3.6.6. Phyllachora qualeae (Viégas) Bat. \& Peres, Atas Inst. Micol. Univ. Recife 4: 66 (1967). (Nova hospedeira $\left.n^{\circ} 2\right)$. Figura $24(\mathrm{~A}-\mathrm{F})$ .81

3.6.7. Phyllachora qualeae (Viégas) Bat. \& Peres, Atas Inst. Micol. Univ. Recife 4: 66 (1967). Figura $25($ A-G) .84

3.6.8. Phyllachora subcircinans Speg., Revista Argent. Hist. Nat. 1(6): 413 (1891). Figura $26(\mathrm{~A}-\mathrm{G})$ 86

3.6.9. Phyllachoraceae (provável gênero novo $\mathrm{n}^{\circ}$ 1). Figura 27 (A-E) ... .89

3.7. Membros da família Pseudoperisporiaceae .92 
3.8. Membros da família Saccardiaceae

3.8.1. Johansonia amadelpha (Syd.) Arx, Müller \& von Arx, Beitr. Kryptfl. Schweiz 11(no. 2): 212 (1962). (Nova hospedeira $\mathrm{n}^{\mathrm{o}} 3$ ). Figura 29 (A-F) 97

3.8.2. Johansonia chapadensis Crous, R.W. Barreto, Alfenas \& R.F. Alfenas, IMA Fungus 1(2): 119 (2010). (Nova hospedeira $\mathrm{n}^{\circ}$ 4). Figura 30 (A-F) 102

3.8.3. Johansonia setosa (G. Winter) Sacc., Syll. fung. (Abellini) 8: 785 (1889). (Nova hospedeira $\mathrm{n}^{\circ}$ 5). Figura $31(\mathrm{~A}-\mathrm{F})$. 104

3.8.4. Phillipsiella atra Cooke, Grevillea 7(no. 42): 48 (1878). (Nova hospedeira $\mathrm{n}^{\circ}$ 6). Figura $32(\mathrm{~A}-\mathrm{F})$ 106

3.8.5. Phillipsiella nigella W. Phillips \& Harkn., Bull. Calif. Acad. Sci. 1(no. 1): 23 (1884). (Nova hospedeira $\left.n^{\circ} 7\right)$. Figura 33 (A-F)

3.8.6. Vonarxella (provável espécie nova $\left.\mathrm{n}^{\circ} 11\right)$. Figura $34(\mathrm{~A}-\mathrm{F})$

CONCLUSÃO 


\section{LISTA DE TABELAS}

Tabela 1. Gêneros novos proveniente dos trabalhos na CMHUB. 8

Tabela 2. Características morfométricas das espécies de Harknessia conhecidas na literatura.

Tabela 3. Características morfométricas das espécies de Lasmeniella relatadas em Fabaceae.

Tabela 4. Características morfométricas de espécies de Phomopsis relatadas no Brasil.

Tabela 5. Características morfométricas de espécies de Pseudocercospora em plantas do gênero Palicourea (Rubiaceae). .23

Tabela 6. Características morfométricas da espécie Trichomatoclava cerradensis. 26

Tabela 7. Características morfométricas de espécies de Zasmidium encontradas em Rubiaceae. 30

Tabela 8. Características morfométricas das espécies de Dothidasteromella. 34

Tabela 9. Características morfométricas da espécie tipo de Ophiociliomyces e do espécime encontrado sobre Emmotum nittens.

Tabela 10. Características morfométricas das espécies de Asterina em plantas da família Celastraceae. 41

Tabela 11. Características morfométricas das espécies de Lembosia relatadas no Brasil. ..... 45

Tabela 12. Características morfométricas das espécies de Uleothyrium. 48

Tabela 13. Características morfométricas das espécies de Stomiopeltis relatadas no Brasil. . 54

Tabela 14. Características morfométricas das espécies de Dictyopeltis. .58

Tabela 15. Comparação das espécies de Dothidasteroma com a encontrada sobre Psidium laurottenum. 62

Tabela 16. Características morfométricas de espécies de Parmularia relatadas no Brasil..... 65

Tabela 17. Características morfométricas das espécies de Phaeochorella. .70 
Tabela 18. Características morfométricas de espécies da família Phyllachoraceae presentes em plantas da família Proteaceae. .73

Tabela 19. Características morfométricas das espécies de Phyllachora reportadas em Machaerium spp. .76

Tabela 20. Características morfométricas de espécies de Phyllachora relatadas em espécies de Mimosa. 79

Tabela 21. Características morfométricas das espécies do gênero Phyllachora associadas a hospedeiras da família Vochysiaceae. 82

Tabela 22. Características morfométricas de espécies de Phyllachora reportadas no Brasil em plantas da família Myrtaceae. .87

Tabela 23. Características morfométricas de espécies de Phyllachora em plantas do gênero Salacia. .90

Tabela 24. Características morfométricas de espécies de Nematostoma. .94

Tabela 25. Características morfométricas das espécies de Johansonia. .99

Tabela 26. Características morfométricas das espécies de Phillipsiella. 108

Tabela 27. Características morfométricas das espécies de Vonarxella. 113 


\section{LISTA DE FIGURAS}

Figura 1. Placa indicativa da Reserva ecológica Mirante, na Embrapa CPAC....................... 4

Figura 2. Espécies novas resultante do trabalho na CMHUB............................................ 7

Figura 3. A-D. Harknessia qualae em folhas de Qualea grandiflora (Vochysiaceae) (UBMicol. Col. 23374). A. Lesões foliares. B. Lesão com borda marrom a marrom escura e centro mais claro, contendo os conidiomas escuros. C. Conidioma sub- a intraepidérmico imerso no mesófilo da hospedeira. D. Conídio maduro apendiculado. 13

Figura 4. E-F. Lasmeniella machaerii em folhas de Machaerium sp. (Fabaceae) (UB-Micol. Col. 23378). A. Lesões foliares. B. Estromas. C. Corte transversal do conidioma estromático. D. Células conidiogênicas. E-F. Conídios.

Figura 5. A-E. Phomopsis mangiferae em folhas de Qualea grandiflora (Vochysiaceae) (UB-Micol. Col. 23379). A. Folha com lesão. B. Detalhe da lesão com picnidiomas. C. Corte transversal mostrando picnidioma subcuticular. D. Conidióforos ramificados. E. Conídios alfa. 20

Figura 6. A-G. Pseudocercospora rigidae em folhas de Palicourea rigida (Rubiaceae) (UBMicol. Col. 23398). A. Lesões foliares. B. Detalhe da lesão com borda escura e centro claro. C. Corte transversal contendo estroma imerso no mesófilo da planta. D. Conidióforos. E. Células conidiogênicas. F-G. Conídios. 24

Figura 7. A-F. Trichomatoclava cerradensis em folhas de Emmotum nitens (Icacinaceae) (UB-Micol. Col. 23371). A. Tricomas colonizados. B-C. Conídios e hifas cobrindo o tricoma. D. Conidióforos. E-F. Conídios e células conidiogênicas.

Figura 8. A-G. Zasmidium sp. em folhas de Tocoyena formosa (Rubiaceae) (UB-Micol. Col. 23394). A. Lesões foliares. B. Detalhe da lesão com centro acinzentado e bordas arroxeadas. C. Corte transversal com estroma eruptivo, parcialmente superficial. D. Conidióforos. E. Células conidiogênicas. F-G. Conídios. 31 
Figura 9. A-I. Dothidasteromella sp. em folhas de Connarus suberosus. (Connaraceae) (UBMicol. Col. 23388). A. Colônias na folha. B. Detalhe de uma colônia com bordas roxas. C. Aberturas dos ascomas (poros). D. Hifas na borda das colônias. E. Conte transversal contendo estroma. F. Ascos bitunicados. G-I. Ascósporos 35

Figura 10. A-F. Ophiociliomyces sp. em folhas de Emmotum nitens (Icacinaceae) (UBMicol. Col. 23371). A-B. Ascomas entre tricomas. C. Ascoma redondo com textura angularis. D. Corte transversal do ascoma. E. Asco parafisados. F. Asco e ascósporos. ........ 38 Figura 11. A-G. Asterina salaciae em folhas de Salacia crassifolia (Celastraceae) (UBMicol. Col. 23395). A-B. Colônias sobre a folha. C. Conidiomas arredondados com abertura estelar a irregular. D. Micélio com hifopódios. E. Corte transversal mostrando a posição dos ascos. F. Asco. G. Ascósporo. 42

Figura 12. A-G. Lembosia sp. em folhas de Baccharis sp. (Asteraceae) (UB-Micol. Col. 23381). A. Colônia sobre a folha. B. Tiriotécios com abertura em fenda e em forma de Y. C. Corte transversal mostrando a disposição dos ascos. D. Hifopódios. E. Ascos parafisados. FG. Ascósporos. .46

Figura 13. A-G. Uleothyrium amazonicum em folhas de Salacia crassifolia (Celastraceae) (UB 23395). A-B. Colônias sobre a folha. C. Ascomas e hifas. D. Corte transversal mostrando a posição dos ascos. E. Ascos e ascósporos. F-G. Conídios do anamorfo Septothyrella.

Figura 14. A-F. Erysiphe heringeriana em folhas de Qualea grandiflora (Vochysiaceae) (UB-Micol. Col. 23379). A. Colônias ocupando grande parte da folha. B-C. Ascomas. D. Ascomas com apêndices. E. Apêndices uncinulados. F. Asco e ascósporos 51

Figura 15. A-G. Stomiopeltis sp. em folhas de Psittacanthus robustus (Loranthaceae) (UBMicol. Col. 23391). A-B. Colônias sobre a folha. C. Ascoma dimidiado com abertura 
irregular. D. Corte transversal mostrando posição do asco e pseudoparáfises. E-F. Ascos. G. Ascósporos. .55

Figura 16. A-F. Dictyopeltis sp. em folhas de Qualea grandiflora (Vochysiaceae) (UBMicol. Col. 23379). A. Ascomas sobre a folha. B. Ascoma com bordas mais claras. C. Corte transversal mostrando a disposição dos ascos. D. Ascoma e ascos. E. Ascos. F. Ascósporos.59 Figura 17. A-G. Dothidasteroma psidii em folhas de Psidium laruotteanum. (Myrtaceae) (UB-Micol. Col. 23390). A. Folha com lesões na face adaxial e abaxial. B. Detalhe da lesão. C. ascoma. D. Corte transversal mostrando colonização do fungo nas células foliares. E. Ascos imaturos. F-G. Ascos e ascósporos.

Figura 18. A-F. Parmularia styracis em folhas de Styrax ferrugineus (Stiracaceae) (UBMicol. Col. 23396). A. Lesões foliares. B. Ascoma. C. Corte transversal mostrando lóculos. D. Haustórios. E. Ascos parafisados. F. Ascósporos. 66

Figura 19. A-E. Apiosphaeria guaranitica em folhas de Handroanthus ochraceus (Bignoniaceae) (UB-Micol. Col. 23393). A. Folha com lesões. B. Pseudoestorma. C. Corte transversal contendo peritécios. D. Ascos. E. Ascósporos. 68

Figura 20. A-I. Phaeochorella parinari em folhas de Parinari obtusifolia (Chrysobalanaceae) (UB-Micol. Col. 23397). A. Lesões foliares. B. Estroma na folha. C. Corte transversal contendo lóculo. D. Ascos parafisados. E-H. Ascos. I. Ascósporo. .71

Figura 21. A-G. Phyllachora sp. em folhas de Roupala montana (Proteaceae) (UB-Micol. Col. 23375). A. Lesões foliares. B. Estromas. C. Corte transversal contendo lóculos. D. Ascos parafisados. E-F. Ascos. G. Ascósporos. .74

Figura 22. A-G. Phyllachora sp. em folhas de Machaerium sp. (Fabaceae) (UB-Micol. Col. 23378). A. Lesões foliares. B. Estroma com cirros. C. Corte transversal contendo lóculos. DF. Ascos e ascósporos. G. Ascósporos provenientes dos cirros. .77 
Figura 23. A-F. Phyllachora sp. em folhas de Mimosa sp. (Fabaceae) (UB-Micol. Col. 23392). A-B. Lesões foliares. C. Corte transversal contendo peritécio. D. Ascos parafisados. E-F. Ascos e ascósporos 80

Figura 24. A-F. Phyllachora qualae em folhas de Qualea grandiflora (Vochysiaceae) (UBMicol. Col. 23376). A. Lesões foliares. B. Estroma na parte abaxial da folha. C. Corte transversal da folha contendo peritécios. D. Fase espermacial. E. Ascos parafisados. F. Asco e ascósporos. .83

Figura 25 A-G. Phyllachora qualeae em folhas de Qualea parviflora (Vochysiaceae) (UBMicol. Col. 23377). A. Lesões foliares. B. Estroma na parte abaxial da folha. C. Corte transversal da folha mostrando o estroma multilocular. D-E. Ascos parafisados. F. Asco. G. Ascósporos.

Figura 26. A-G. Phyllachora subcircinans em folhas de Psidium sp. (Myrtaceae) (UBMicol. Col. 23380). A. Lesões foliares. B. Pseudoestromas. C-D. Corte transversal mostrando inserção do pseudoestroma e disposição de ascos parafisados. E-F. Ascos. G. Ascósporos gutulados. .88

Figura 27. A-E. Phyllachoraceae em folhas de Salacia crassifolia (Clelastraceae) (UBMicol. Col. 23399). A. Lesões foliares. B-C. Corte transversal contendo lóculos anfígenos e tecido foliar modificado. D. Ascos parafisados. E. Asco e ascósporos. 91

Figura 28. A-G. Nematostoma sp. em folhas de Clusia sp. (Clusiaceae) (UB-Micol. Col. 23372). A. Ascoma na folha. B. Ascoma com setas. C. Corte transversal mostrando himênio e posição das setas. D. Subiculum. E. Ascos. F-G. Ascósporos. .96

Figura 29. A-F. Johansonia amadelpha. em folhas de Qualea grandiflora (Vochysiaceae) (UB-Micol. Col. 23374). A-B. Ascomas e setas na face abaxial da folha. C. Corte transversal mostrando a disposição dos ascos em paliçada. D. Seta. E. Ascos. F. Ascósporos 101 
Figura 30. A-F. Johansonia chapadiensis. em folhas de Byrsonima sp. (Malpighiaceae) (UB-Micol. Col. 23373). A. Ascoma com setas ao redor. B. Corte transversal mostrando ascos em paliçada. C. Ascoma e ascos. D. Seta. E-F. Ascos e ascósporos 103

Figura 31. A-F. Johansonia setosa. em folhas de Siagrus flexuosa (Arecaceae) (UB-Micol. Col. 23382). A. Face abaxial da folha parasitada pelo fungo. B. Detalhe do ascoma com numerosas setas ao redor. C. Corte transversal mostrando diposição dos ascos em paliçada. D. Seta. E. Ascos. F. Ascósporos. 105

Figura 32. A-F. Phillipsiella atra em folhas de Byrsonima (Malpighiaceae) (UB-Micol. Col. 23373). A. Ascoma sobre a folha. B. Corte transversal mostrando disposição dos ascos em paliçada. C. Ascoma rodeado de micélio. D-E. Ascos. F. Ascósporos. 109

Figura 33. A-F. Phillipsiella nigella em folhas de Qualea grandiflora (Vochysiaceae) (UBMicol. Col. 23374). A. Colônia na parte abaxial da folha. B. Ascoma sobre a folha. C. Corte transversal mostrando disposição dos ascos em paliçada. D. Micélio. E. Ascos. F. Ascósporos.

Figura 34. A-F. Vonarxella sp. em folhas de Qualea grandiflora (Vochysiaceae) (UBMicol. Col. 23379). A. Colônia na face abaxial da folha. B. Ascoma e micélio. C. Corte transversal mostrando disposição dos ascos em paliçada. D. Ascoma rodeado por micélio. E. Ascos. F. Ascósporos. 


\section{RESUMO}

SOUZA, Bruno Cézar Pereira de. Ascomicetos associados a plantas da reserva natural da Embrapa Cerrados, Distrito Federal. 2017. 148p. Dissertação (Mestrado em Fitopatologia) - Universidade de Brasília, Brasília, DF.

Considerando a carência de conhecimento das espécies fúngicas no Cerrado, este trabalho de identificação de espécies objetivou prover informação sobre os microfungos da reserva naturtal da Embrapa Cerrados. Foram realizadas coletas no período de julho de 2015 a março de 2016, onde 136 amostras de plantas foram coletadas. As amostras foram depositadas na Coleção Micológica do Herbário da Universidade de Brasília (CMHUB). Foram documentados ascomicetos parasitando plantas provenientes de 15 famílias botânicas distintas. Foram descritos seis ascomicetos conidiais, sendo três celomicetos e três hifomicetos, além de 28 ascomicetos sexuados, totalizando 34 ascomicetos. Dentre estes há uma provável espécie nova de hifomiceto pertencente à Zasmidium, um provável gênero novo de Phyllachoraceae e dez prováveis espécies novas de ascomicetos sexuados que foram apenas parcialmente definidas em termos taxonômicos, são elas: Ophiociliomyces, Dothidasteromella, Lembosia, Stomiopeltis, Nematostoma, Dyctyopeltis, três espécies de Phyllachora e uma de Vonarxella. Também foram registrados seis novos hospedeiros para fungos já conhecidos.

Palavras chaves: Fungi, Cerrado, Diversidade, Micobiota, Taxonomia.

Orientador: José Carmine Dianese, Universidade de Brasília. 


\begin{abstract}
SOUZA, Bruno Cézar Pereira de. Ascomycetes associated to plants of the Embrapa Cerrados natural reserve, Federal District. Dissertation (Masters in Phytopathology) University of Brasília, Brasília, DF.

Considering the lack of knowledge of fungal species in the Cerrado, this study on species identification aimed to provide information about the microfungi found in the natural reserve of Embrapa Cerrados. Samples were collected from July 2015 to March 2016, when 136 plant samples were obtained. The samples were deposited in the Mycological Collection of the Herbarium of the University of Brasília (CMHUB). Ascomycetes were documented parasitizing plants from 15 different botanical families. Six conidial ascomycetes were described, being three coelomycetes and three hyphomycetes, besides 28 sexual ascomycetes, totalizing 34 ascomycetes. Among these there is a probable new species of hyphomycete belonging to Zasmidium, a probable new genus of Phyllachoraceae and ten probable new species of sexual ascomycetes that were only partially defined in taxonomic terms, which are: Ophiociliomyces, Dothidasteromella, Lembosia, Stomiopeltis, Nematostoma, Dyctyopeltis, three species of Phyllachora and one of Vonarxella. Six new hosts were also registered for fungi already known.
\end{abstract}

Keywords: Fungi, Cerrado, Diversity, Mycobiota, Taxonomy. 


\section{INTRODUÇÃO}

O bioma Cerrado originalmente ocupava cerca de um quarto do território brasileiro, 1.783.200 $\mathrm{km}^{2}$, restando atualmente apenas $20 \%$ do bioma original, ou seja, $356.630 \mathrm{~km}^{2}$ preservados em reservas oficiais e particulares (Scariot, Sousa-Silva e Felfili, 2005), entre elas a reserva natural da Embrapa Cerrados em Planaltina-DF, com uma área aproximada de 700 ha (Parron, Sousa-Silva e Camargo, 1998). A flora do Cerrado possui uma elevada riqueza de espécies, com plantas herbáceas, arbustivas, arbóreas e cipós, totalizando mais de 12000 espécies de plantas, com alto nível de endemismo, tornando-o a savana tropical mais diversa do mundo (Klink e Machado, 2005; Sano, Almeida e Ribeiro, 2008).

O Cerrado também constitui um hábitat para diversas espécies de fungos e a Universidade de Brasília (UnB) com o projeto "Fungos do Cerrado", iniciado em 1992, avançou de forma significativa quanto ao conhecimento da micobiota do cerrado (Dianese, Medeiros e Santos, 1997; Dianese, 2000). Com isso veio a expansão da Coleção Micológica do Herbário da UnB, onde atualmente estão depositadas mais de 23.000 exsicatas, representativas da ampla diversidade constituída pelos microfungos do Cerrado. Entre elas estão 154 espécies e 15 gêneros novos descritos a partir de 1993 (Dianese et al., 1993a), no entanto com a maior parte do material ainda sendo caracterizado e identificado.

Os fungos têm amplo papel nos ecossistemas, funcionando em associações antagônicas ou parasíticas, com praticamente todos os grupos de seres vivos, inclusive como parasitas ou hiperparasitas de fungos fitopatogênicos. Atualmente conhece-se cerca de 130 mil espécies fúngicas (Roskov et al., 2017). Estimativas recentes do número total de espécies de fungos sugerem que a estimativa amplamente utilizada de 1,5 milhão de espécies (Hawksworth e Rossman, 1997; Hawksworth, 2012) é baixa, e números de até 5,1 milhões têm sido propostos nos últimos anos (Blackwell, 2011). Estudos exaustivos, especialmente nos trópicos, são de extrema importância para melhorar a eficácia dessas estimativas. Em estudos mais recentes 
sugeriu-se que o número estimado de fungos seja mantido como pelo menos 1,5 milhões, podendo chegar ao dobro, ou seja, 3 milhões (Hawksworth, 2012).

No Reino Fungi, destaca-se o Filo Ascomycota, grupo de fungos com maior número de espécies que abrange grande número das espécies fitopatogênicas. Eles apresentam uma fase dicariótica em seu ciclo de vida e um estado diploide curto, o que o aproxima do filo Basidiomycota (Piepenbring, 2015).

O reconhecimento de que muitas espécies novas ainda têm de ser encontradas é de fundamental importância para fitopatologistas, que continuam a enfrentar doenças causadas por fungos anteriormente desconhecidos ou pouco estudados. Hábitats inexplorados com seu arsenal de fungos desconhecidos também são de interesse para todos aqueles que procuram novos organismos para uso em controle biológico, biotecnologia, na indústria farmacêutica, produção de ácidos orgânicos entre outros (Hawksworth e Rossman, 1997).

\section{OBJETIVOS}

Dada à importância da biodiversidade do Cerrado e a carência de conhecimento das espécies fúngicas presentes no mesmo, este trabalho de identificação de espécies objetiva prover informação sobre os microfungos da reserva ecológica da Embrapa Cerrados e em outras áreas de Cerrado do DF, no intuito de catalogar e descrever as espécies encontradas e contribuir para a proposição de espécies anteriormente deconhecidas pela ciência, além de ampliar o acervo da Coleção Micológia do Herbário UB (Col. Micol.-UB).

\section{REVISÃO DE LITERATURA}

\section{Cerrado}

No bioma Cerrado, há uma diversidade de paisagens constituídas por diferentes fitofisionomias, associados a fatores físicos, ecológicos e fisiográficos, que determinaram sua grande riqueza florística (Cochrane et al., 1985; Mendonça et al., 1998). Bioma é uma 
subdivisão biológica que reflete, entre outros, o caráter fisionômico e ecológico da vegetação. Consiste de uma comunidade biótica e geográfica com características que permitem serem reconhecidas na prática. Os Biomas podem corresponder a regiões climáticas bem definidas, ainda que outros controles ambientais sejam algumas vezes importantes. Neles, estão presentes, além das formações vegetais, todo um conjunto de organismos interagindo com a vegetação e com os demais componentes do meio ambiente. Tipicamente, biomas distintos são reconhecidos para todas as principais regiões climáticas no mundo, enfatizando as adaptações dos organismos aos seus ambientes, por exemplo, bioma das florestas tropicais pluviais, bioma dos desertos, bioma das tundras (Oxford, 2004).

O cerrado sensu lato é um Bioma complexo podendo ser subdividido até em um conjunto de Biomas, que podem ser assim classificados: campo tropical (campo limpo), a savana (campo sujo, campo cerrado e cerrado sensu stricto) e a floresta estacional (cerradão) (Batalha, 2011).

Algumas características comuns a todo o Bioma Cerrado sensu lato são: a presença de solos antigos, profundos, ácidos, de baixa fertilidade e ricos em alumínio. O clima é estacional, prevalecendo um período chuvoso, de outubro a março, seguido por um período seco, de abril a setembro. A precipitação média anual é de $1500 \mathrm{~mm}$, com temperaturas médias entre 22 a $27^{\circ} \mathrm{C}$ (Klink e Machado, 2005).

Sua vegetação possui uma grande diversidade, com mais de 12000 espécies de plantas, com alto nível de endemismo (mais de 4000 plantas). As plantas estão distribuídas em 170 famílias, sendo as mais representativas (aproximadamente $50 \%$ da riqueza florística do Cerrado) as famílias Fabaceae, Asteraceae, Orchidaceae, Poaceae, Rubiaceae, Myrtaceae, Malpighiaceae, Lythraceae, Euphobiaceae e Melastomataceae (Sano, Almeida e Ribeiro, 2008). 
O Cerrado é considerado um "hotspot" para a conservação da biodiversidade no mundo (Myers et al., 2000), já que grande parte do mesmo, cerca de $80 \%$, já foi destruída ou modificada pela ação antrópica (Scariot, Sousa-Silva e Felfili, 2005).

A Embrapa Cerrados, localizada em Planaltina-DF, é uma das 47 Unidades da Empresa Brasileira de Pesquisa Agropecuária (Embrapa), é um centro de pesquisa ecorregional cujo foco é o desenvolvimento sustentável da agricultura no Bioma Cerrado. Nesta unidade, há cerca de 700 ha de reservas, que foram criadas com o intuito de preservar áreas com diferentes fitofisionomias, oferecer condições para o desenvolvimento de trabalhos de pesquisa sobre o cerrado sensu lato, proteger os recursos hídricos e edáficos da área, além de promover a educação ambiental (Parron, Sousa-Silva e Camargo, 1998). A reserva ecológica Mirante, local onde foram coletadas as amostras presentes neste trabalho, tem a área de 244,2 ha e apresenta diversas fitofisionomias, tais como, campo limpo, cerrado stricto sensu e mata de galeria (Figura 1).

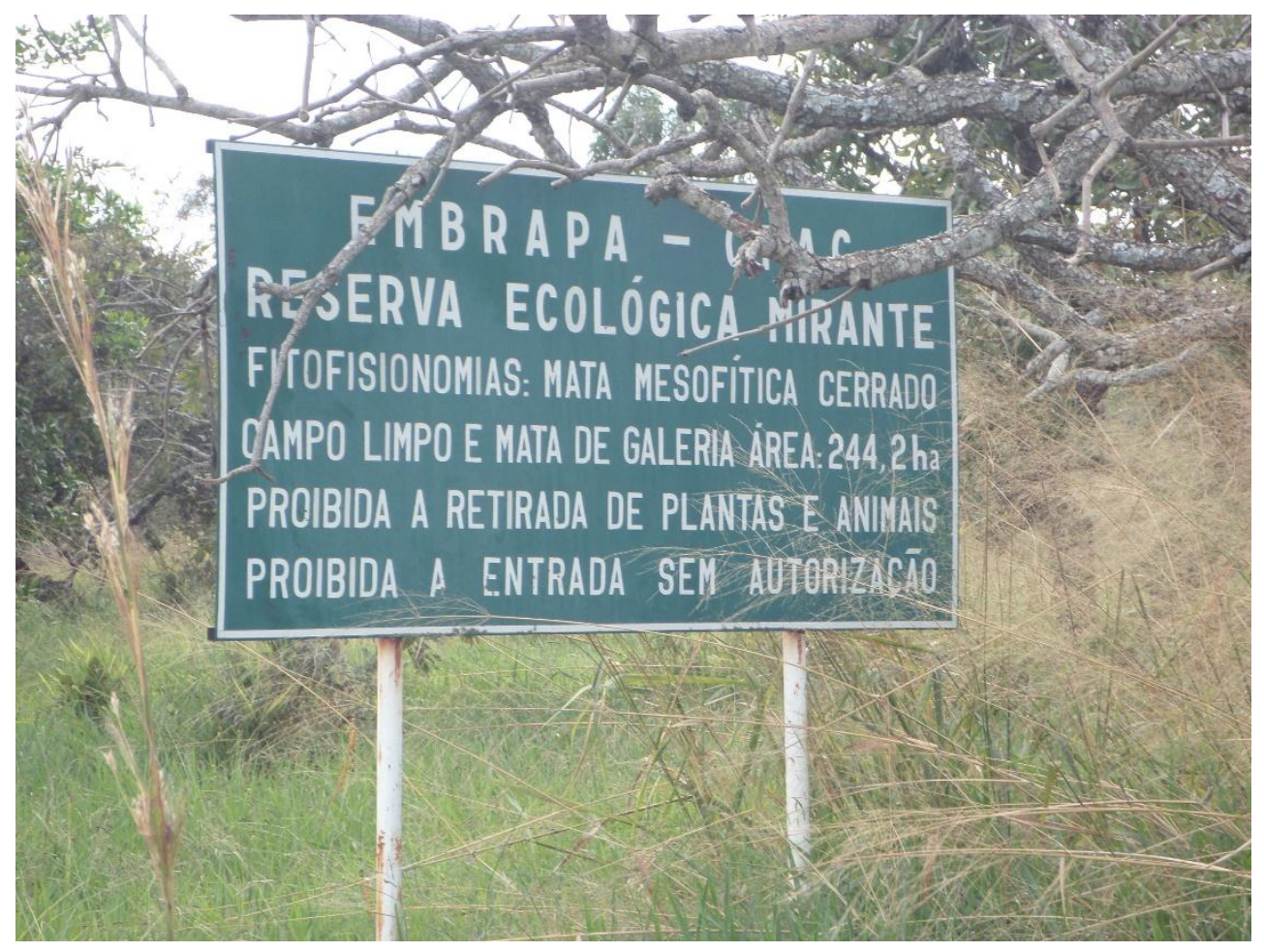

Figura 1. Placa indicativa da Reserva ecológica Mirante, na Embrapa CPAC. 


\section{Fungos}

Os fungos são importantes em todos os ecossistemas naturais porque são decompositores de matéria orgânica morta, contribuindo na ciclagem de carbono e nitrogênio; formam micorrizas com as raízes das plantas, auxiliando em seu desenvolvimento; são parasitas que reduzem a abundância de espécies dominantes de plantas e animais, contribuindo para a manutenção da biodiversidade; servem como alimento para diversos insetos e animais, inclusive humanos; são importantes para a indústria farmacêutica pois servem de base para vários medicamentos (penicilina, ciclosporina, etc.); são produtores de enzimas usadas na fabricação de detergentes, vitaminas e vários outros produtos utilizados na indústria; são parasitas de insetos e plantas daninhas (controle biológico), mas podem também afetar a saúde humana (micotoxinas e várias doenças em pacientes imunodeprimidos), podem ser parasitas de plantas cultivadas e animais, afetar alimentos e edifícios (mofo de paredes e sistemas de condicionamento de ar) (Piepenbring, 2015).

Os fungos sensu lato constituem-se em um grupo tipicamente polifilético e são distribuídos nos Reinos Protozoa, Chromista (Stramenopila sensu Dick 2001) e Fungi (fungos verdadeiros). Em uma definição ampla, os fungos são organismos eucarióticos, heterotróficos, osmotróficos, com talo em geral filamentoso com hifas ramificadas formando o micélio, às vezes, são unicelulares (leveduras), os quais se reproduzem por gemulação ou cissiparidade e por meio de esporos (ascósporos). Entre os Fungi (fungos verdadeiros), os organismos apresentam mitocôndrias com cristas achatadas, talo haploide ou dicariótico, parede contendo microfibrilas de quitina cimentadas por $\beta$-glucanas. Apresentam reprodução sexuada ou assexuada (Kirk et al., 2008).

Dentro do reino Fungi o filo mais importante, ou maior, é o Ascomycota. Estes são fungos em sua maioria com micélio apocítico (septado), cujos septos contêm poros simples. Formam seus esporos meióticos, os ascósporos, dentro de estruturas em forma de sacos, 
chamadas de ascos. Os ascósporos são haplóides e darão origem a hifas que normalmente formarão o talo somático do fungo, ou micélio. Em alguns casos o talo pode ser leveduriforme e unicelular (Alexopoulos, Mins e Blackwell, 1996).

Muitos ascomicetos em sua fase sexuada produzem os ascos dentro ou sobre corpos de frutificação complexos, os ascomas, que podem ser apotécios (em forma de taça), peritécios (em forma de garrafa), cleistotécios (esférico, sem ostíolo, abertura através de fendas), casmotécios (globóide, sem ostíolo, com himênio e ascos em fascículo), ascostroma (estroma fúngico com um ou mais lóculos onde os ascos se desenvolvem), pseudotécio (lóculo isolado envolto por tecido estromático), histeriotécio (em forma de barco), tiriotécio (em forma de escudo), gminotécio (formado por hifas frouxas) e ascóforo, que é uma hifa semelhante a uma estipe que suporta os ascos (Luz, 2009).

$\mathrm{Na}$ fase assexuada os ascomicetos já foram designados como fungos imperfeitos, Fungi imperfecti, deuteromicetos, Deuteromycetes, Deuteromycotina (Kirk et al., 2008). São também divididos em dois grupos para fins didáticos, os hifomicetos e os celomicetos. Os celomicetos produzem conídios em corpos (ditos conidiomas) fechados ou cobertos, como picnídios, acérvulos, picnotírios e estromas (Sutton, 1980). Já os hifomicetos produzem conídios em hifas que em geral se diferenciam em conidióforos, isolados ou agregados em sinêmios ou esporodóquios, os quais sustentam uma ou mais células conidiogênicas, que por sua vez produzem os conídios (Seifert et al., 2011).

O estudo da micobiota do Cerrado iniciou-se em 1895 com os trabalhos de Paul Hennings, que descreveu fungos dos estados de Goiás e São Paulo (Hennings, 1895; Hennings, 1902b). Posteriormente merecem destaques as contribuições de Augusto Chaves Batista, Ahmés Pinto Viégas, Spegazzini, entre outros, que deram uma grande contribuição para o conhecimento da micobiota do Cerrado (Dianese, Medeiros e Santos, 1997). A partir de 1993, quando pesquisadores da Universidade de Brasília deram sua primeira contribuição 
com a descrição de Phleosporella flavio-moralis Dianese, Sutton \& Tessmann (Dianese, Sutton e Tessman, 1993), com o suporte da Fundação Banco do Brasil, passou a haver um esforço continuo e direcionado visando a descrição da micodiverdidade do Cerrado, que até o presente resultou na descrição de 107 espécies novas (Figura 2) e 18 gêneros novos (Tabela 2). Como consequência a Coleção Micológica do Herbário UB (CMHUB) que em 1993 continha apenas 342 espécimes tombados, acumula atualmente mais de 23.300 exsicatas, um grande número delas contendo mais de uma espécie de fungo.

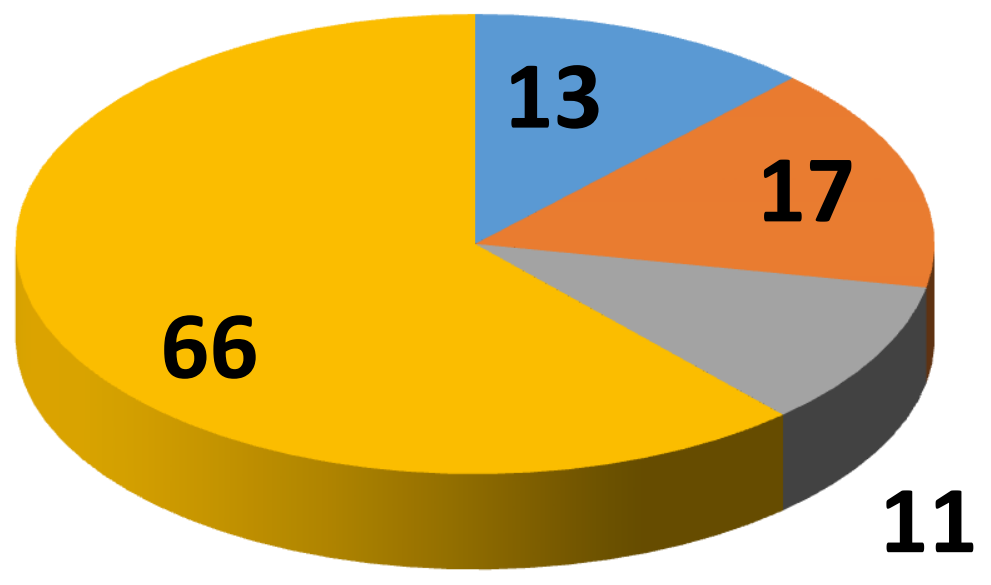

Ascomiceto sexuado

Ascomiceto assexuado (Celomiceto)
Basidiomiceto

Ascomiceto assexuado (Hifomiceto)

Figura 2. Espécies novas resultante do trabalho na CMHUB.

O trabalho de descrição das espécies do Cerrado possui atualmente uma ampla literatura publicada, que mostra a revelação de:

A). Novas espécies de ascomicetos em sua forma sexual (Dianese, Inácio e DorneloSilva, 2001; Souza et al., 2008; Pereira-Carvalho et al., 2009; Inácio et al., 2012; Souza Armando, Chaves e Dianese, 2015; Firmino et al., 2016);

B). Novos Erysiphales (Dianese e Dianese, 1995; Braun et al., 2006); 
C). Novas espécies de fungos anamorfos de picnídio e acérvulo (Dianese, Sutton e Tessman, 1993; Dianese et al., 1993b; Dianese, Tessmann e Furlanetto, 1994; Furlanetto e Dianese, 1998; Inácio e Dianese, 1999);

D). Novas espécies de fungos cercosporóides (Dianese e Câmara, 1994; Medeiros e Dianese, 1994; Dianese, Hasan e Sobhian, 1996; Inácio et al., 1996; Furlanetto e Dianese, 1999; Inácio e Dianese, 1999; Dianese, Costa e Dianese, 2008; Hernandéz-Gutiérrez e Dianese, 2008; Hernández-Gutiérrez e Dianese, 2009; Dianese et al., 2014; HernándezGutiérrez, Braun e Dianese, 2014; Hernández-Gutiérrez e Dianese, 2014b; a; HernandézGutiérrez et al., 2015);

E). Novas espécies e gêneros de fungos tricomáticos (Furlanetto e Dianese, 1996; Inácio e Dianese, 1998; Dornelo-Silva e Dianese, 2003; Inácio e Dianese, 2006; Dornelo-Silva, Pereira-Carvalho e Dianese, 2007; Pereira-Carvalho et al., 2009; Cantrell et al., 2011);

F). Novas espécies de fungos causadores de ferrugens (Dianese et al., 1993a; Dianese, Buriticá e Hennen, 1994; Dianese e Santos, 1995; Rezende e Dianese, 2001; 2002; 2003b; a; Souza et al., 2015).

Tabela 1. Gêneros novos proveniente dos trabalhos na CMHUB.

\begin{tabular}{|c|c|c|c|}
\hline $\begin{array}{c}\text { Acesso } \\
\text { (UB Col. Micol.) }\end{array}$ & Gêneros & Epíteto específico & Autores \\
\hline 3917 & Batistopsora $^{1}$ & crucis-filli & Dianese, Medeiros \& Santos \\
\hline 12116 & Chaetothyriomyces ${ }^{2}$ & brasiliensis & $\begin{array}{l}\text { Pereira-Carv., Dorn-Silva, } \\
\text { Inácio \& Dianese }\end{array}$ \\
\hline 19589 & Echnoconidiophorum ${ }^{2}$ & cerradense & Pereira-Carv. \& Dianese \\
\hline 9926 & Globoconidiopis $^{2}$ & cerradensis & $\begin{array}{l}\text { Sepúlv.-Chavera, } \\
\text { Carv. \& Dianese }\end{array}$ \\
\hline 8387 & Globoconidium $^{2}$ & cerradense & $\begin{array}{l}\text { Sepúlv.-Chavera, Pereira- } \\
\text { Carv. \& Dianese }\end{array}$ \\
\hline 15086 & Helminthosporiomyces ${ }^{2}$ & cerradensis & $\begin{array}{l}\text { Sepúl.-Chavera, Pereira-Carv. } \\
\text { \& Dianese }\end{array}$ \\
\hline 4474 & Kimuromyces ${ }^{3}$ & cerradensis & $\begin{array}{l}\text { Dianese, Santos, Medeiros \& } \\
\text { Furlanetto }\end{array}$ \\
\hline 9851 & Phaeoidiomyces $^{4}$ & qualeae & Dorn.-Silva \& Dianese \\
\hline 18404 & Phaeostilbelloides $^{5}$ & velloziae & $\begin{array}{l}\text { Armando, Z.M. Chaves \& } \\
\text { Dianese }\end{array}$ \\
\hline 19439 & Phragmoconidium $^{2}$ & cerradense & $\begin{array}{l}\text { Sepúlv.-Chavera, } \\
\text { Carv. \& Dianese }\end{array}$ \\
\hline 1940 & Plurispermiopsis $^{6}$ & cerradensis & $\begin{array}{l}\text { Pereira-Carv., Inácio } \quad \& \\
\text { Dianese }\end{array}$ \\
\hline
\end{tabular}


Continuação.

\begin{tabular}{|c|c|c|c|}
\hline 19442 & Trichomatoclava ${ }^{2}$ & cerradensis & $\begin{array}{l}\text { Sepúlv.-Chavera, Pereira- } \\
\text { Carv. \& Dianese }\end{array}$ \\
\hline 9851 & Trichomatomyces ${ }^{4}$ & cerradensis & Dorn.-Silva \& Dianese \\
\hline 19597 & Trichomatosphaera ${ }^{2}$ & cerradensis & $\begin{array}{l}\text { Pereira-Carv., } \\
\text { Chavera, \& Dianese }\end{array}$ \\
\hline 10042 & Trichosporodochium ${ }^{4}$ & cerradensis & Dorn.-Silva \& Dianese \\
\hline 8849 & Velloziomyces ${ }^{5}$ & ramosiconidialis & $\begin{array}{l}\text { Armando, Z.M. Chaves \& } \\
\text { Dianese }\end{array}$ \\
\hline 14594 & Vesiculohyphomyces $^{2}$ & cerradensis & $\begin{array}{l}\text { Armando, Pereira-Carv. \& } \\
\text { Dianese }\end{array}$ \\
\hline 8438 & Wilmia $^{7}$ & brasiliensis & Dianese, Inácio \& Dorn.-Silva \\
\hline
\end{tabular}

1(Dianese et al., 1993a); ${ }^{2}$ (Pereira-Carvalho et al., 2009); ${ }^{3}$ (Dianese et al., 1995); ${ }^{4}$ (Dornelo-Silva e Dianese, 2004); ${ }^{5}$ (Souza Armando, Chaves e Dianese, 2015); ${ }^{6}$ (Pereira-Carvalho, Inácio e Dianese, 2010); ${ }^{7}$ (Dianese, Inácio e Dornelo-Silva, 2001).

\section{MATERIAL E MÉTODOS}

Cinco coletas foram realizadas na Reserva do Mirante da Embrapa Cerrados no período de julho de 2015 a março de 2016. Após cada coleta, o material vegetal foi prensado para secagem durante 5 a 7 dias. Em seguida o material foi rotulado, exsicatado e congelado a $20^{\circ} \mathrm{C}$ para o controle de insetos e ácaros. Os materiais foram identificados incialmente com o uso de microscópio estereoscópico e microscopia de luz, cortes foram feitos em criomicrótomo (LEICA, CM 1850) e lâminas semipermanentes foram preparadas. Antes do corte, o material herborizado foi mergulhado em solução aquosa de álcool $10 \%$ e Tween- 20 a 0,1 $\%$ por aproximadamente 4 horas para hidratação. As espessuras dos cortes variaram de 10 a $30 \mu \mathrm{m}$, dependendo das condições do material. A morfometria das estruturas fúngicas e a foto-documentação foram realizadas em microscópio de luz Leica DM 2500, provido de câmara digital Leica DFC 490, acoplada a um computador, contendo o programa Leica Qwin - Plus, para a documentação fotográfica e a obtenção dos dados morfométricos dos espécimes.

Para a determinação do gênero e espécie fúngica, utilizou-se as chaves de identificação e literatura pertinente para cada fungo estudado, partindo de chaves mais generalistas, tais como: Hanlin (1998), Von Arx e Müller (1975), Batista (1959) para ascomicetos sexuados, 
Seifert et al. (2011) para hifomicetos e Sutton (1980) para celomicetos. A verificação dos nomes científicos e nomes das autoridades foram realizadas no Index Fungorum (Index Fungorum, 2017). Para verificação dos registros de fungos por planta hospedeira, utilizou-se a página do United State Department of Agriculture (Farr e Rossman, 2016).

Para comparação morfométrica foram escolhidas as espécies mais próximas descritas em literatura acessível, sendo que algumas espécies, devido o grande número de registros, foram comparadas com espécimes descritas no mesmo local (país) ou mesma família de hospedeiras.

\section{RESULTADOS E DISCUSSÃO}

\section{ASCOMICETOS FORMADORES DE PICNÍDIO E ESTROMA}

1.1. Harknessia qualeae Furlan. \& Dianese, Mycol. Res. 102(1): 27 (1998) Figura $3(\mathrm{~A}-\mathrm{D})$

Lesões anfígenas, 2,5-7 mm, com o centro marrom-claro e bordas de marrom a violeta. Hifas septadas, hialinas a marrom-clara. Conidiomas picnidiais a estromáticos, imersos, eruptivos, 133-180 $\mu \mathrm{m}$, globosos a subglobosos, uniloculares, marrons a marrom-claros, parede com textura angularis, 6-10,5 $\mu \mathrm{m}$ de largura. Células conidiogênicas $6-7 \times 2,5-4 \mu \mathrm{m}$, discretas, determinadas, sem ramificações, ampuliformes, originadas a partir de células da camada interior da parede do conidioma. Conidióforos reduzidos a células conidiogênicas. Conídios formados de forma holoblástica, 12-23 × 6,5-10 $\mu \mathrm{m}$, acrógenos, elipsoides a fusóides, marrom-claros, com paredes espessas e 2 apêndices. Os apêndices apicais filiforme, hialinos, $17-45 \times 1-2 \mu \mathrm{m}$. Os apêndices basais quando presentes atingem $0,5-1 \mu \mathrm{m}$ de comprimento, em geral estão ausentes e são constituídos pelos restos da célula conidiogênica. A fase sexual não foi observada. 
Espécime examinado: em folhas de Qualea grandiflora (Vochysiaceae), BRASIL, Distrito Federal, Planaltina, Reserva do Mirante, EMBRAPA CPAC; 21/06/2015, Bruno Cézar Pereira de Souza \#10, UB (Col. Micol.) 23374.

O gênero Harknessia caracteriza-se por ter conidioma picnidial estromático e conídios castanho-escuros com apêndices basais em forma de tubo, podendo mostrar estrias longitudinais e secessão rexolítica, com apêndices basais, ou laterais, filiformes, flexuosos (Crous et al., 2012). Dentro da família Vochysiaceae são conhecidas duas espécies de Harknessia, uma em Qualea grandiflora (H. qualeae) e outra em Salvertia convallaliodora (H. salvertiana), ambas somente na fase assexual (Furlanetto e Dianese, 1998). Os membros do gênero Harknessia têm uma distribuição mundial e são comumente associados a folhas e ramos (galhos) de uma ampla gama de hospedeiros, atualmente totalizam 62 espécies (Nag Raj, 1993; Sankaran, Sutton e Minter, 1995; Farr e Rossman, 2001). A espécie tipo é Harknessia eucalypti Cooke (Cooke e Harkness, 1881).

Tendo em vista a similaridade morfométrica e a hospedeira em comum (Tabela 2), conclui-se que o material estudado trata-se da espécie Harknessia qualeae relatada em Qualea grandiflora, na Estação Ecológica das Águas Emendadas, Brasília, Distrito Federal, Brasil (Furlanetto e Dianese, 1998). 
Tabela 2. Características morfométricas das espécies de Harknessia conhecidas na literatura.

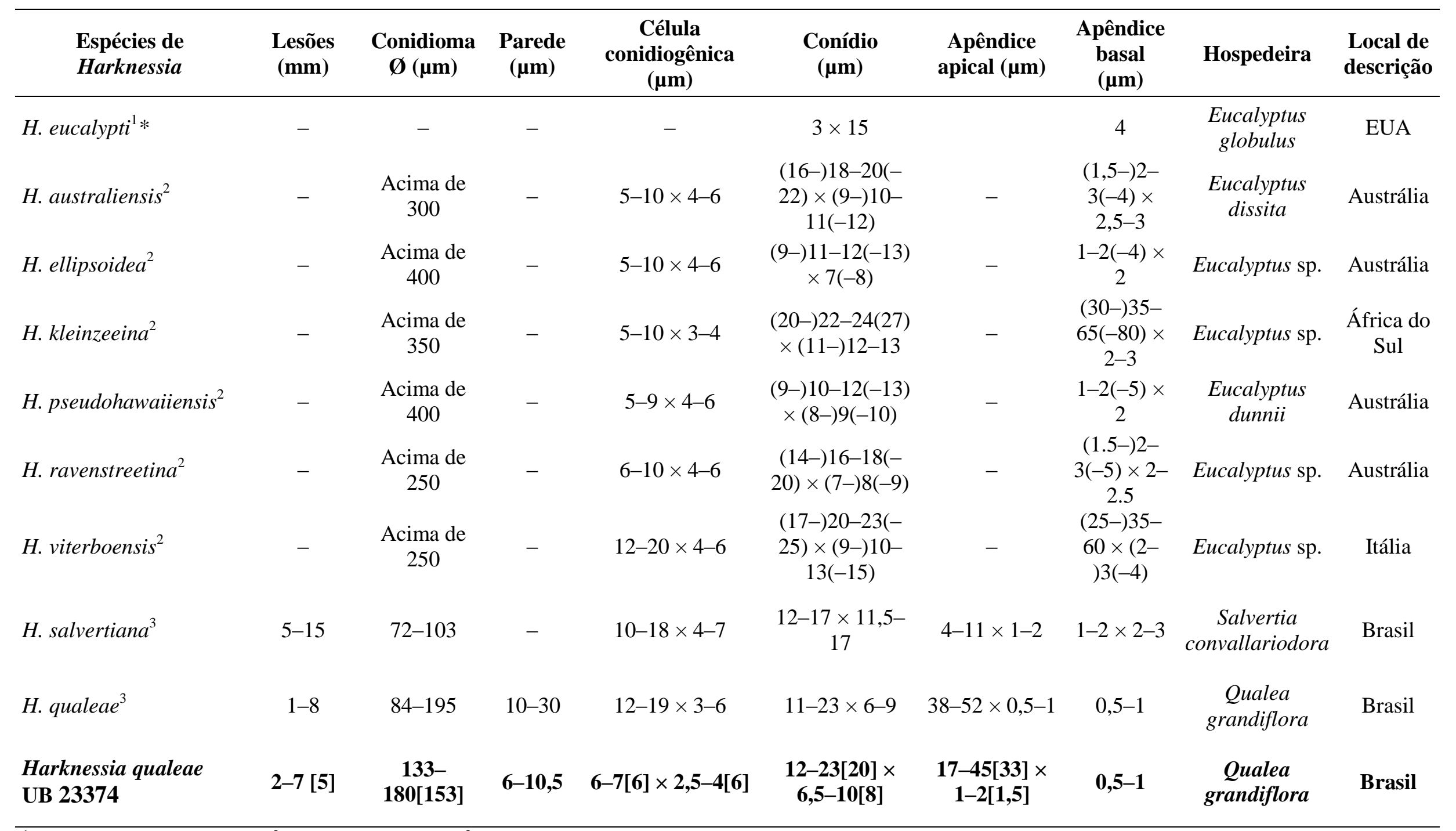

${ }^{1}$ (Cooke e Harkness, 1881); ${ }^{2}$ (Crous et al., 2012); ${ }^{3}$ (Furlanetto e Dianese, 1998). 


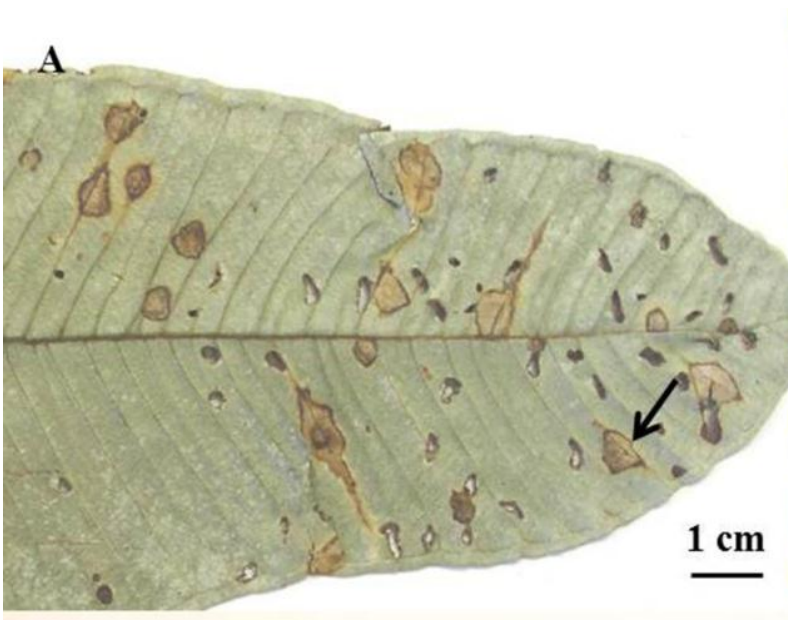

C

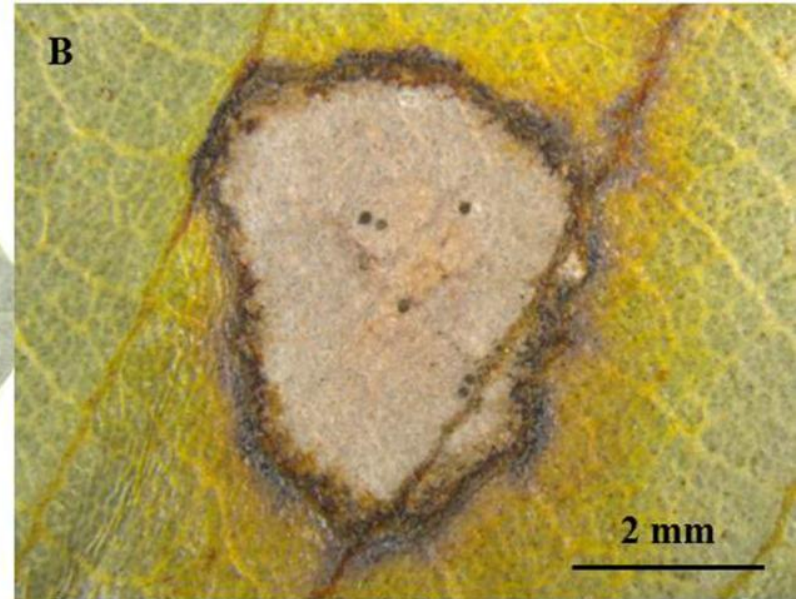

D

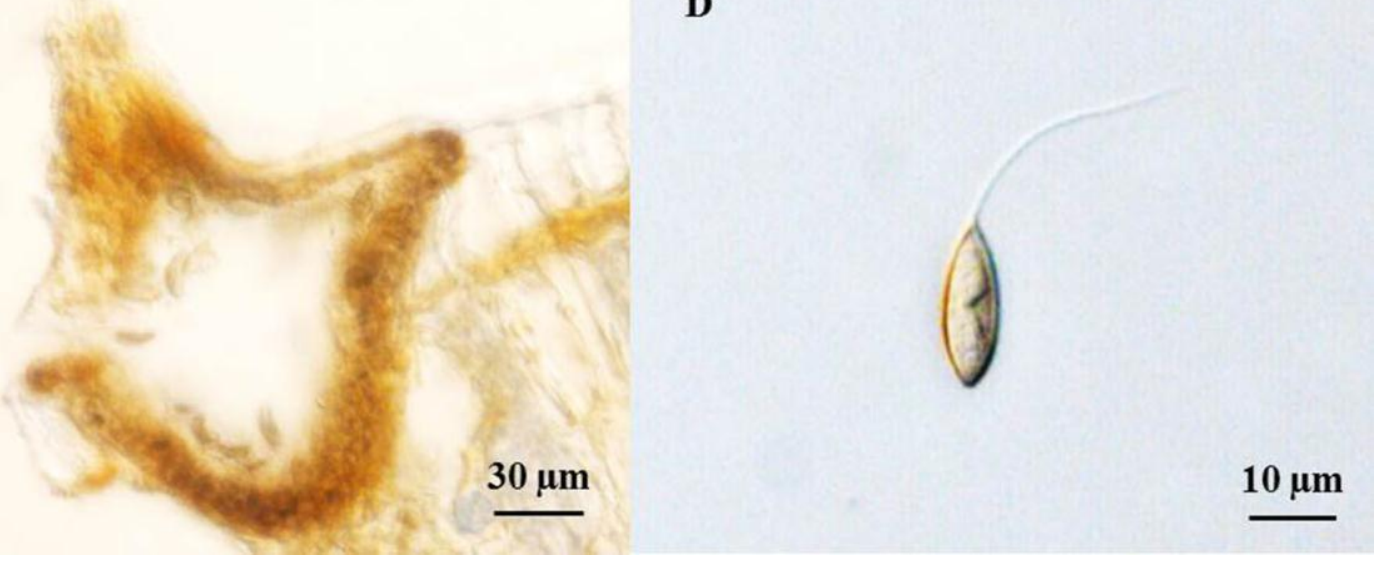

Figura 3. A-D. Harknessia qualae em folhas de Qualea grandiflora (Vochysiaceae) (UBMicol. Col. 23374). A. Lesões foliares. B. Lesão com borda marrom a marrom escura e centro mais claro, contendo os conidiomas escuros. C. Conidioma sub- a intraepidérmico imerso no mesófilo da hospedeira. D. Conídio maduro apendiculado. 
1.2. Lasmeniella machaerii (Henn.) Petr. \& Syd., Feddes Repert. Spec. Nov. Regni Veg., Beih. 42: 309 (1927). Figura 4 (A-F)

Lesões epifilas, enegrecidas, medindo 0,5-3 mm de diâmetro. Conidiomas estromáticos, subepidérmicos, multiloculares, separados ou agregados, 120-300 $\mu \mathrm{m}$ de diâmetro. Células conidiogênicas 10-20 × 1,5-2 $\mu \mathrm{m}$, holoblásticas, dilatadas na base e afiladas no ápice, lageniformes e formadas a partir de células mais internas da parede do conidioma. Conídios globosos, irregulares, 7-8 $\mu \mathrm{m}$ de diâmetro, asseptados, com paredes espessas, lisas, com base truncada, marrom-escuros, com poro central, 1-2,5 $\mu \mathrm{m}$.

Espécime examinado: em folhas de Machaerium sp. (Fabaceae), BRASIL, Distrito Federal, Planaltina, Reserva do Mirante, EMBRAPA CPAC; 21/06/2015, Bruno Cézar Pereira de Souza \#22, UB (Col. Micol.) 23378.

A espécie tipo do gênero Lasmeniella é L. guaranitica (Speg.) Petrak \& Sydow e tem como basiônimo Lasmenia guaranitica Speg. (1886). Atualmente o gênero possui 13 espécies, sendo que quatro hospedeiras da família Fabaceae (Index Fungorum, 2017): L. congoensis (Har. \& Pat.) Petr. \& Syd., L. dalbergiae Petr., L. machaerii (Henn.) Petr. \& Syd. e L. pterocarpi Petr. A espécie L. dalbergiae Petrak foi encontrada associada a Pseudothis, cujos peritécios frequentemente estão presentes no mesmo estroma, sendo esta a fase sexuada de Lasmeniella (Petrak, 1929). Lasmeniella sp. foi relatada em Machaerium villosum juntamente com sua fase sexuada Pseudothis coccodes e uma espécie de Phyllachora em Lavras, Minas Gerais (Beserra Júnior e Pfenning, 2006).

A espécie de Lasmeniella encontrada neste trabalho foi comparada com as demais descritas na literatura (Tabela 3) e verificou-se que a mesma apresenta estromas semelhantes a L. guaranitica, conidiomas e células conidiogênicas maiores que todas as outras. Quanto o tamanho dos conídios, o espécime em estudo não apresenta diferença em relação aos outros espécimes. A espécie L. machaerii possui apenas os dados do tamanho de conídios para 
comparação, sendo os mesmos são semelhantes ao da espécie em estudo, que também possui a hospeira do mesmo gênero (Machaerium sp.). Lasmenia machaerii, atual sinonímia de Lasmeniella machaerii, foi relatada por P. Hennings, parasitando folhas vivas de Machaerium lanatum, na Serra da Cantareira, São Paulo (Hennings, 1902a). Portanto, pode-se inferir que se trata da mesma espécie.

Tabela 3. Características morfométricas das espécies de Lasmeniella relatadas em Fabaceae.

\begin{tabular}{|c|c|c|c|c|c|c|}
\hline $\begin{array}{l}\text { Espécie de } \\
\text { Lasmeniella }\end{array}$ & $\begin{array}{c}\text { Estroma } \\
(\mathbf{m m})\end{array}$ & $\begin{array}{c}\text { Conidioma } \\
(\mu \mathrm{m})\end{array}$ & $\begin{array}{c}\text { Célula } \\
\text { conidiogênica } \\
(\mu \mathrm{m})\end{array}$ & $\begin{array}{c}\text { Conídio } \\
\emptyset(\mu \mathrm{m})\end{array}$ & $\begin{array}{c}\text { Poro } \\
\text { central } \\
\varnothing(\mu \mathrm{m})\end{array}$ & Local \\
\hline L. congoensis $^{1}$ & $0,5-1$ & 200 & - & $6 \times 8$ & - & Congo \\
\hline L. dalbergiae ${ }^{2}$ & $0,3-1,5$ & $100-250$ & $8 \times 1,5-2$ & $6-7,5$ & $1,5-2$ & Filipinas \\
\hline L. guaranitica ${ }^{1} *$ & $1-3$ & $150-200$ & $7-8 \times 1$ & $5-7$ & - & Brasil \\
\hline L. machaerii ${ }^{1}$ & - & - & - & $6-8$ & - & Brasil \\
\hline L. pterocarpi ${ }^{2}$ & $0,3-1$ & $100-200$ & $6-10 \times 2$ & $6-8(-10)$ & $2,5-4$ & $\begin{array}{c}\text { África do } \\
\text { Sul }\end{array}$ \\
\hline $\begin{array}{l}\text { L. machaerii } \\
\text { UB } 23378\end{array}$ & $0,5-3[1,5]$ & $120-300[230]$ & $\begin{array}{c}13-20[15,5] \times \\
1,5-2[2]\end{array}$ & $7-8[7,5]$ & $1-2,5[1,5]$ & Brasil \\
\hline
\end{tabular}

${ }^{1}$ (Petrak e Sydow, 1927); ${ }^{2}$ (Petrak, 1929); *Espécie tipo. Os valores entre [] referem-se ao valor médio encontrado. 

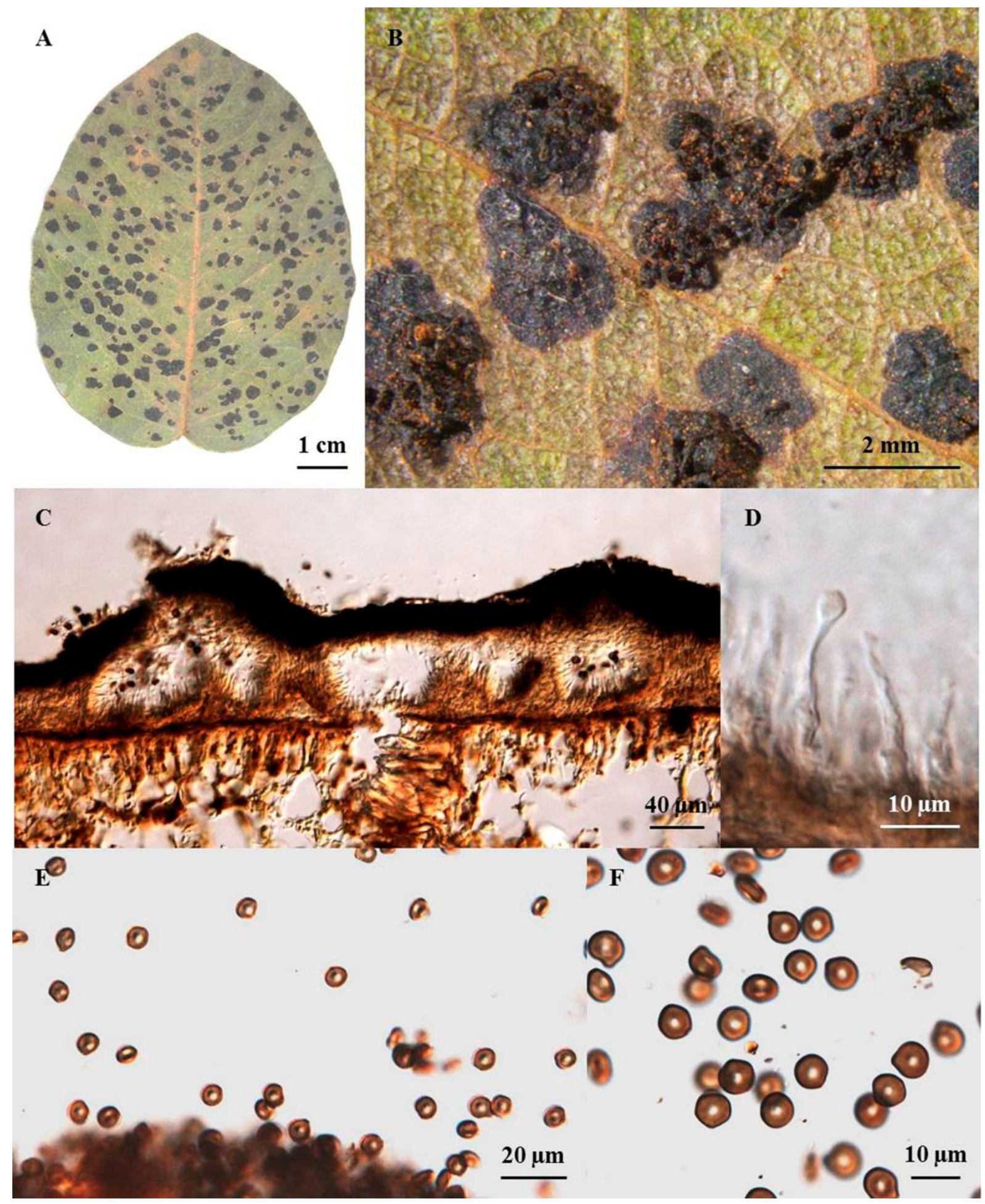

Figura 4. E-F. Lasmeniella machaerii em folhas de Machaerium sp. (Fabaceae) (UB-Micol. Col. 23378). A. Lesões foliares. B. Estromas. C. Corte transversal do conidioma estromático. D. Células conidiogênicas. E-F. Conídios. 
1.3. Phomopsis mangiferae S. Ahmad, Sydowia 8(1-6): 183 (1954). (Nova hospedeira $\left.n^{\circ} 1\right)$. Figura $5(\mathrm{~A}-\mathrm{E})$

Lesões epífilas, elipsóides, marom-claras, isoladas ou confluentes, dispersas, 2,5-9 mm de diâmetro. Picnídios subcuticulares, 130,5-261 $\mu \mathrm{m}$ de diâmetro, membranosos, dispersos, glabros, globosos a elipsoides. Conidióforos lageniformes, simples, hialinos, 7-9 $\times 2-2,5 \mu \mathrm{m}$. Conídios alfa elipsóides, com pontas lanceoladas, hialinos, lisos, bigutulados, 3,5-7,5 × 2-2,5 $\mu \mathrm{m}$. Conídios beta ausentes.

Espécime examinado: em folhas de Qualea grandiflora (Vochysiaceae), BRASIL, Distrito Federal, Planaltina, Reserva do Mirante, EMBRAPA CPAC; 21/06/2015, Bruno Cézar Pereira de Souza \#23, UB (Col. Micol.) 23379.

O gênero Phomopsis tem como espécie tipo P. lactucae (Sacc.) Bubák e apresenta as seguintes características: conidioma negro, ostiolado, contendo fiálides cilíndricas, alongadas, que podem produzir dois tipos de conídios hialinos, não septados, denominados alfa e beta, podendo haver conídios intermediários; os conídios alfa são geralmente fusóides, gutulados e os conídios beta filiformes e não gutulados; os conidióforos são hialinos, ramificados, ocasionalmente curtos, com 1 a 2 septos e a conidiogênese fialídica, enteroblástica (Sutton, 1980; Rehner e Uecker, 1994).

Atualmente o gênero Phomopsis apresenta mais de 900 registros e várias espécies possuem ampla gama de hospedeiros (Mostert et al., 2001; Crous, 2005), por conseguinte, para descrição de uma nova espécie sugere-se uma abordagem polifásica, incluindo morfologia, filogenia molecular, patogenicidade e virulência de espécies biológicas isoladas (Santos e Phillips, 2009; Diogo, Santos e Phillips, 2010), como recomendado para outros gêneros, tais como Colletotrichum, Fusarium e Pencillium (Hawksworth, 2011; Schroers et al., 2011; Udayanga et al., 2011). 
O espécime em estudo foi comparado com espécies de Phomopsis relatadas no Brasil (Tabela 4). Com relação ao tamanho do picnidioma $P$. cajani, $P$. mangiferae, $P$. obscurans apresentaram similaridade com o espécime encontrado sobre Qualea grandiflora. Já em relação ao tamanho de conidióforos, somente $P$. mangiferae se aproximou do espécime estudado. Quanto o tamanho dos conídios alfa, $P$. anacardii, $P$. cajani, $P$. citri, $P$. lantanae, P. longicolla, $P$. mangiferae, $P$. obscurans, $P$. rhizophorae, possuem tamanhos semelhantes aos da espécie em questão. Notou-se que $P$. mangiferae possui várias características semelhantes ao espécime estudado, podendo ser a mesma espécie. Trata-se do primeiro relato do gênero Phomopsis em plantas da família Vochysiaceae. Devido o relato da ampla gama de hospedeiros deste fungo e da grande similaridade morfométrica com outros espécimes, convém que esse espécime em estudo seja confirmado futuramente com trabalhos envolvendo caracterização molecular para melhor comparação dentro do gênero. 
Tabela 4. Características morfométricas de espécies de Phomopsis relatadas no Brasil.

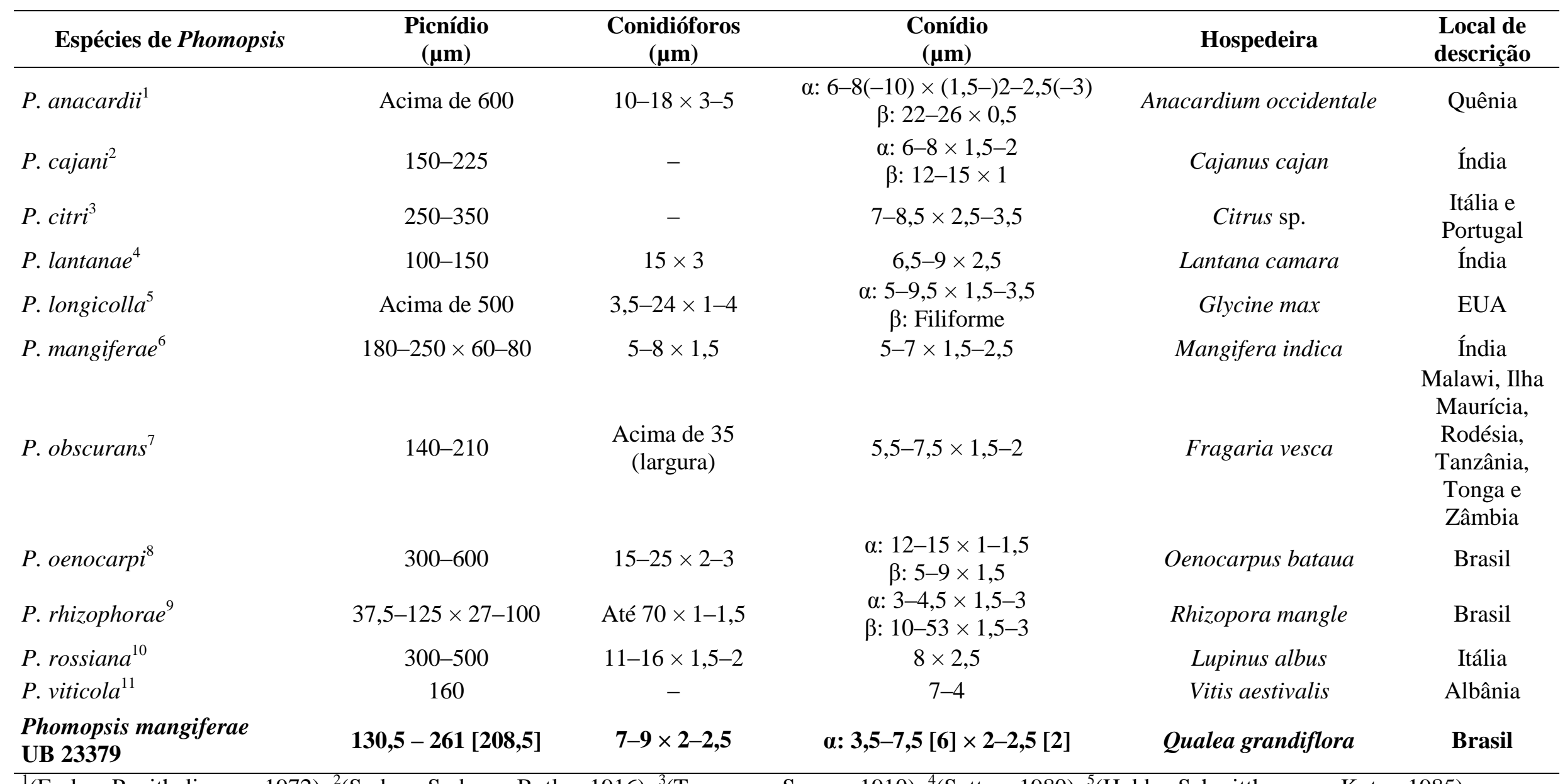

${ }^{1}$ (Early e Punithalingam, 1972); ${ }^{2}$ (Sydow, Sydow e Butler, 1916); ${ }^{3}$ (Traverso e Spessa, 1910); ${ }^{4}$ (Sutton, 1980); ${ }^{5}$ (Hobbs, Schmitthenner e Kuter, 1985);

${ }^{6}$ (Petrak e Ahmad, 1954); ${ }^{7}$ (Sutton, 1965); ${ }^{8}$ (Batista, Bezerra e Castro, 1964); ${ }^{9}$ (Batista et al., 1955); ${ }^{10}$ (Saccardo, 1906); ${ }^{11}($ Saccardo, 1915). 

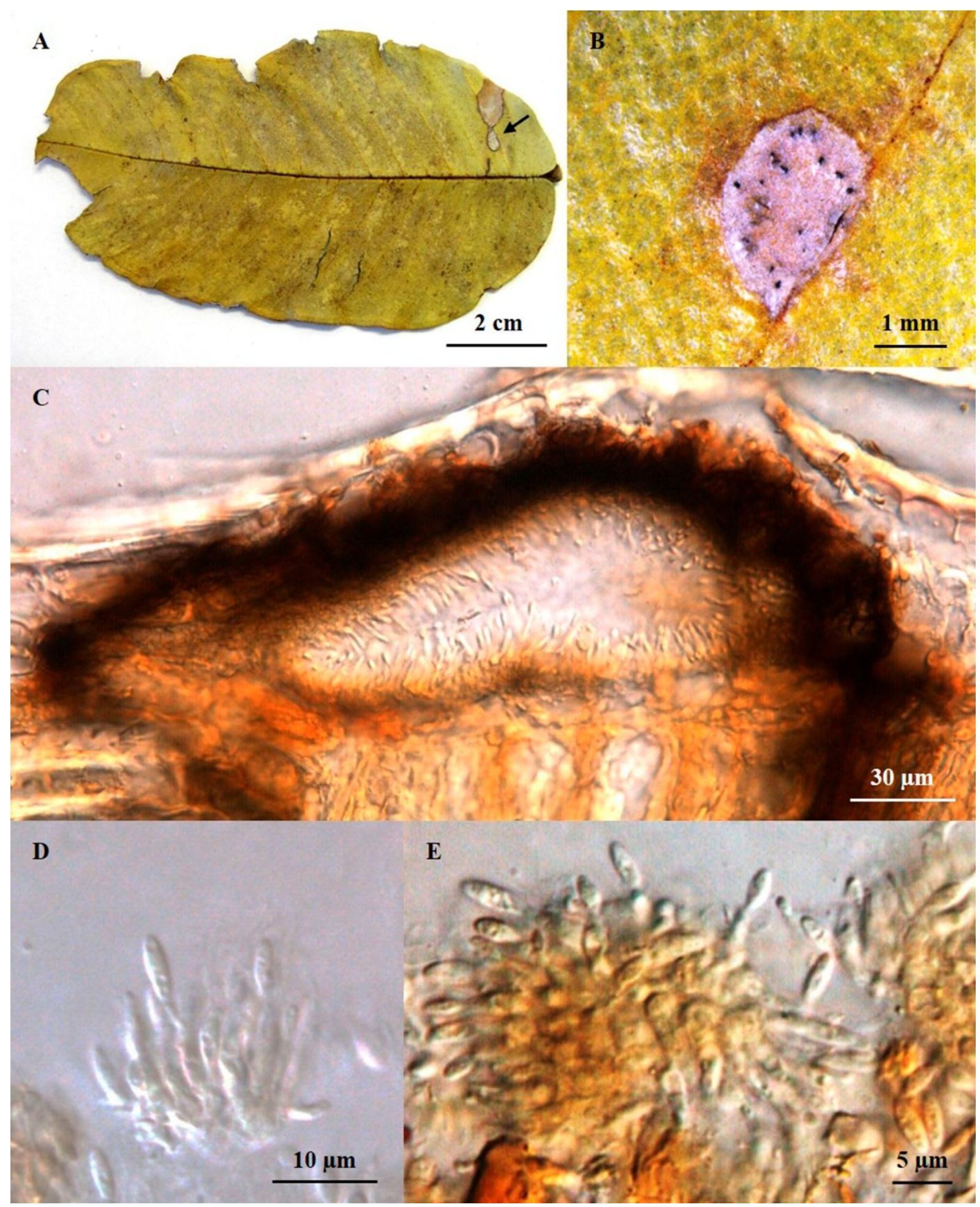

Figura 5. A-E. Phomopsis mangiferae em folhas de Qualea grandiflora (Vochysiaceae) (UB-Micol. Col. 23379). A. Folha com lesão. B. Detalhe da lesão com picnidiomas. C. Corte transversal mostrando picnidioma subcuticular. D. Conidióforos ramificados. E. Conídios alfa. 


\section{ASCOMICETOS FORMADORES DE CONIDIÓFOROS LIVRES,}

ESPORODÓQUIO E SINÊMIO

2.1. Pseudocercospora rigidae Meir. Silva \& O.L. Pereira, Mycotaxon 102: 261 (2007). Figura $6(A-G)$

Lesões anfígenas, delimitadas pela nervura ou irregulares, necróticas, acinzentadas com margens marrons, medindo de 3 a $40 \mathrm{~mm}$ de diâmetro. Estroma bem desenvolvido, subepidérmico, eruptivo, marrom escuro, 31-83 $\mu \mathrm{m}$ de diâmetro. Fascículos geralmente hipófilos, marrons. Conidióforos sobre estroma subepidérmico, em fascículos densos, eretos a decumbentes, retos cilíndricos a geniculados sinuosos, não ramificados, $28-42 \times 2,5-3 \mu \mathrm{m}$, com paredes finas, oliváceos a marrom-claros, 0-3 septos. Células conidiogênicas terminais, integradas, 1-3 $\mu \mathrm{m}$ de largura, marrom claro. Locos conidiogênicos inconspícuos, não escurecidos, planos. Conídios solitários, obclavados a cilíndricos, retos a levemente curvos, 50-75 × 2,5-4 $\mu \mathrm{m}$, ápice obtuso, base cônica truncada, 4-9 septos, oliváceos a marromclaros, suaves, com paredes finas, hilos sem cicatrizes, não escurecidos.

Espécime examinado: em folhas de Palicourea rigida (Rubiaceae), BRASIL, Distrito Federal, Planaltina, Reserva do Mirante, EMBRAPA CPAC; 15/03/2016, Bruno Cézar Pereira de Souza \#130, UB (Col. Micol.) 23398.

Atualmente três espécies de Pseudocercospora estão associadas a plantas do gênero Palicourea (Rubiaceae), sendo elas: P. palicoureae O.L. Pereira \& R.W. Barreto relatada em Palicourea marcgravii no Brasil; P. palicoureina (Petr. \& Cif.) U. Braun, relatada em Palicourea domingensis na República Dominicana (Braun, 2001) e P. rigidae Meir. Silva \& O.L. Pereira relatada em Palicourea rigidae no Brasil (Tabela 5).

O espécime aqui descrito é idêntico ao material tipo de Pseudocercospora rigidae (Silva e Pereira, 2007). Ambas compartilham a mesma hospedeira, Palicourea rigidae, e 
apresentam características morfométricas semelhantes, tais como o tamanho das lesões, estromas, conidióforos, células conidiogênicas e conídios. 
Tabela 5. Características morfométricas de espécies de Pseudocercospora em plantas do gênero Palicourea (Rubiaceae).

\begin{tabular}{|c|c|c|c|c|c|c|c|}
\hline $\begin{array}{c}\text { Espécies de } \\
\text { Pseudocercospora }\end{array}$ & $\begin{array}{l}\text { Lesões } \\
(\mathbf{m m})\end{array}$ & $\begin{array}{c}\text { Estroma } \\
(\mu \mathrm{m})\end{array}$ & $\begin{array}{c}\text { Conidióforo } \\
(\mu \mathrm{m})\end{array}$ & $\begin{array}{c}\text { Célula conidiogênica } \\
(\mu \mathrm{m})\end{array}$ & $\begin{array}{c}\text { Conídios } \\
(\mu \mathrm{m})\end{array}$ & Septos & Hospedeira \\
\hline P. palicourea $e^{2}$ & $2-12$ & Ausente & $15-70 \times 3-4,5$ & $5-15 \times 3,5-4,5$ & $13-115 \times 2,5-3,5$ & $0-5$ & $\begin{array}{l}\text { Palicourea } \\
\text { marcgravii }\end{array}$ \\
\hline P. palicoureina ${ }^{3}$ & $5-20$ & $10-40$ & $10-150 \times 3-5$ & $10-30$ & $10-75 \times 2,5-4$ & $1-7$ & $\begin{array}{c}\text { Palicourea } \\
\text { domingensis }\end{array}$ \\
\hline
\end{tabular}

${ }^{1}$ (Silva e Pereira, 2007); ${ }^{2}$ (Pereira e Barreto, 2006); ${ }^{3}$ (Braun, 2001). 

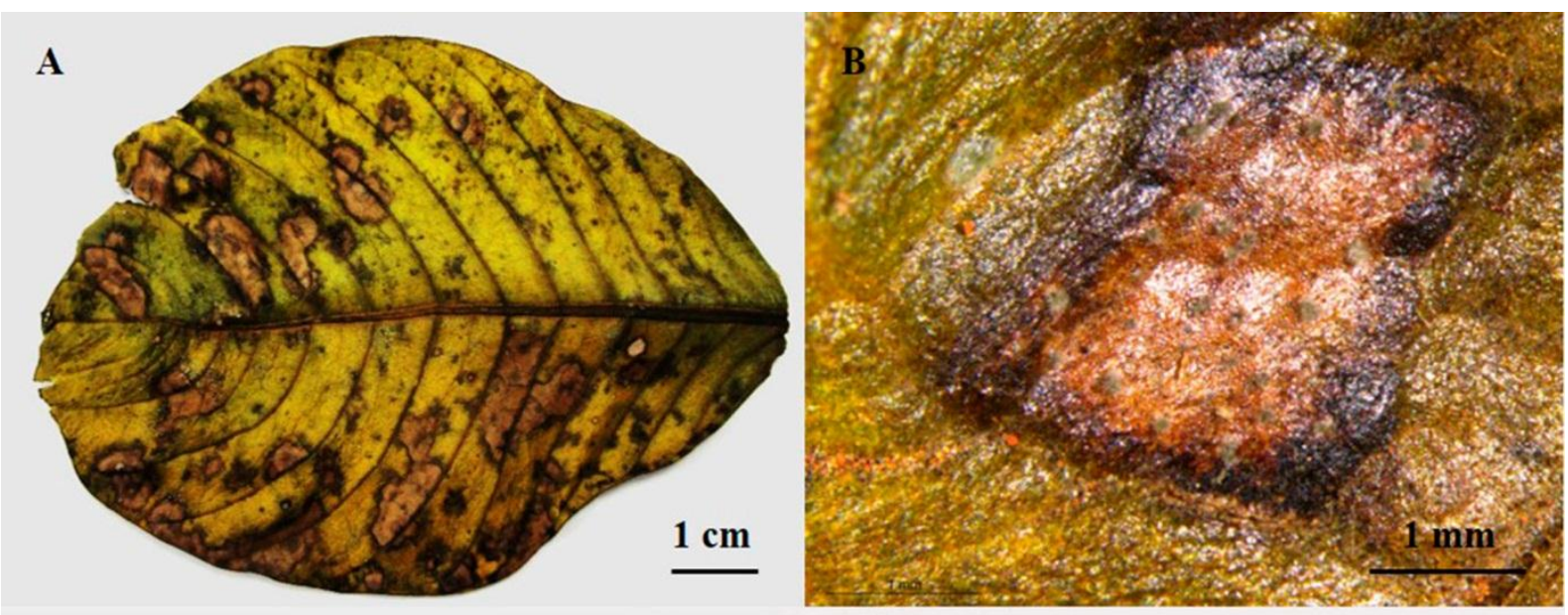

C

D

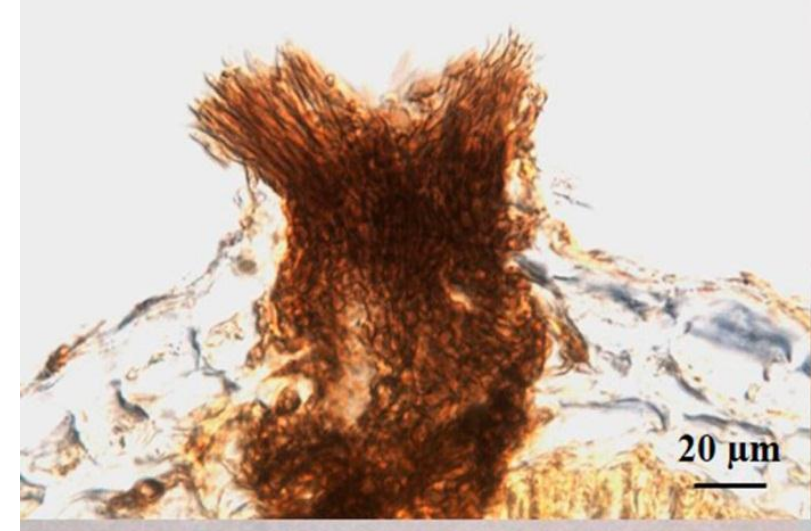

$\mathbf{E}$

$\mathbf{F}$

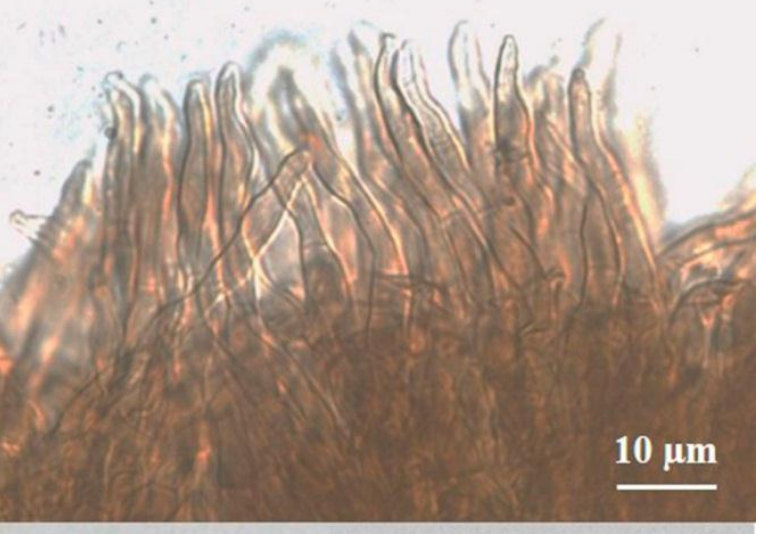

$$
\mathbf{E}
$$

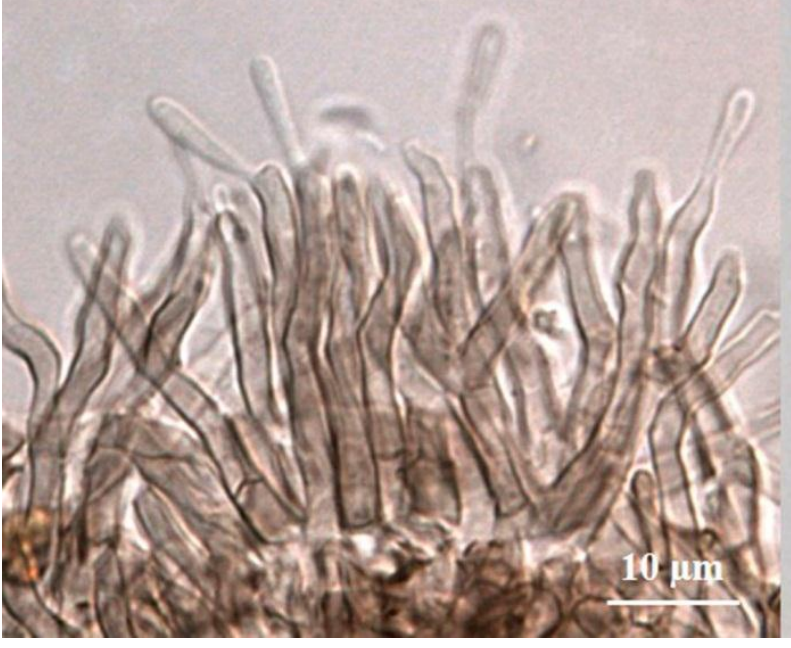

G

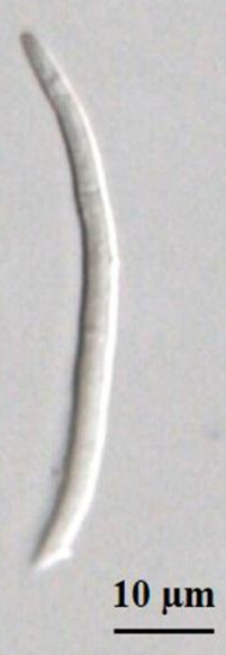

G

$10 \mu \mathrm{m}$

$10 \mu \mathrm{m}$

Figura 6. A-G. Pseudocercospora rigidae em folhas de Palicourea rigida (Rubiaceae) (UBMicol. Col. 23398). A. Lesões foliares. B. Detalhe da lesão com borda escura e centro claro. C. Corte transversal contendo estroma imerso no mesófilo da planta. D. Conidióforos. E. Células conidiogênicas. F-G. Conídios. 
2.2. Trichomatoclava cerradensis G.F. Sepúlveda, Pereira-Carv. \& Dianese, Mycol. Res. 113(2): 262 (2009). Figura 7 (A-F)

Colônias hipófilas, oliváceas a marrom-escuras, associadas com tricomas. Micélio superficial com coloração de castanho claro a castanho, crescendo em tricomas. Hifas 1-2,5 $\mu \mathrm{m}$ de largura, marrom claro a marrom, septadas, lisas e ramificadas. Conidióforos $5-15 \times 1-$ $3 \mu \mathrm{m}$, semimacronemáticos para macronemáticos, esporodoquiais, marrons a verde-oliva, às vezes septados, simples ou ramificados, em linha reta ou curvados, com uma ou mais células conidiogênicas. Células conidiogênicas 1-2,5 ㅆ monoblásticas ou poliblásticas, simpodiais, integradas, subglobosas, cilíndricas, com coloração de castanho claro a castanho. Conídios solitários, secos, marrom-claras a marrom, irregularmente clavados, raramente curvos, com secessão rexolítica, possuindo de 0 a 5 septos transversalmente dispostos, distoseptados, raramente euseptados, 5-19,5 × 3-5 $\mu \mathrm{m}$, com paredes grossas e verruculosas.

Espécime examinado: em folhas de Emmotum nitens (Icacinaceae), BRASIL, Distrito Federal, Planaltina, Reserva do Mirante, EMBRAPA CPAC; 21/06/2015, Bruno Cézar Pereira de Souza \#1, UB (Col. Micol.) 23371.

A espécie Trichomatoclava cerradensis G.F. Sepúlveda, Pereira-Carv. \& Dianese é monotípica, foi descrita em Roraima, parasitando Emmotum nitens. O gênero é caracterizado por conter conidióforos, células conidiogênicas e conídios verrucosos, conídios na maioria das vezes distoseptados, irregularmente clavados, fragmospóricos e marrom-claros (PereiraCarvalho et al., 2009).

Comparações morfométricas comprovaram que o espécime estudadopertence á espécie T. cerradensis (Tabela 6). Portanto esse é o primeiro relato desse fungo no Distrito Federal. 
Tabela 6. Características morfométricas da espécie Trichomatoclava cerradensis.

\begin{tabular}{|c|c|c|c|c|c|}
\hline Espécie & $\begin{array}{l}\text { Hifas } \\
(\mu \mathrm{m})\end{array}$ & $\begin{array}{c}\text { Conidióforos } \\
\qquad(\mu \mathrm{m})\end{array}$ & $\begin{array}{c}\text { Células } \\
\text { conidiogênicas } \\
(\mu \mathrm{m})\end{array}$ & $\begin{array}{l}\text { Conídios } \\
(\mu \mathrm{m})\end{array}$ & $\begin{array}{c}\text { Septos } \\
(\mu \mathrm{m})\end{array}$ \\
\hline T. cerradensis $^{1}$ & $1-2$ & $\begin{array}{c}4-9(-14) \times \\
2-3\end{array}$ & $1-2$ & $9-30[18] \times 4-7[5]$ & $1-6$ \\
\hline $\begin{array}{l}\text { T. cerradensis } \\
\text { UB } 23371\end{array}$ & $\begin{array}{c}1-2,5 \\
{[2]}\end{array}$ & $\begin{array}{c}5-15[9,5] \times \\
1-3[2]\end{array}$ & $1-2,5[2]$ & $5-19,5[9,5] \times 3-5[4]$ & $0-5$ \\
\hline
\end{tabular}

${ }^{1}$ (Pereira-Carvalho et al., 2009). 


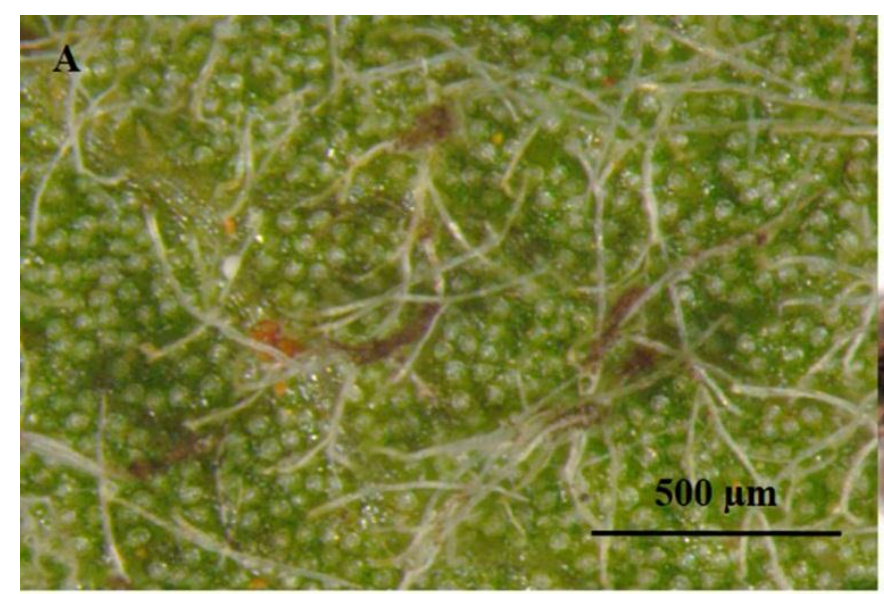

C

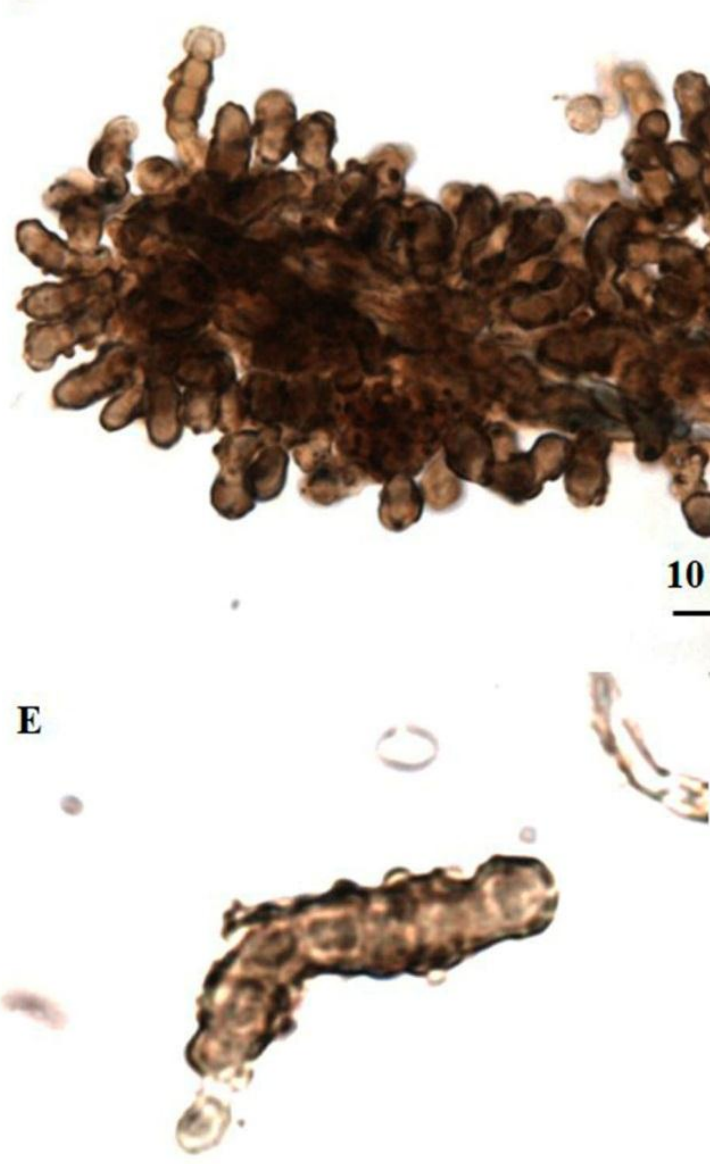

$10 \mu \mathrm{m}$

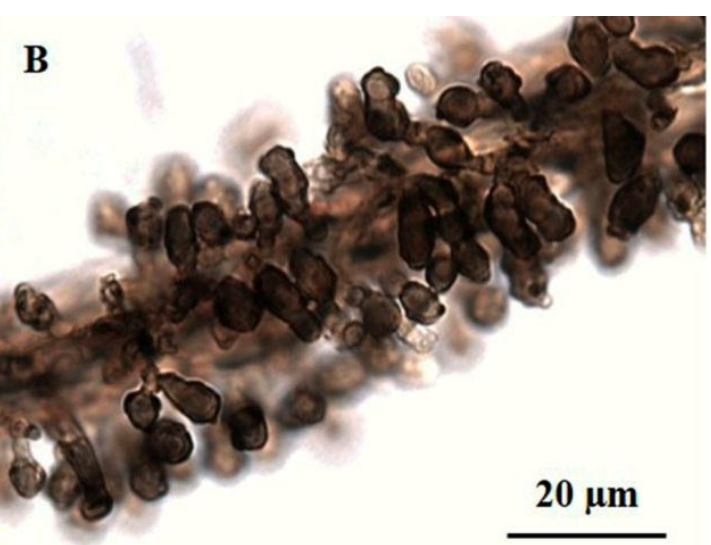

D 


\subsection{Zasmidium (provável espécie nova $\mathrm{n}^{\circ} 1$ ). Figura $8(\mathrm{~A}-\mathrm{G})$}

Lesões anfígenas, necróticas, marrons, circulares, isoladas ou coalescentes, porém, quando maduras, ocorre a abscisão da área necrosada, deixando furos nas folhas. Colônias anfígenas, marrom-claras, velutinosas. Micélio externo 3-5 $\mu \mathrm{m}$ de diâmetro, ramificado, septado, verrugoso e marrom-claro. Micélio interno, ramificado, septado, marrom, formando estromas. Estromas 50-71 $\mu \mathrm{m}$ de diâmetro, parcialmente superficiais, com textura globosa, marrom-escuros. Conidióforos 57-170 × 3-6 $\mu \mathrm{m}$, cespitosos, cilíndricos a irregulares, retos, recurvados, geniculados, marrons, septados. Células conidiogênicas poliblásticas, integradas, terminais, geniculadas, simpodiais, com locos conidiogênicos planos e escuros. Conídios 21$119 \times 3,5-5 \mu \mathrm{m}$, cilíndricos, bases truncadas e ápices arredondados, às vezes truncados e com cicatrizes, verrugosos, multisseptados (0-17 septos), solitários ou catenulados (2-3 conídios por cadeia), cadeias simples, marrom-claros e com hilo escuro.

Espécime examinado: em folhas de Tocoyena formosa (Rubiaceae), BRASIL, Distrito Federal, Planaltina, Reserva do Mirante, EMBRAPA CPAC; 15/03/2016, Bruno Cézar Pereira de Souza \#126, UB (Col. Micol.) 23394.

O espécime estudado possui as características morfológicas do gênero Zasmidium como micélio superficial verrugoso, conídios verrugosos, solitários ou catenulados e células conidiogênicas com locos conidiogênicos planos e escuros (Crous et al., 2009; Braun et al., 2013). A diferença morfológica entre os gêneros Zasmidium e Stenella se dá somente pelo formato do loco conidiogênico, que no primeiro é plano e no segundo é pileado (Braun, Nakashima e Crous, 2013). O gênero possui 209 registros, sendo que e a espécie tipo é Zasmidium cellare (Pers.) Fr. Na família Rubiaceae já foram descritas 11 espécies do gênero (Tabela 7), no entanto, até o momento não é conhecida nenhuma espécie em Tocoyena formosa. 
O fungo encontrado neste hospedeiro possui conídios estritamente cilíndricos, retos e longos, causando lesões necróticas com abscisão do tecido infectado. Morfologicamente, a espécie se diferencia das demais pelos conidióforos e conídios maiores, além do maior número de septos nos conídios, segregando-se inclusive da única espécie descrita na América do Sul, Z. genipae-americanae Braun \& Urtiaga (Braun e Urtiaga, 2013). Sendo assim, sugere-se que provavelmente se trata de uma nova espécie de Zasmidium. 
Tabela 7. Características morfométricas de espécies de Zasmidium encontradas em Rubiaceae.

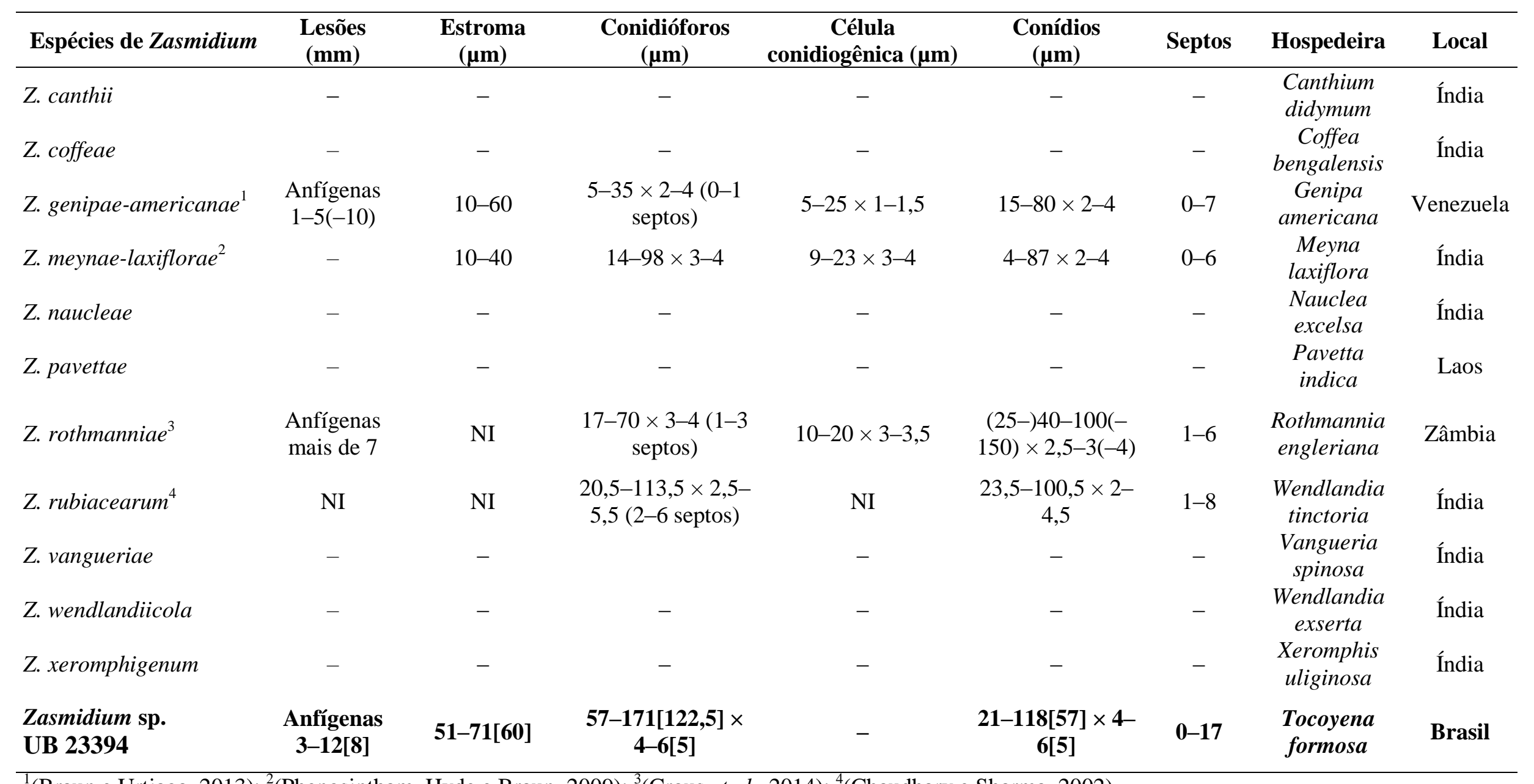

${ }^{1}$ (Braun e Urtiaga, 2013); ${ }^{2}$ (Phengsintham, Hyde e Braun, 2009); ${ }^{3}$ (Crous et al., 2014); ${ }^{4}$ (Chaudhary e Sharma, 2002). 


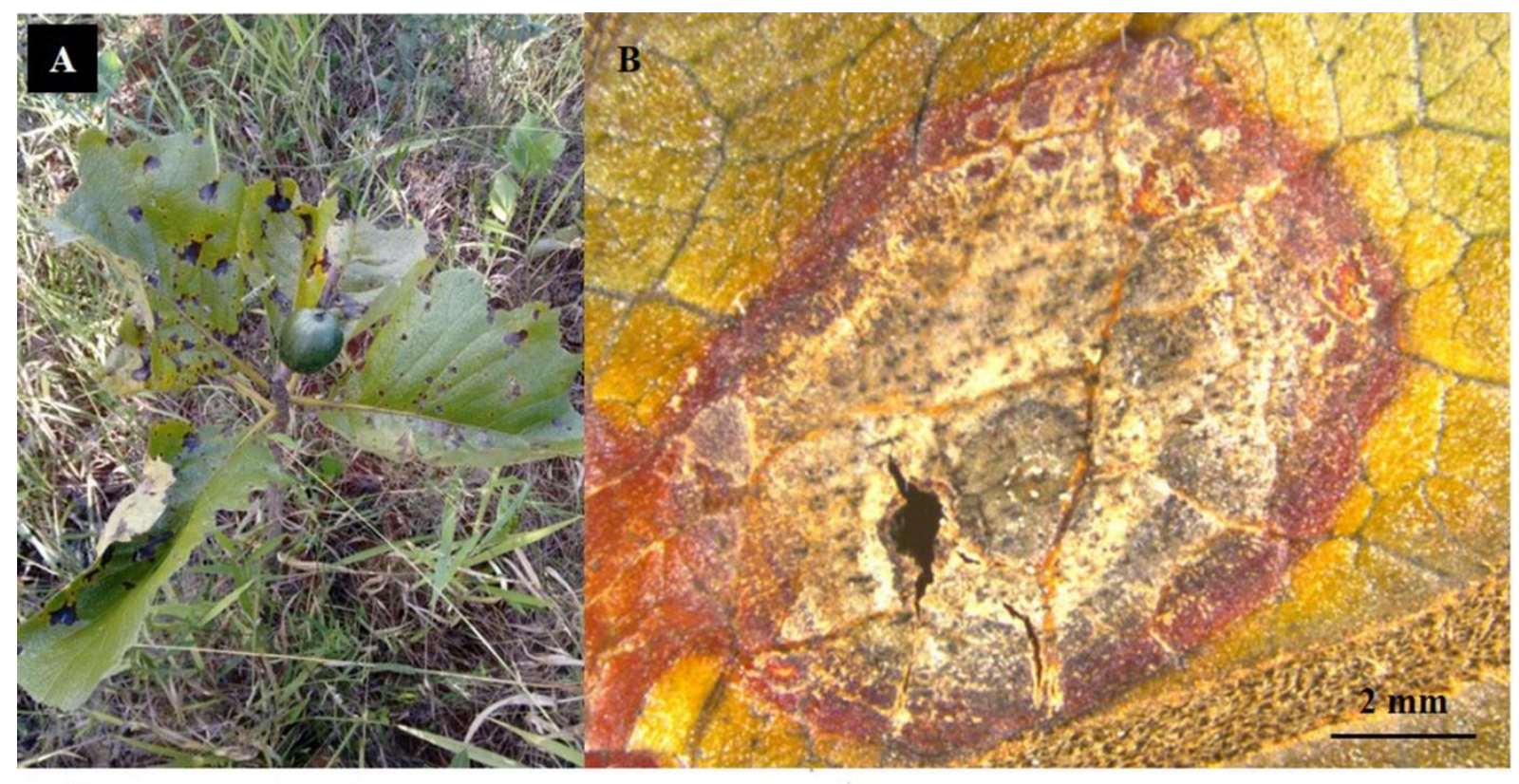

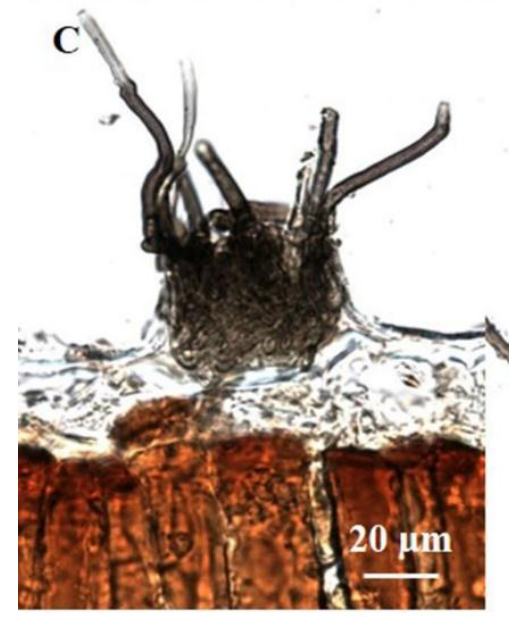

$\mathbf{F}$
D

D
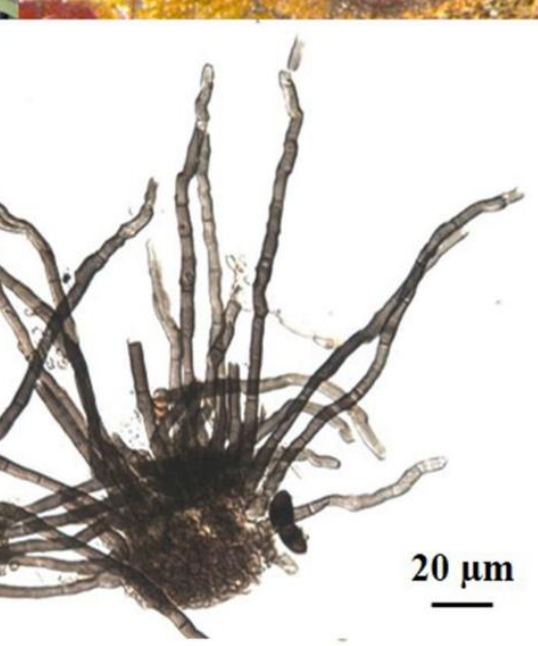

$\mathbf{E}$

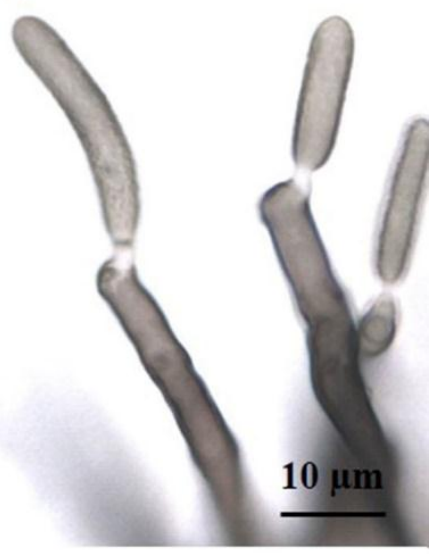

G

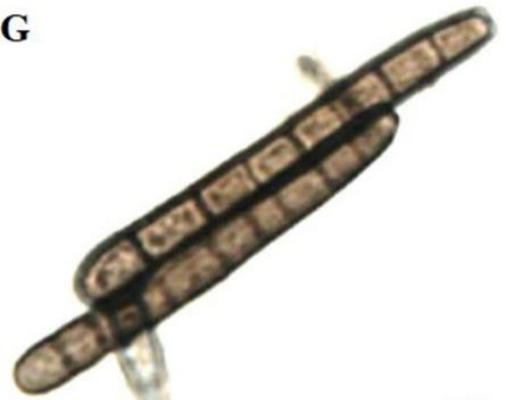

$20 \mu \mathrm{m}$

Figura 8. A-G. Zasmidium sp. em folhas de Tocoyena formosa (Rubiaceae) (UB-Micol. Col. 23394). A. Lesões foliares. B. Detalhe da lesão com centro acinzentado e bordas arroxeadas. C. Corte transversal com estroma eruptivo, parcialmente superficial. D. Conidióforos. E. Células conidiogênicas. F-G. Conídios. 


\section{ASCOMICETOS SEXUADOS}

\subsection{Genera Incertae sedis}

\subsubsection{Dothidasteromella (provável espécie nova $\mathrm{n}^{\circ}$ 2). Figura 9 (A-I)}

Colônias de 2,5-4 mm de diâmetro, epifilas, superficiais, escuras, solitárias ou confluentes, circulares. Micélio superficial ausente. Hifas marrom escuras, difíceis de remover da superfície do hospedeiro. Ascomas tiriotecióides, 118-188 × 48-77 $\mu \mathrm{m}$, superficiais, eruptivos, marrom-escuros a negros, glabros, agregados ou solitários, com abertura através de ostíolos. Ascos bitunicados, 31-42 × 14-23 $\mu$ m, obovoides a clavados, persistentes, contendo oito ascósporos. Ascósporos 15,5-20 × 7,5-10 $\mu \mathrm{m}$, elipsoides, bicelulares, apresentando constrição no septo, hialinos a oliváceos quando jovens e marrons quando na maturidade.

Espécime examinado: em folhas de Connarus suberosus. (Connaraceae), BRASIL, Distrito Federal, Planaltina, Reserva do Mirante, EMBRAPA CPAC; 03/03/2016, Bruno Cézar Pereira de Souza \#117, UB (Col. Micol.) 23388.

O gênero Dothidasteromella tem como espécie tipo D. sepulta (Berk. \& M.A. Curtis) Höhn., e possui as seguintes características: Hipostroma subcuticular, formado um uma única camada, ordenado radialmente de bandas ramificadas compostas de hifas paralelas, tendo ao seu redor um tecido de hifas, o que o diferencia de Dothidasteroma (Höhnel, 1910); estroma plano, superficial, carbonáceo por cima, por baixo suave e pálido, ligado em vários pontos ao hipostroma; lóculos planos, projetados irregularmente, de formas variadas, muitas vezes fusionados em forma de rede, se abrindo por meio de poros ou fendas; ascos ovoides a clavados, contendo oito ascósporos marrons, bicelulares (Höhnel, 1909b).

O gênero Dothidasteromella foi criado por Höhnel (1910). Von Arx e Müller (1975) alolocaram o gênero na família Asterinaceae devido a características do hipostroma subcuticular e hifas superficiais sem apressórios. Dothidasteromella é um gênero distinto por 
apresentar tiriotécios carbonáceos e hifas formando áreas circulares enegrecidas, que é típico da família Parmulariaceae. Em estudo recente o gênero Dothidasteromella foi alocado em Dothidoemycetes genera incertae sedis, até que novas espécies do gênero sejam recolhidas para estabelecer seus caracteres e relacionamentos, também através de sequenciamento (Hongsanan et al., 2014).

O espécime em estudo foi comparado com as espécies descritas na literatura (Tabela 8), notou-se que há semelhanças em relação ao tamanho da colônia da espécie estudada com $D$. hansfordii e $D$. sepulta, já quanto as hifas o espécime estudado se aproxima de $D$. sepulta e $D$. floridana. A espécie em questão possui ascos menores e ascósporos semelhantes a $D$. parvispora. Trata-se do primeiro relato deste fungo em plantas da família Connraceae. Sendo assim, pode afirmar que se trata de uma nova espécie de Dothidasteromella. 
Tabela 8. Características morfométricas das espécies de Dothidasteromella.

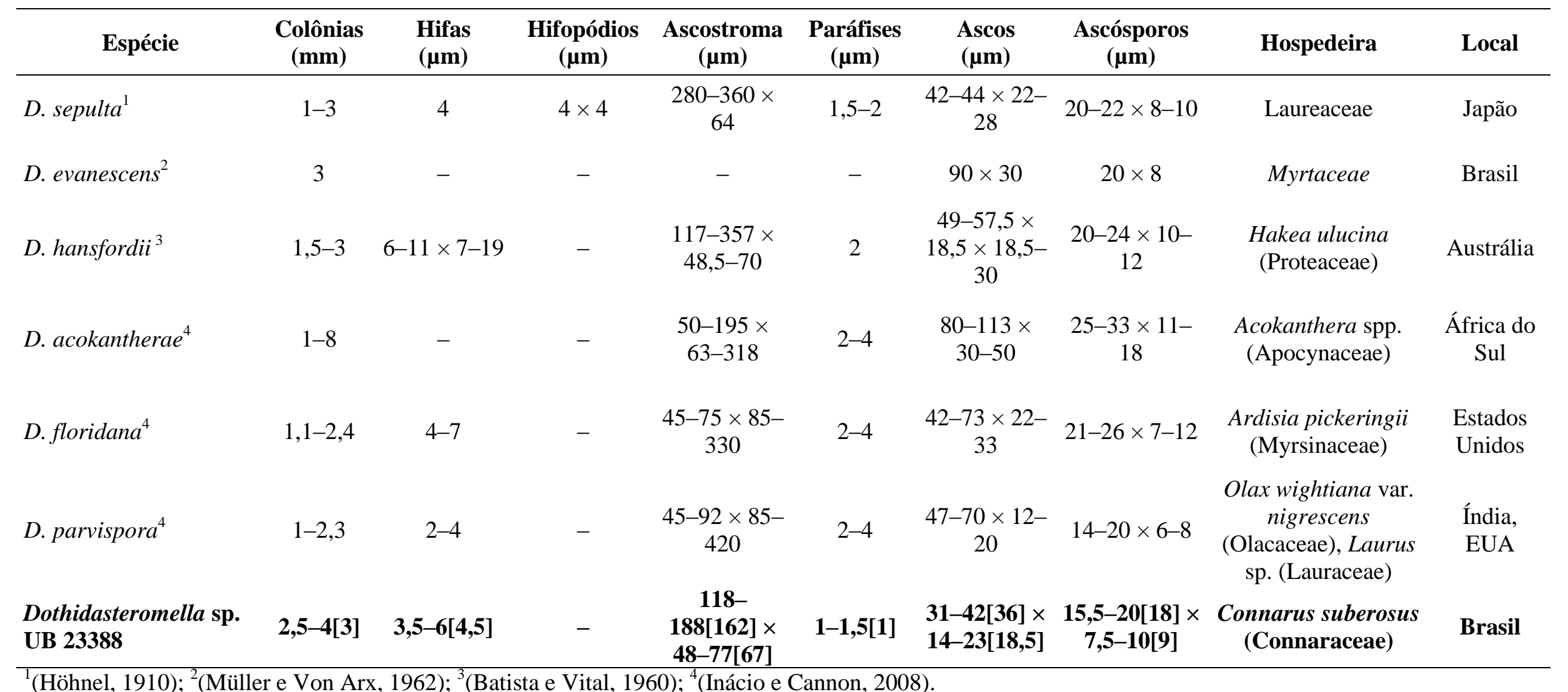

${ }^{1}$ (Höhnel, 1910); ${ }^{2}$ (Müller e Von Arx, 1962); ${ }^{3}$ (Batista e Vital, 1960); ${ }^{4}$ (Inácio e Cannon, 2008). 

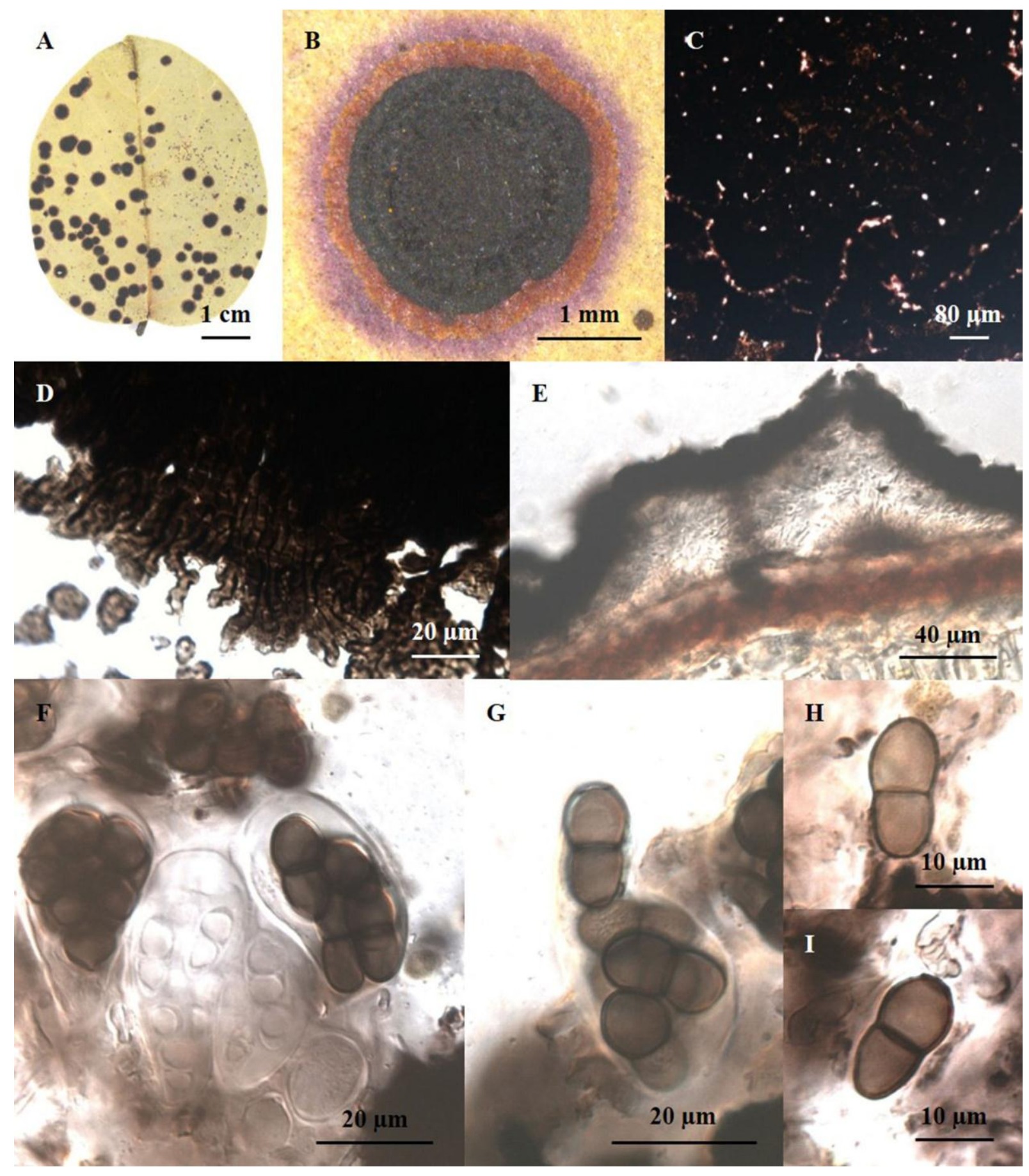

Figura 9. A-I. Dothidasteromella sp. em folhas de Connarus suberosus. (Connaraceae) (UBMicol. Col. 23388). A. Colônias na folha. B. Detalhe de uma colônia com bordas roxas. C. Aberturas dos ascomas (poros). D. Hifas na borda das colônias. E. Conte transversal contendo estroma. F. Ascos bitunicados. G-I. Ascósporos. 


\subsubsection{Ophiociliomyces (provável espécie nova nº 3). Figura 10 (A-F)}

Ascomas globosos, 110-229 $\mu \mathrm{m}$ de diâmetro, marrom escuros, localizados na parte abaxial das folhas, entre os tricomas, apresentando subiculum hialino, suave. Ascos 41-54 $\times$ 8-11 $\mu \mathrm{m}$, cilíndricos, clavados, com ápices arredondados, bitunicados, possuindo oito ascósporos. Paráfises filiformes, hialinas, 1,5-2 diâmetro, septadas. Ascósporos 10-14 × 23,6 $\mu \mathrm{m}, 3$ septos transversais, hialinos, elipsóides a clavados.

Espécime examinado: em folhas de Emmotum nitens (Icacinaceae), BRASIL, Distrito Federal, Planaltina, Reserva do Mirante, EMBRAPA CPAC; 21/06/2015, Bruno Cézar Pereira de Souza \#1, UB (Col. Micol.) 23371.

O gênero Ophiociliomyces tem como espécie tipo O. bauhiniae Bat. \& I.H. Lima e apresenta quatro registros atualmente. $O$ gênero já foi incluído na família Pseudoperisporiaceae, classe Dothideomycetes (Hyde et al., 2013), mas posteriormente foi excluído da ordem Meliolales e alocado como gênero incertae sedis no filo Ascomycota (Hongsanan et al., 2015). As características do gênero são as seguintes: ascoma superficial em folhas, solitário, globoso, rompendo-se quando seco; hifas superficiais e hifopódios ausentes; perídio marrom-escuro, compreendendo células entrelaçadas, mais escuras na borda, com dois estratos, estrato externo de paredes grossas, células marrom-escuras e estrato interno de células hialinas a marrom-pálidas; ascos contendo oitos esporos, bitunicados, clavados a ovoides, ou subglobosos, apedicellados, com ápice arredondado, sem câmara ocular; ascósporos fasciculados, hialinos a acinzentados, fusiformes a clavados, 10-13 septos, sem constrição nos septos, retos a ligeiramente curvos, de paredes lisas (Hongsanan et al., 2015)

A espécie em estudo foi comparada com a espécie tipo (Tabela 9), e verificou-se diferenças morfológicas claras quanto ao tamanho dos ascósporos e septação dos mesmos, já que a espécie em estudo apresenta ascósporos menores e com apenas 3 septos. Trata-se do 
primeiro relato do gênero em uma espécie da família Icacinaceae. As diferenças aqui relatadas sustentam a afirmação de que se trata de uma provável nova espécie de Ophiociliomyces.

Tabela 9. Características morfométricas da espécie tipo de Ophiociliomyces e do espécime encontrado sobre Emmotum nittens.

\begin{tabular}{lccccc}
\hline \multicolumn{1}{c}{$\begin{array}{c}\text { Espécie de } \\
\text { Ophiociliomyces }\end{array}$} & $\begin{array}{c}\text { Ascoma } \\
(\boldsymbol{\mu m})\end{array}$ & $\begin{array}{c}\text { Ascos } \\
(\boldsymbol{\mu m})\end{array}$ & $\begin{array}{c}\text { Ascósporos } \\
(\boldsymbol{\mu m})\end{array}$ & Septos & Hospedeira \\
\hline O. bauhiniae ${ }^{1 *}$ & $185-240$ & $46-67,5 \times 13-32$ & $52-77 \times 5-9,5$ & $10-13$ & $\begin{array}{c}\text { Bauhinia } \\
\text { raddiana }\end{array}$ \\
Ophiociliomyces sp. & $\mathbf{1 1 0}-$ & $\mathbf{4 1 - 5 4 [ 5 0 ] \times \mathbf { 8 , 5 } -}$ & $\begin{array}{c}\mathbf{1 0 , 5 - 1 4}[\mathbf{1 2}] \times \\
\mathbf{2 - 3 , 5}[\mathbf{3}]\end{array}$ & $\mathbf{3}$ & $\begin{array}{c}\text { Emmotum } \\
\text { nitens }\end{array}$ \\
\hline UB 23371 & $\mathbf{2 2 9}[\mathbf{1 6 0}]$ & $\mathbf{1 1 , 5 [ 1 0 ]}$ & & &
\end{tabular}

${ }^{1}$ (Hongsanan et al., 2015). *Espécie tipo. 


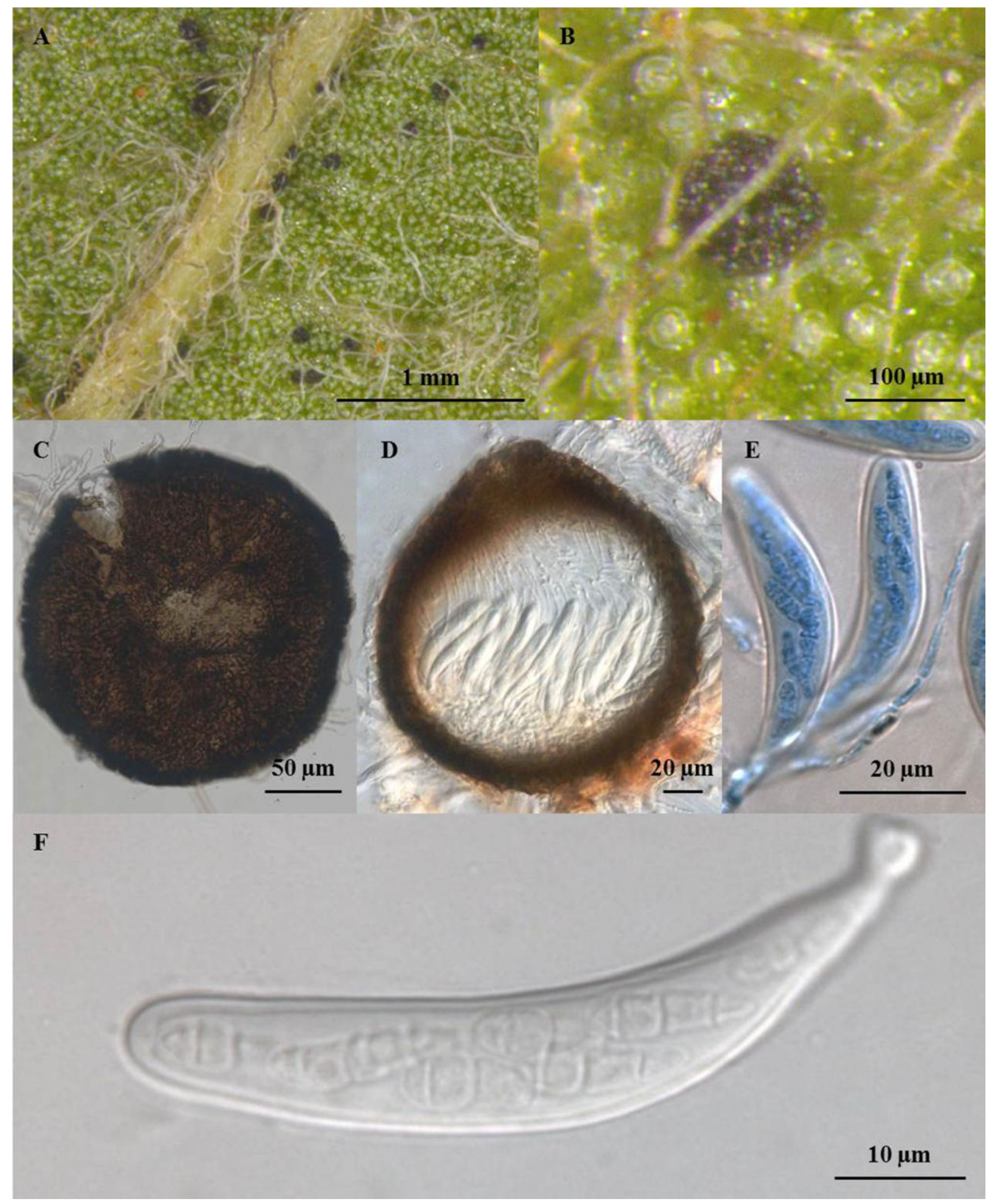

Figura 10. A-F. Ophiociliomyces sp. em folhas de Emmotum nitens (Icacinaceae) (UBMicol. Col. 23371). A-B. Ascomas entre tricomas. C. Ascoma redondo com textura angularis. D. Corte transversal do ascoma. E. Asco parafisados. F. Asco e ascósporos. 


\subsection{Membros da família Asterinaceae}

3.2.1. Asterina salaciae Allesch. Hedwigia 36(4): 235 (1897). Figura 11 (A-G)

Colônias superficiais, epifilas, negras, circulares a irregulares, cobrindo parcialmente o limbo foliar, compostas de ascomas, circulares, isolados ou confluentes. Micélio superficial na margem dos ascomas e conidiomas, composto de hifas marrons, hifopodiadas. Hifas 3-5,5 $\mu \mathrm{m}$ de espessura, marrons, septadas, sinuosas, ramificadas. Apressórios unicelulares, capitados, unilaterais ou alternos, hemisféricos, 5-7 × 6,5-9 $\mu \mathrm{m}$. Ascomas superficiais, dimidiados, escudados, circulares, marrom-escuros, 161-251 $\mu \mathrm{m}$ de diâmetro, apresentando aberturas irregulares, estelares, textura radiata. Ascos bitunicados, clavados a subglobosos,

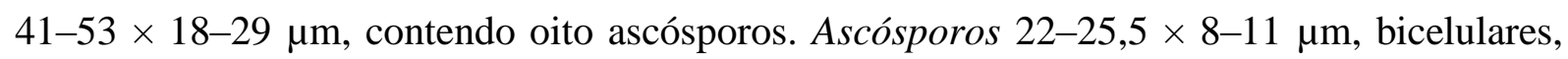
elípticos, constritos no septo, inicialmente hialinos tornando-se marrons na maturidade.

Espécime examinado: em folhas de Salacia crassifolia (Celastraceae), BRASIL, Distrito Federal, Planaltina, Reserva do Mirante, EMBRAPA CPAC; 03/03/2016, Bruno Cézar Pereira de Souza \#125, UB (Col. Micol.) 23395.

O espécime estudado trata-se de uma espécie de Asterina (gênero tipo da família Asterinaceae), tendo como espécie tipo Asterina melastomatis Lév., e contendo atualmente 1113 nomes diferentes, englobando espécies e táxons subespecíficos (Index Fungorum, 2017). As características principais do gênero são: presença de micélio escuro, hifas hifopodiadas, apressórios unicelulares, lateralmente distribuídos; ascomas lenticulares a subglobosos, achatados, de textura radiata, não ostiolados, apresentando deiscência estelar a irregular; ascos clavados, obovoides a esféricos; ascósporos bicelulares, marrons, lisos a rugosos. A forma conidial pode estar presente ou ausente, quando presente, formando picnotírios ao redor dos ascomas, característicos do gênero Asterostomela Speg. e outros gêneros (Von Arx e Müller, 1975). 
Dentro da família Celastraceae estão relatadas nove espécies de Asterina, que foram comparadas com a espécie em questão (Tabela 10). Em relação aos ascomas, somente as espécies A. gymnosporiae possui medidas semelhantes ao do espécime em estudo, as demais possuem ascomas maiores ou menores. Uma espécie descrita como A. salaciae coletada em Brasília apresenta medidas semelhantes às da espécie encontrada neste trabalho, porém, neste trabalho não foi detectada a fase anamorfa, detectada por Santos (Santos, 2011). As medidas de ascos e ascósporos são correspondentes à A. salaciae, descrita por P. Hennings, coletada no estado de Goiás por Glaziou em Salacia sp. (Hennings, 1897). Assim, conclui-se que a espécime analisada neste trabalho pertence a Asterina salaciae. 
Tabela 10. Características morfométricas das espécies de Asterina em plantas da família Celastraceae.

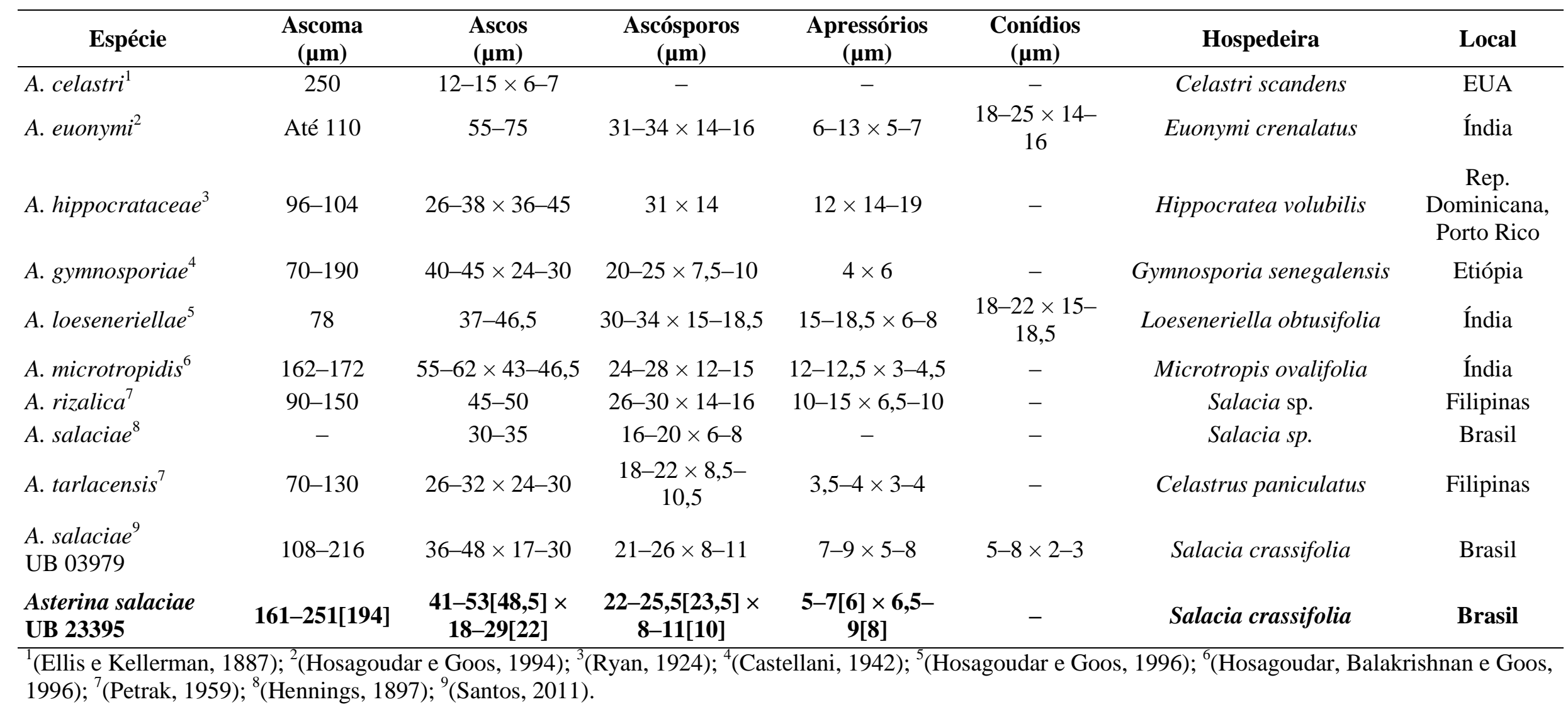




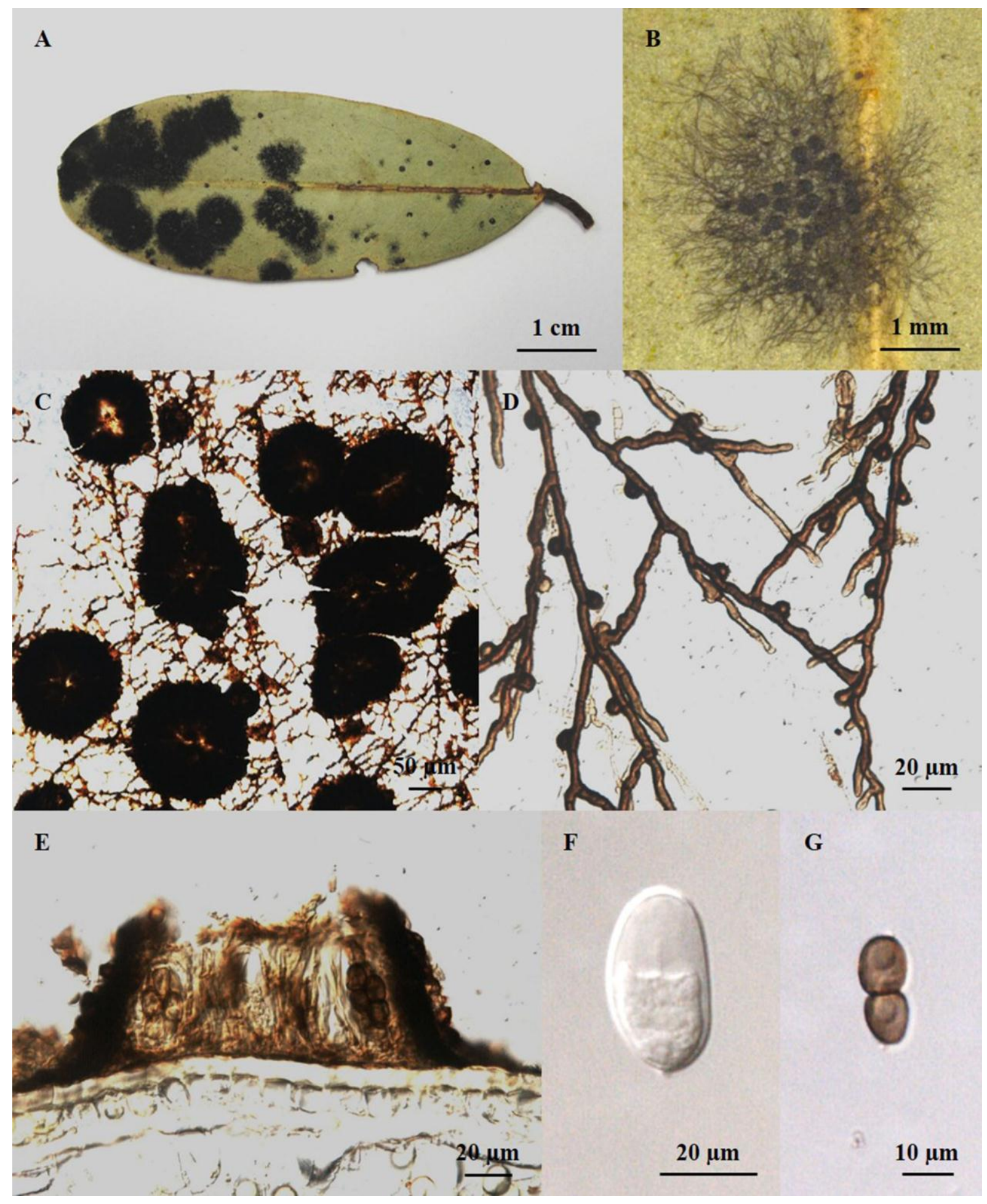

Figura 11. A-G. Asterina salaciae em folhas de Salacia crassifolia (Celastraceae) (UBMicol. Col. 23395). A-B. Colônias sobre a folha. C. Conidiomas arredondados com abertura estelar a irregular. D. Micélio com hifopódios. E. Corte transversal mostrando a posição dos ascos. F. Asco. G. Ascósporo. 


\subsubsection{Lembosia (provável espécie nova $\mathrm{n}^{\circ}$ 4). Figura $12(\mathrm{~A}-\mathrm{G})$}

Colônias 1-3,5 mm de diâmetro, epifilas, superficiais, escuras, solitárias ou confluentes, circulares a irregulares. Micélio superficial, septado. Hifas marrom escuras, retas ou flexuosas, ramificadas, contendo apressórios. Apressórios 4,5-9 × 5,5-7 $\mu \mathrm{m}$, redondos, asseptados, unilaterais a alternados. Ascomas tiriotecióides, 205-781 × 177-369 $\mu \mathrm{m}$, superficiais, marrom-escuros a negros, glabros, isolados ou coalescentes, demonstrando várias formas, elípticos, agregados, com deiscência por fendas longitudinais ou em forma de Y, com bordos fimbriados, facilmente removíveis da superfície do hospedeiro. Ascos bitunicados, 34 $48 \times 14,5-28 \mu \mathrm{m}$, obovoides a clavados, dispostos em paliçada, persistentes, contendo oito ascósporos. Ascósporos 13-17 × 8-9 $\mu \mathrm{m}$, elipsoides, bicelulares, apresentando constrição no septo, hialinos a marrom-claros quando jovens e marrom-escuros quando na maturidade.

Espécime examinado: em folhas de Baccharis sp. (Asteraceae), BRASIL, Distrito Federal, Planaltina, Reserva do Mirante, EMBRAPA CPAC; 21/06/2015, Bruno Cézar Pereira de Souza \#30, UB (Col. Micol.) 23381.

Espécies do gênero Lembosia estão distribuídas nas regiões tropicais e subtropicais do mundo, com taxonomia baseada na morfologia e na especificidade fungo/planta hospedeira, tem L. tenella Lev. como espécie tipo e atualmente possui 260 nomes registrados (Index Fungorum, 2017). A família Lembosiaceae compreende obrigatoriamente fungos biotróficos epífitos, geralmente encontrados nas folhas e caracterizam-se por ter ascoma tiriotecial plano, que se abre por fendas longitudinais, em X ou Y e hifas com apressórios para obter nutrientes do hospedeiro (Hosagoudar, Abraham e Biju, 2001; Hyde et al., 2013), e se diferem das espécies da família Asterinaceae por terem o tiriotécio alongado (Hongsanan et al., 2014).

O espécime em estudo foi comparado com as espécies de Lembosia relatadas no Brasil (Tabela 11), já que não há relatos do fungo sobre plantas da família Asteraceae. As espécies L. epidendri e L. philodendri são similares ao espécime estudado, no entanto, L. epidendri 
difere por ter ascomas menores, ascos e ascósporos maiores. Já L. epidendri difere do espécime estudado por ter ascomas mais compridos, ascos menores e mais estreitos, além de ascósporos mais estreitos. A diferença morfológica e a relação inédita com a hospedeira permitem concluir que se trata de uma provável nova espécie de Lembosia. 
Tabela 11. Características morfométricas das espécies de Lembosia relatadas no Brasil.

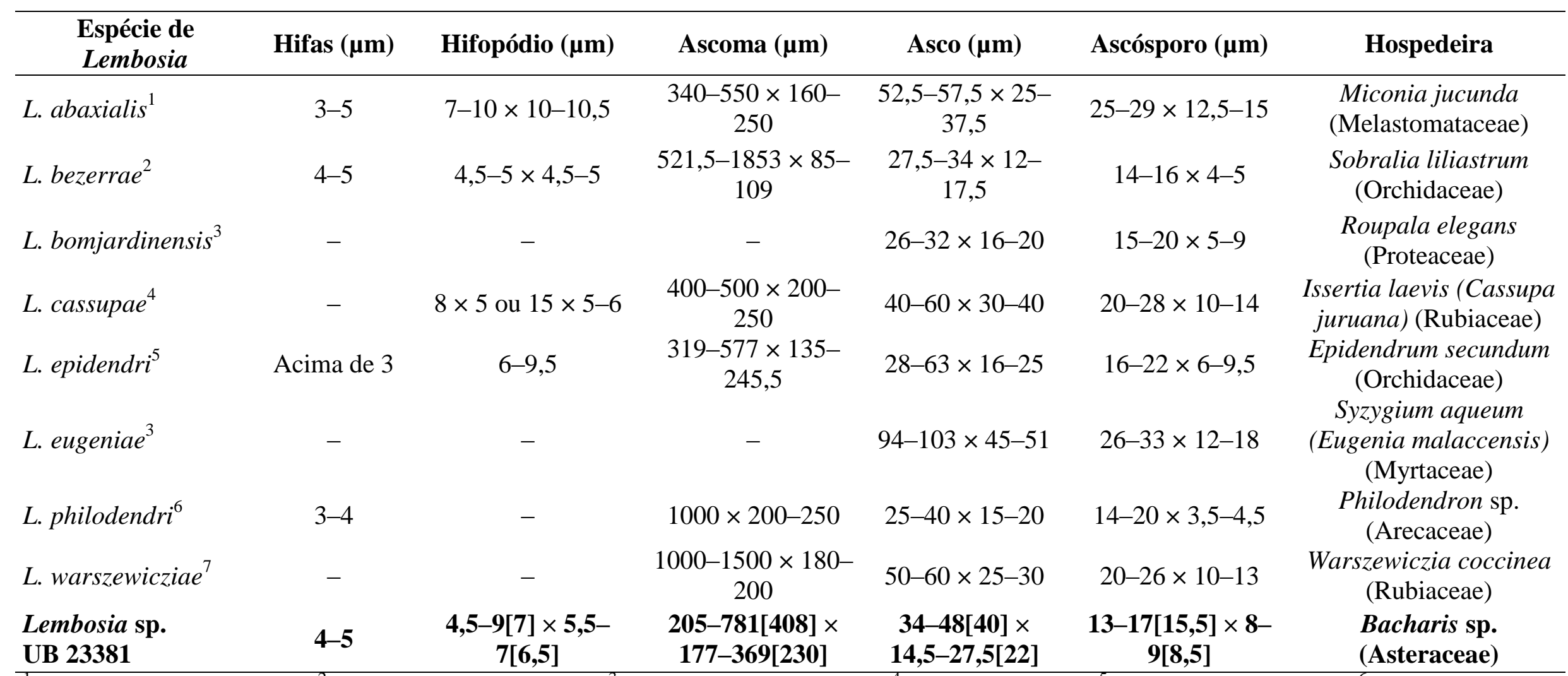

${ }^{1}$ (Guatimosim et al., 2015); ${ }^{2}$ (Firmino e Pereira, 2014); ${ }^{3}$ (Hongsanan et al., 2014); ${ }^{4}$ (Hennings, 1905$) ;{ }^{5}$ (Silva e Pereira, 2008); ${ }^{6}($ Hennings, 1904b); ${ }^{7}$ (Hennings, 1904a). 


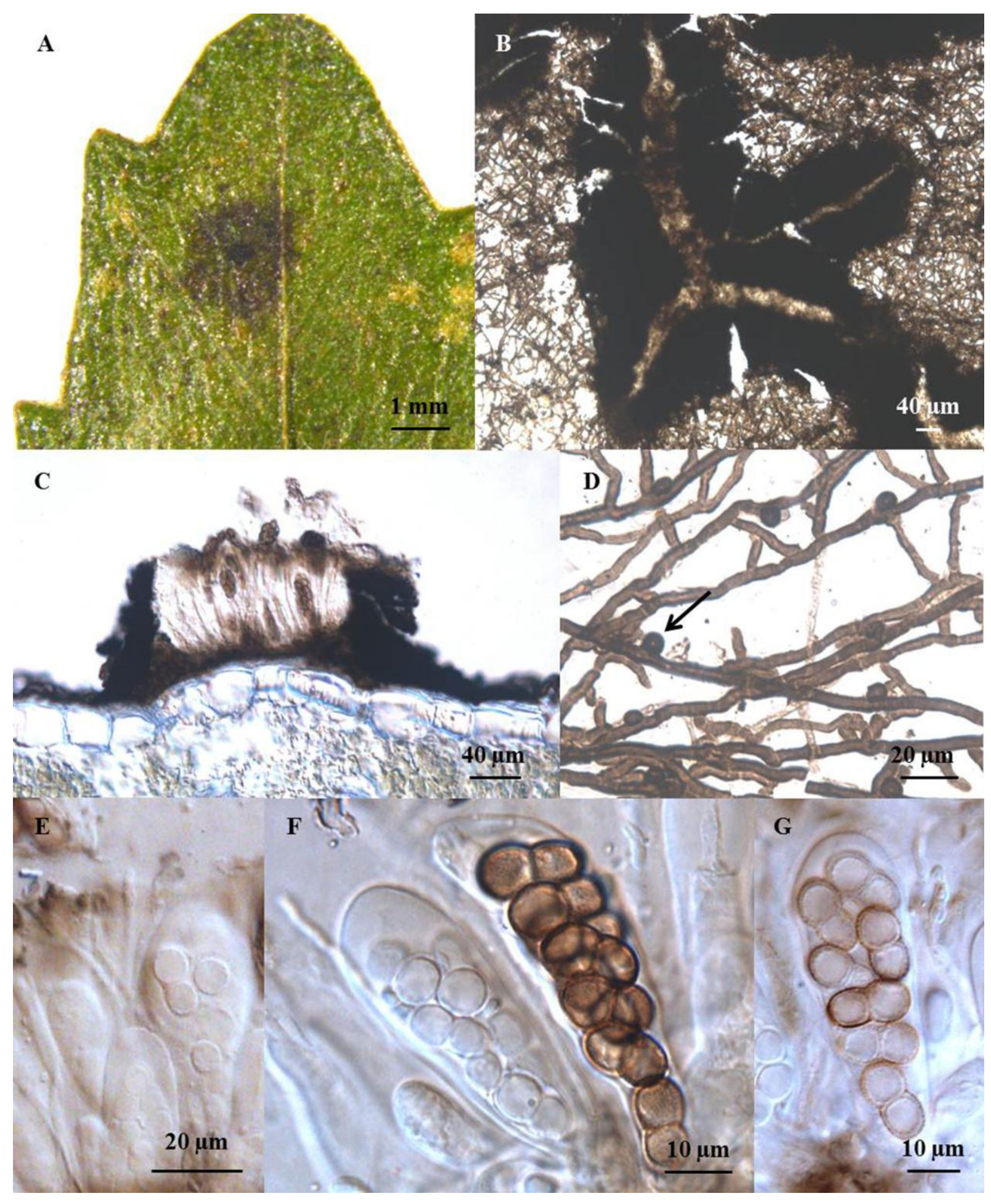

Figura 12. A-G. Lembosia sp. em folhas de Baccharis sp. (Asteraceae) (UB-Micol. Col. 23381). A. Colônia sobre a folha. B. Tiriotécios com abertura em fenda e em forma de Y. C. Corte transversal mostrando a disposição dos ascos. D. Hifopódios. E. Ascos parafisados. FG. Ascósporos. 
3.2.4. Uleothyrium amazonicum Petrak. Annls mycol. 27(5/6): 388 (1929). Figura $13(\mathrm{~A}-\mathrm{G})$

3.2.4.1. Forma conidial picnotírica: Septothyrella Höhn. Sber. Akad. Wiss. Wien, Math.-naturw. Kl., Abt. 1 120: 393 [15 repr.] (1911)

Forma sexuada: Colônias superficiais, anfígenas, negras, confluentes a solitárias, 1-2 mm de diâmetro, dispersas no limbo foliar, com ascomas redondos a elípticos. Micélio superficial nas margens dos ascomas e conidiomas, hifas com 3-4 $\mu \mathrm{m}$ de diâmetro, marrons, septadas, ramificadas, não hifopodiadas. Ascomas misturados com conidiomas, redondos a

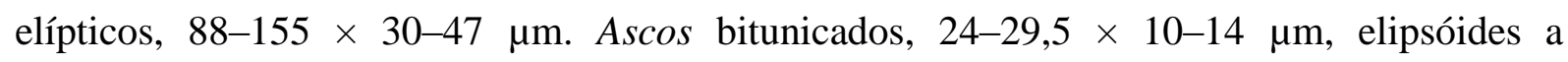
clavados, com pedicelos curtos ou ausentes, contendo oito ascósporos, raramente quatro ou seis. Ascósporos 19-20 × 3-4 $\mu \mathrm{m}$, hialinos a marrom-claros, uniseptados, fusóides, alongados e lisos.

Forma conidial: Conidiomas picnotíricos, superficiais, 90-158 × 25,5-39 $\mu \mathrm{m}$, associados aos ascomas, redondos a elípticos, isolados ou agrupados, globosos, ostiolados, apresentando textura radiata e himênio invertido. Conídios hialinos, 17-20 × 2-4 $\mu \mathrm{m}, 0-4$ septos, sem constrição nos septos, cilíndricos a clavados.

Espécime examinado: em folhas de Salacia crassifolia (Celastraceae), BRASIL, Distrito Federal, Planaltina, Reserva do Mirante, EMBRAPA CPAC; 03/03/2016, Bruno Cézar Pereira de Souza \#125, UB (Col. Micol.) 23395.

O gênero Uleothyrium possui apenas duas espécies registradas, U. amazonicum Petr. e U. leptocarpum Syd., sendo a primeira a espécie tipo do gênero e relatada em Salacia sp (Index Fungorum, 2017).

As características do gênero são as seguintes: a parede de tiriotécio composta de células de textura radiata, ascósporos com 1-3 septos dispostos paralelamente nos ascos, abertura longitudinal do tiriotécio na maturidade e estado conidial picnotírico (Petrak, 1929; Sydow, 
1932; Von Arx e Müller, 1975; Sivanesan, 1984). Outros gêneros com ascósporos cilíndricos em Asterinaceae são Parasterinopsis e Schenckiella. O primeiro difere de Uleothyrium pela abertura larga do tiriotécio, já Schenckiella, por ter ascósporos marrons, assim não são pertencentes ao mesmo gênero (Hongsanan et al., 2014).

O espécime em estudo possui as mesmas características que a espécie tipo, além de ter as medidas de ascomas, ascos e ascósporos semelhantes (Tabela 12). A forma conidial deste fungo foi descrita como Septothyrella uleana Syd. também sobre Salacia sp., proveniente de Rio Acre no Peru, e também foi observada e descrita neste trabalho (Petrak, 1929).

Tabela 12. Características morfométricas das espécies de Uleothyrium.

\begin{tabular}{|c|c|c|c|c|c|c|}
\hline Espécie & $\begin{array}{c}\text { Ascoma } \\
(\mu \mathrm{m})\end{array}$ & $\begin{array}{c}\text { Ascos } \\
(\mu \mathrm{m})\end{array}$ & $\begin{array}{c}\text { Ascósporos } \\
(\mu \mathrm{m})\end{array}$ & $\begin{array}{c}\text { Conidioma } \\
(\mu \mathrm{m})\end{array}$ & $\begin{array}{l}\text { Conídios } \\
(\mu \mathrm{m})\end{array}$ & Septos \\
\hline U. amazonicum ${ }^{1}$ & $\begin{array}{c}200-350 \times \\
100-150\end{array}$ & $\begin{array}{c}30-38 \times 15- \\
17,5\end{array}$ & $\begin{array}{c}24-30 \times 3- \\
5\end{array}$ & até 150 & $\begin{array}{c}18-25 \times \\
3-4\end{array}$ & $1-3$ \\
\hline U. leptocarpum ${ }^{2}$ & $100-150$ & $\begin{array}{c}27-34 \times 10- \\
14\end{array}$ & $\begin{array}{c}22-25 \times 3- \\
3,5\end{array}$ & $80-110$ & $\begin{array}{c}10-12,5 \times \\
2-3\end{array}$ & 0 \\
\hline $\begin{array}{l}\text { U. amazonicum } \\
\text { UB } 01925\end{array}$ & $\begin{array}{c}245-650 \times \\
130-360\end{array}$ & $\begin{array}{c}29-35 \times 14- \\
17\end{array}$ & $\begin{array}{c}20-33 \times 3- \\
5\end{array}$ & $\begin{array}{c}80-170 \times \\
77-180\end{array}$ & $\begin{array}{c}15-21 \times \\
2-4\end{array}$ & $1-3$ \\
\hline $\begin{array}{l}\text { U. amazonicum } \\
\text { UB } 23395\end{array}$ & $\begin{array}{c}88-155[115] \times \\
30-47[36]\end{array}$ & $\begin{array}{c}24-30[27] \times \\
10-14[13]\end{array}$ & $\begin{array}{c}19-20 \\
4\end{array}$ & $\begin{array}{c}90- \\
158[115] \times \\
25,5- \\
39[33]\end{array}$ & $\begin{array}{c}17-20[19] \\
\times 2-4[3]\end{array}$ & $0-4$ \\
\hline
\end{tabular}

${ }^{1}\left(\right.$ Petrak, 1929) ; ${ }^{2}$ (Sydow, 1932); ${ }^{3}$ (Santos, 2011). 


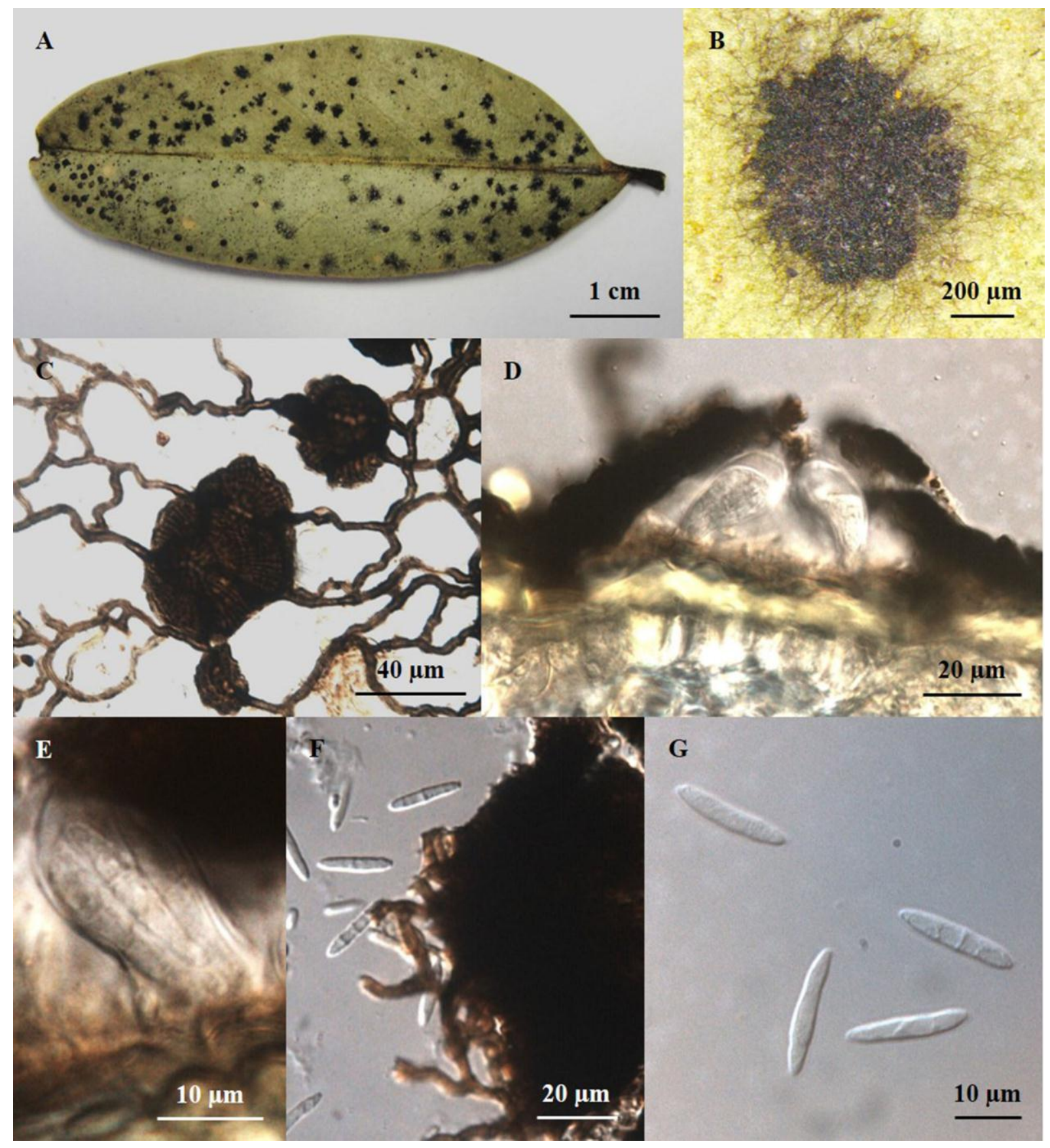

Figura 13. A-G. Uleothyrium amazonicum em folhas de Salacia crassifolia (Celastraceae) (UB 23395). A-B. Colônias sobre a folha. C. Ascomas e hifas. D. Corte transversal mostrando a posição dos ascos. E. Ascos e ascósporos. F-G. Conídios do anamorfo Septothyrella. 


\subsection{Membros da família Erysiphaceae}

3.3.1. Erysiphe heringeriana (U. Braun ex Dianese \& A.C. Dianese) U. Braun \& S. Takam. , Schlechtendalia 4: 20 (2000). Figura 14 (A-F)

Colônias epígenas, esbranquiçadas para cinza claro, circulares ou irregulares, que se aglutinam para produzir manchas que podem ocupar até a superfície inteira da folha. Micélio epifilo, abundante, fino, branco a cinza-claro, subpersistente a persistente formando numerosos ascomas. Hifas 4-5 $\mu \mathrm{m}$ de largura. Conidióforos e conídios ausentes. Ascomas 90-103 $\mu \mathrm{m}$ de diâmetro, epígenos, espalhados na área foliar contendo o micélio, coloração de creme a marrom quando jovens, se tornando marrom-escuros a negros na maturidade, globosos, com paredes mostrando textura angularis. Apêndices 118-190 × 5,5-7 $\mu \mathrm{m}$, ligeiramente mais largos na base, hialinos, asseptados ou com um septo perto da base, circinados. Ascos 50-60 × 40-48 $\mu \mathrm{m}, 3-4$ por ascoma, hialinos, evanescentes, obovoides, subglobosos a globosos, com 2-4 ascósporos. Ascósporos grandes, 20,5-29,5 × 12-21 $\mu \mathrm{m}$, elipsoides, oblongos, hialinos, às vezes gutulados.

Espécime examinado: em folhas de Qualea grandiflora (Vochysiaceae), BRASIL, Distrito Federal, Planaltina, Reserva do Mirante, EMBRAPA CPAC; 21/06/2015, Bruno Cézar Pereira de Souza \#23, UB (Col. Micol.) 23379.

A espécie tipo do gênero Erysiphe é E. polygoni DC, e apresenta as seguintes características: Ascomas subglobosos, ligeiramente achatados, perídios com várias camadas, pigmentados, com apêndices simples, irregulares a dicotomicamente ramificados, com ápice uncinado a circinado; pluriascal, com ascos contento (2-)3-8 ascósporos (Braun e Takamatsu, 2013). A espécie Erysiphe heringeriana (U. Braun ex Dianese \& A.C. Dianese) U. Braun \& S. Takam. conhecida anteriormente por Uncinula heringeriana U. Braun ex Dianese \& A.C. Dianese (Dianese e Dianese, 1995), foi descrita em Qualea grandiflora e possui 
características e dimensões semelhantes à do fungo em questão. Sendo assim, pode-se concluir que se trata da mesma espécie.
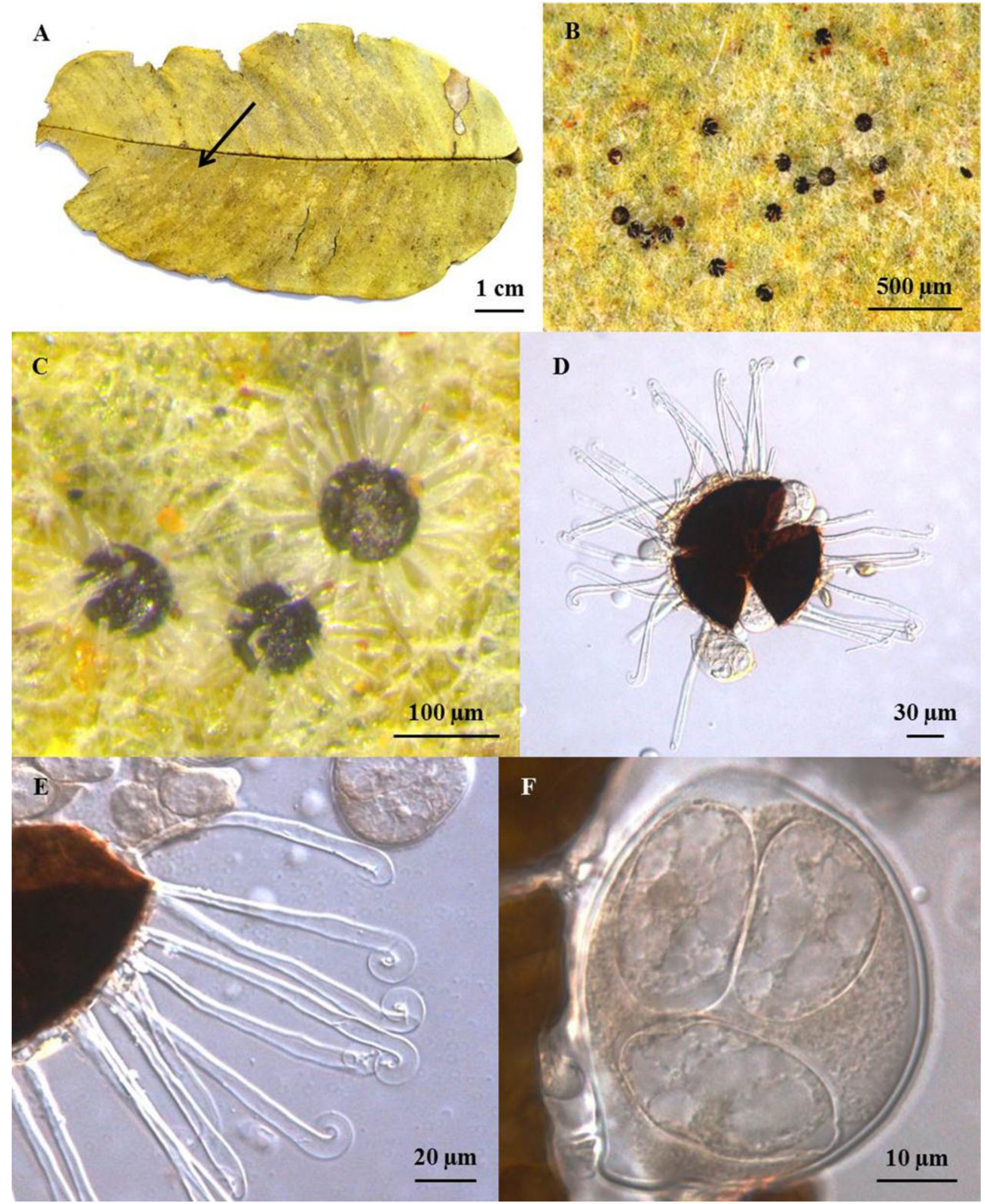

Figura 14. A-F. Erysiphe heringeriana em folhas de Qualea grandiflora (Vochysiaceae) (UB-Micol. Col. 23379). A. Colônias ocupando grande parte da folha. B-C. Ascomas. D. Ascomas com apêndices. E. Apêndices uncinulados. F. Asco e ascósporos. 


\subsection{Membros da família Micropeltidaceae}

3.4.1. Stomiopeltis (provável espécie nova $\mathrm{n}^{\circ}$ 5). Figura $15(\mathrm{~A}-\mathrm{G})$

Colônias hipófilas, gregárias, marrom-escuras a pretas. Micélio superficial, hipófilo, glabro, constituído de hifas marrons, com ausência de hifopódios, flexuosas, ramificadas e septadas. Ascomas 176-384 × 48-87 $\mu \mathrm{m}$, superficiais, glabros, escudatos, com parede de textura radial. Ascos bitunicados, 62,5-81 × 14,5-25 $\mu \mathrm{m}$, clavados a cilíndricos, pedicelados, pseudoparafisados, contendo oito ascósporos. Paráfises filiformes, hialinas, septadas, com

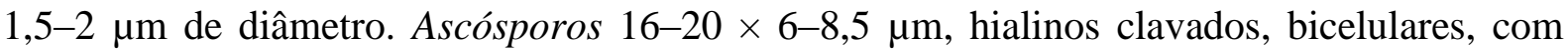
leve constrição no septo.

Espécime examinado: em folhas de Psittacanthus robustus (Loranthaceae), BRASIL, Distrito Federal, Planaltina, Reserva do Mirante, EMBRAPA CPAC; 03/03/2016, Bruno Cézar Pereira de Souza \#119, UB (Col. Micol.) 23391.

O gênero Stomiopeltis foi estabelecido por Theissen no ano de 1914, a espécie tipo é denominada Stomiopeltis aspersa (Berk.) Theissen, e foi relatada em uma espécie de Laureaceae. O gênero está alocado na classe Dothideomycetes, subclasse Incertae sedis, ordem Microthyriales e família Micropeltidaceae. As principais características do gênero são: micélio superficial reticulado, marrom; ascomas superficiais, dimidiados, escudados, uni ou multiloculares, apresentando textura meandriformis; ascos bitunicados, pseudoparafisados e ascósporos bicelulares, hialinos (Batista, 1959).

Atualmente existem 48 registros de espécies de Stomiopeltis, entre elas, dez foram relatadas no Brasil (Index Fungorum, 2017). Essas espécies juntamente com quatro espécies descritas em trabalhos realizados na UnB, foram comparadas com o espécime em estudo (Tabela 13). Quanto o tamanho do ascoma, somente S. batistae, S. suttonniae e S. tetrasperma se aproximam do espécime em estudo, que apresenta ascos e ascósporos menores que $S$. batistae, porém, maiores que todos os demais espécimes. Mediante tais divergências pode-se 
inferir que o espécime em estudo é provavelmente uma nova espécie do gênero Stomiopeltis, além de tratar-se do primeiro relado do mesmo na família Loranthaceae. 
Tabela 13. Características morfométricas das espécies de Stomiopeltis relatadas no Brasil.

\begin{tabular}{|c|c|c|c|c|}
\hline Espécies de Stomiopeltis & $\begin{array}{c}\text { Ascoma } \\
(\mu \mathrm{m})\end{array}$ & $\begin{array}{c}\operatorname{Ascos} \\
(\mu \mathrm{m})\end{array}$ & $\begin{array}{c}\text { Ascósporos } \\
(\mu \mathrm{m})\end{array}$ & Hospedeira \\
\hline S. aspersa (Berk.) Theiss. ${ }^{1 *}$ & $137-180$ & $35 \times 9-10$ & $8-9 \times 2-2,7$ & Laurus (Lauraceae) \\
\hline S. batistae Arx ${ }^{2}$ & $400-600 \times 30-40$ & $90-125 \times 8-11$ & $26-31 \times 4-6$ & Rourea glabra (Connaraceae) \\
\hline S. cassiae J.M. Mend ${ }^{3}$ & 88-134 & $33-38 \times 9$ & $8-10,5 \times 2,6-3$ & Cassia sp. (Fabaceae) \\
\hline S. citri BitanC. ${ }^{3}$ & $140-200$ & $22-46 \times 6,5-11$ & $6-11 \times 2-4$ & Citrus sp. (Rutaceae) \\
\hline S. minor (BitanC.) Luttr. ${ }^{3}$ & $50-80$ & $17-28 \times 7-12$ & $6-10 \times 2-3$ & Citrus sp. (Rutaceae) \\
\hline S. myrceae Bat. ${ }^{4}$ & Até $150 \varnothing$ & $27-42 \times 8-11,5$ & $8-9,5 \times 3-4$ & Myrcia sp. (Myrtaceae) \\
\hline S. rubi (Fuckel) Petr. ${ }^{5}$ & $150-200 \times 25$ & $16-20 \times 12-15$ & $7-11 \times 3-4,5$ & Rubus ideaus (Rosaceae) \\
\hline S. suttonniae (J.M. MenD.) Luttr. ${ }^{3}$ & $231-408$ & $30-51 \times 12-15$ & $12-15 \times 3,5-5$ & $\begin{array}{c}\text { Myrsine lessertiana (Suttonia } \\
\text { lessertiana) (Primulaceae) }\end{array}$ \\
\hline S. tephrosiae Viégas ${ }^{6}$ & $80-140$ & $40-60 \times 10-12$ & $12-17 \times 4-5$ & Thephrosia candida (Fabaceae) \\
\hline S. tetrasperma Bat., Bezerra \& Moura ${ }^{7}$ & $240-480$ & $30-55 \times 7,5-11$ & $10-13,5 \times 3-4$ & Anacardium sp. (Anacardiaceae) \\
\hline $\begin{array}{l}\text { Stomiopeltis sp. } \\
\text { UB } 10041\end{array}$ & $103-207 \times 25-46$ & $35-55 \times 8-10$ & $13-17 \times 3-5$ & Qualea sp. (Vochysiaceae) \\
\hline $\begin{array}{l}\text { Stomiopeltis sp. } \\
\text { UB } 1250\end{array}$ & $80-180$ & $25-35 \times 4-8$ & $7-8 \times 1,5-2$ & Salacia crassifolia (Celastraceae) \\
\hline $\begin{array}{l}\text { Stomiopeltis sp. } \\
\text { UB } 6908\end{array}$ & $70-250$ & $38-55 \times 9-15$ & $15-21 \times 3-5$ & Salacia sp. (Celastraceae) \\
\hline $\begin{array}{l}\text { Stomiopeltis sp. } \\
\text { CMEPH M39 } 808\end{array}$ & $\begin{array}{c}70-129[106] \times 15-27 \\
{[15]}\end{array}$ & $23,5-33[33] \times 6,5-9[8,5]$ & $5,5-10,5[7] \times 2-3[2]$ & Ilex affinis (Aquifoliaceae) \\
\hline $\begin{array}{l}\text { Stomiopeltis prov. sp. nv. } \\
\text { UB } 23391\end{array}$ & $\begin{array}{c}176-384[274] \times 48- \\
87[64]\end{array}$ & $62,5-81[70,5] \times 14,5-25[18]$ & $\begin{array}{c}16-20[18] \times 5,5- \\
8,5[7]\end{array}$ & $\begin{array}{l}\text { Psittacanthus robustus } \\
\text { (Loranthaceae) }\end{array}$ \\
\hline
\end{tabular}

${ }^{1}$ (Theissen, 1914); ${ }^{2}$ (Von Arx, 1960); ${ }^{3}$ (Luttrell, 1946); ${ }^{4}$ (Batista, 1959); ${ }^{5}$ (Petrak, 1923); ${ }^{6}$ (Viégas, 1944); ${ }^{7}$ (Batista et al., 1966); ${ }^{8}$ (Dornelo-Silva, 1999);

${ }^{9}\left(\right.$ Santos, 2011); ${ }^{10}$ (Souza, 2011); *Espécie tipo. 


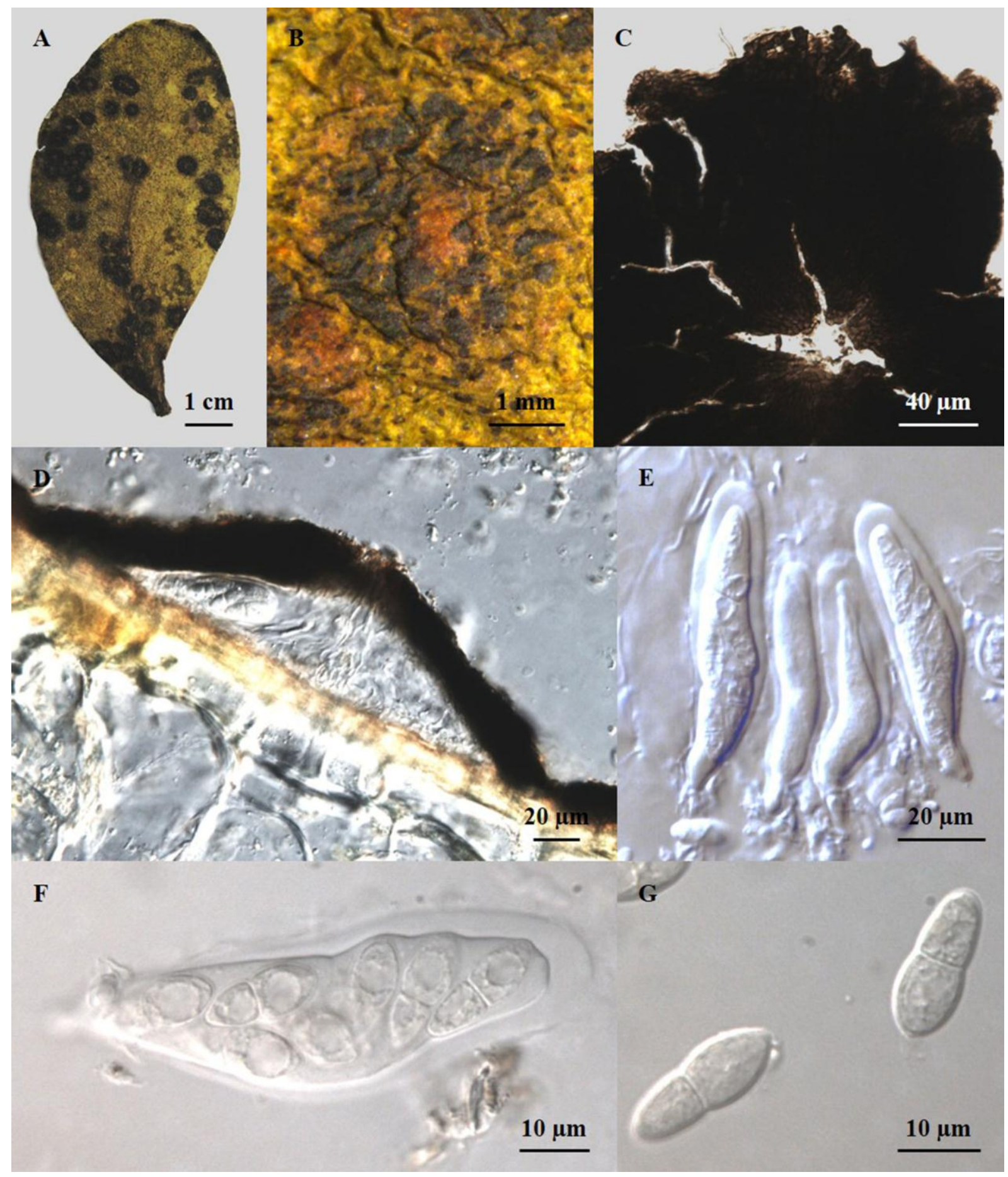

Figura 15. A-G. Stomiopeltis sp. em folhas de Psittacanthus robustus (Loranthaceae) (UBMicol. Col. 23391). A-B. Colônias sobre a folha. C. Ascoma dimidiado com abertura irregular. D. Corte transversal mostrando posição do asco e pseudoparáfises. E-F. Ascos. G. Ascósporos. 


\subsubsection{Dictyopeltis (provável espécie nova ${ }^{\circ}$ 6). Figura $16(\mathrm{~A}-\mathrm{F})$}

Ascomas 105-189 $\mu \mathrm{m}$ de diâmetro, superficiais, sésseis, escuros, escutelares, marromclaros a marrom-escuros, com tecido micelial mais claro nas bordas, isolados, dispersos em todo limbo foliar. Micélio livre não observado. Ascos bitunicados, globosos a obclavados, 2641,5 × 13,5-17 $\mu \mathrm{m}$, contendo oito a dezesseis ascósporos. Ascósporos elipsóides, 7-12 × 3-4 $\mu \mathrm{m}$, hialinos, bicelulares, lisos, com leve constrição no septo.

Espécime examinado: em folhas de Qualea grandiflora (Vochysiaceae), BRASIL, Distrito Federal, Planaltina, Reserva do Mirante, EMBRAPA CPAC; 21/06/2015, Bruno Cézar Pereira de Souza \#23, UB (Col. Micol.) 23379.

O fungo examinado é provavelmente um gênero de Dictyopeltis, membro da família Micropeltidaceae (subfamília Dyctiopeltoideae sensu Batista 1959). A espécie tipo é Dictyopeltis vulgaris (Racib.) Theissen, e as características do gênero são as seguintes: Tiriotécios superficiais, orbiculares, membranosos ou carbonáceos, de estrutura reticulada, não radiada e margens fimbriadas ou não, de coloração negra, cinza-escura ou marrom, sem abertura, abrindo-se irregularmente na maturidade; himênio simples, contendo vários ascos; ascos globosos a subglobosos, elípticos a clavados, aparafisados, sésseis; ascósporos bicelulares, com constrição ou não no septo (Batista, 1959). Atualmente, há onze nomes registrados de Dictyopeltis, no entanto, algumas espécies foram realocadas e outras ainda estão desatualizadas no Index Fungorum, são elas: D. erythroxyli Bat. \& A.F. Vital e D. lucumae Bat., que foram realocados para Microthyriella erythroxylii (Batista \& Vital) Batista e Microthyriella lacumae (Batista) Batista (Batista, 1959). Já Dictyopeltis consimilis Syd. e Dictyopeltis domingensis Petr. \& Cif. foram realocados como Dictyopeltella consimilis (Syd.) Bat. e Dictyopeltella domingensis (Petr. \& Cif.) Bat. \& I.H. Lima, consecutivamente (Index Fungorum, 2017). 
O espécime em estudo foi comparado com oito espécies de Dictyiopeltis (Tabela 14). Em relação ao tamanho dos ascomas, as espécies $D$. applanata, D. colubrina e $D$. costi se assimilaram à espécie em estudo, já em relação aos ascósporos, as espécies D. applanata, D. colubrina, D. costi e D. vulgaris possuem semelhanças com o espécime estudado. As diferenças encontradas são em relação à dimensão dos ascos, que não se assemelha com nenhuma espécie conhecida de Dictyopeltis, em relação ao número de ascósporos dentro dos ascos, pois a espécie em estudo contém de 8 ou 16 ascósporos em cada asco, e em relação à hospedeira, que até então não havia relatado a presença de tal fungo. Sendo assim, pode-se concluir que se trata de uma nova espécie de Dictyopeltis. 
Tabela 14. Características morfométricas das espécies de Dictyopeltis.

\begin{tabular}{|c|c|c|c|c|c|}
\hline $\begin{array}{l}\text { Espécies de } \\
\text { Dictyopeltis }\end{array}$ & $\begin{array}{c}\text { Ascoma } \\
(\mu \mathrm{m})\end{array}$ & $\begin{array}{c}\text { Ascos } \\
(\mu \mathrm{m})\end{array}$ & $\begin{array}{l}\text { Ascósporos } \\
\quad(\mu \mathrm{m})\end{array}$ & Hospedeiro & Local \\
\hline D. caseariae $^{2}$ & 400 & $26-30$ & $16-18 \times 6,5-7$ & Caesaria engleri & Uganda \\
\hline D. colubrina ${ }^{3}$ & $200-250$ & $13-22 \times 8-11$ & $7-8 \times 2-2,5$ & Colubrina reclinata & Índia \\
\hline D. $\cos t i^{2}$ & $95-135$ & $15-25 \times 10-13,5$ & $7-5-10 \times 2,5-4$ & Costus sp. & Brasil \\
\hline D. erythroxyli $i^{2}$ & $230-482$ & $50-57 \times 34-42$ & $34-46 \times 11,5-15$ & Erythroxylon pelletieranum & Brasil \\
\hline D. lucumae ${ }^{2}$ & $350-900$ & $65-80 \times 55-65$ & $50-65 \times 12-16$ & Lucuma sp. & Brasil \\
\hline D. vulgaris ${ }^{4 *}$ & $500-700$ & $17-21$ & $9-12 \times 3-4$ & Hydnocarpus, Garcinia, Canarium sp. & Indonésia \\
\hline
\end{tabular}




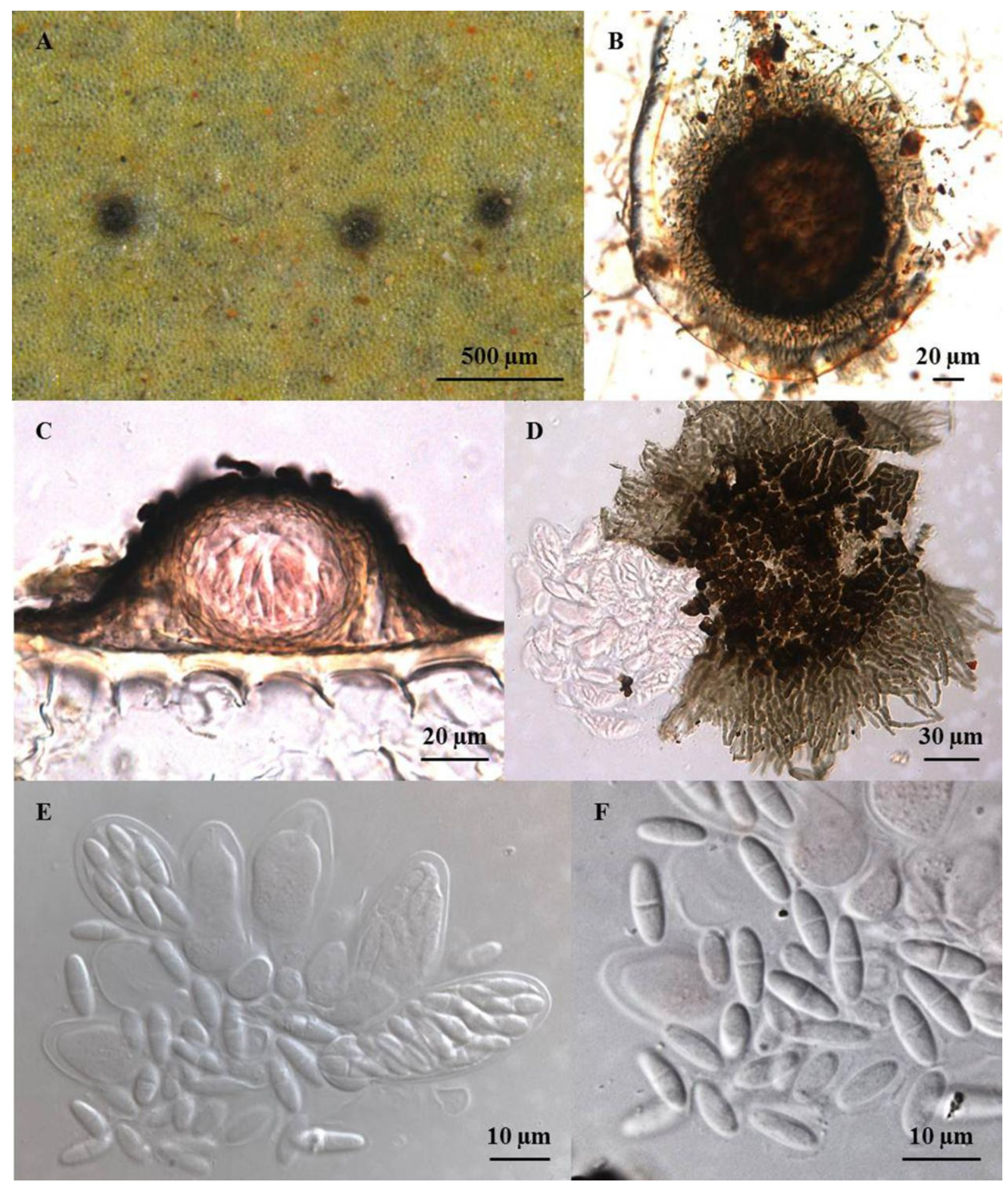

Figura 16. A-F. Dictyopeltis sp. em folhas de Qualea grandiflora (Vochysiaceae) (UBMicol. Col. 23379). A. Ascomas sobre a folha. B. Ascoma com bordas mais claras. C. Corte transversal mostrando a disposição dos ascos. D. Ascoma e ascos. E. Ascos. F. Ascósporos. 


\subsection{Membros da família Parmulariaceae}

3.5.1. Dothidasteroma psidii Inácio, Pereira-Carv., E.S.C. Souza \& Dianese, Mycotaxon 116: 28 (2011). Figura 17 (A-G)

Lesões dispersas pela folha ou confluentes, 1-5 $\mathrm{mm}$ de diâmetro, epifilas e também, mas com menos frequência, hipófilas, elípticas ou circulares a irregulares, de coloração marrom ao marrom escuro, com bordas avermelhadas a roxas; ao longo da nervura central aparecem colônias anfígenas, elípticas ou alongadas, escuras, contendo uma agregação de estromas negros, discoides. Micélio interno, notável, hialino, filamentoso; hifas 2-4 $\mu \mathrm{m}$ de diâmetro. Estromas subcuticulares, intracuticulares a intradérmicos. Ascomas provenientes do estroma imerso, 54,5-207 $\mu \mathrm{m}$, escudados, variáveis em forma, geralmente circulares, marrons a marrom-escuros, confluentes, apresentando abertura em fissuras irregulares. Ascos 29-52,5 $\times$ 13-20 $\mu \mathrm{m}$, obovoides a clavados, hialinos, contendo oito ascósporos dispostos em duas fileiras ou agrupados. Ascósporos 15,5-17 $\times 5-7 \mu \mathrm{m}$, inicialmente hialinos, recebendo uma coloração marrom clara a marrom na maturidade, elipsoides a cilíndricos, paredes finas e lisas, uniseptados, com constrição nos septos.

Espécime examinado: em folhas de Psidium laruotteanum. (Myrtaceae), BRASIL, Distrito Federal, Planaltina, Reserva do Mirante, EMBRAPA CPAC; 03/03/2016, Bruno Cézar Pereira de Souza \#119, UB (Col. Micol.) 23390.

O gênero Dothidasteroma tem D. maculosum como espécie tipo (Bas. Rhytisma maculosum Berk. \& Broome), e apresenta as seguintes características: presença de subicullum subcuticular, formado por uma camada de células; superficial, com estroma plano e lóculos irregulares em sua maioria, abertos por fissuras; ascos contendo oito ascósporos, esses últimos sendo bicelulares (Höhnel, 1909a). Atualmente, o gênero registra quatro espécies, Dothidasteroma pterygotae (Berk. \& Broome) Höhnel, responde como D. maculosum, que foi relatado parasitando folhas de Pterygota alata (Sterculiaceae) e Cansjera rheedii 
(Opiliaceae), no Sri Lanka (Inácio e Cannon, 2008). A única espécie descrita no Brasil é D. psidii Inácio, Pereira-Carv., E.S.C. Souza \& Dianese, relatada sobre Psidium laruotteanum. (Myrtaceae), a mesma hospedeira do fungo estudado (Inácio et al., 2011).

Todas as espécies foram comparadas com o espécime em estudo (Tabela 15), e constatou-se que se trata da mesma espécie já relatada no Brasil, já que as medidas se enquadram nas medidas relatadas e o hospedeiro é o mesmo. 
Tabela 15. Comparação das espécies de Dothidasteroma com a encontrada sobre Psidium laurottenum.

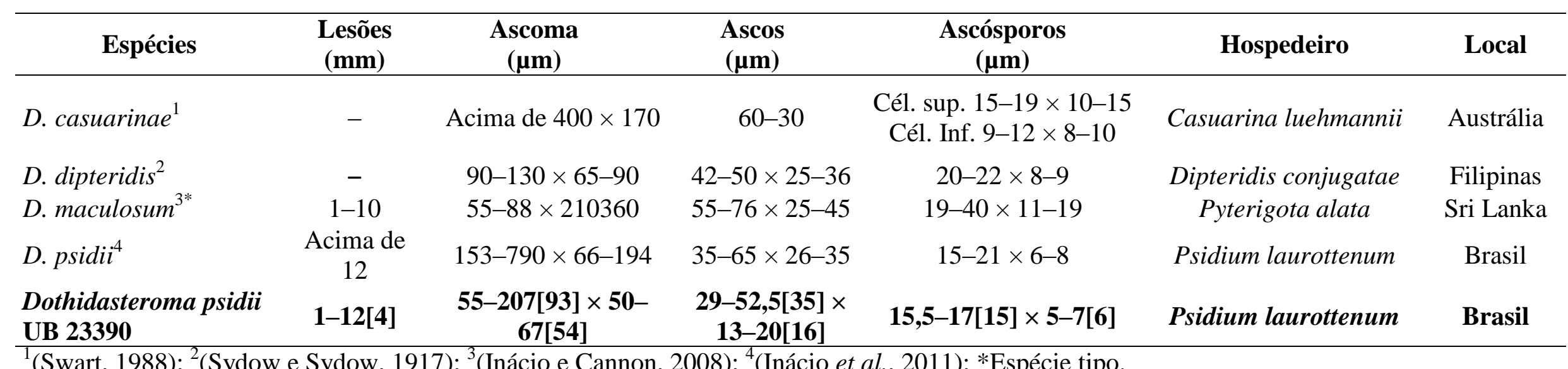



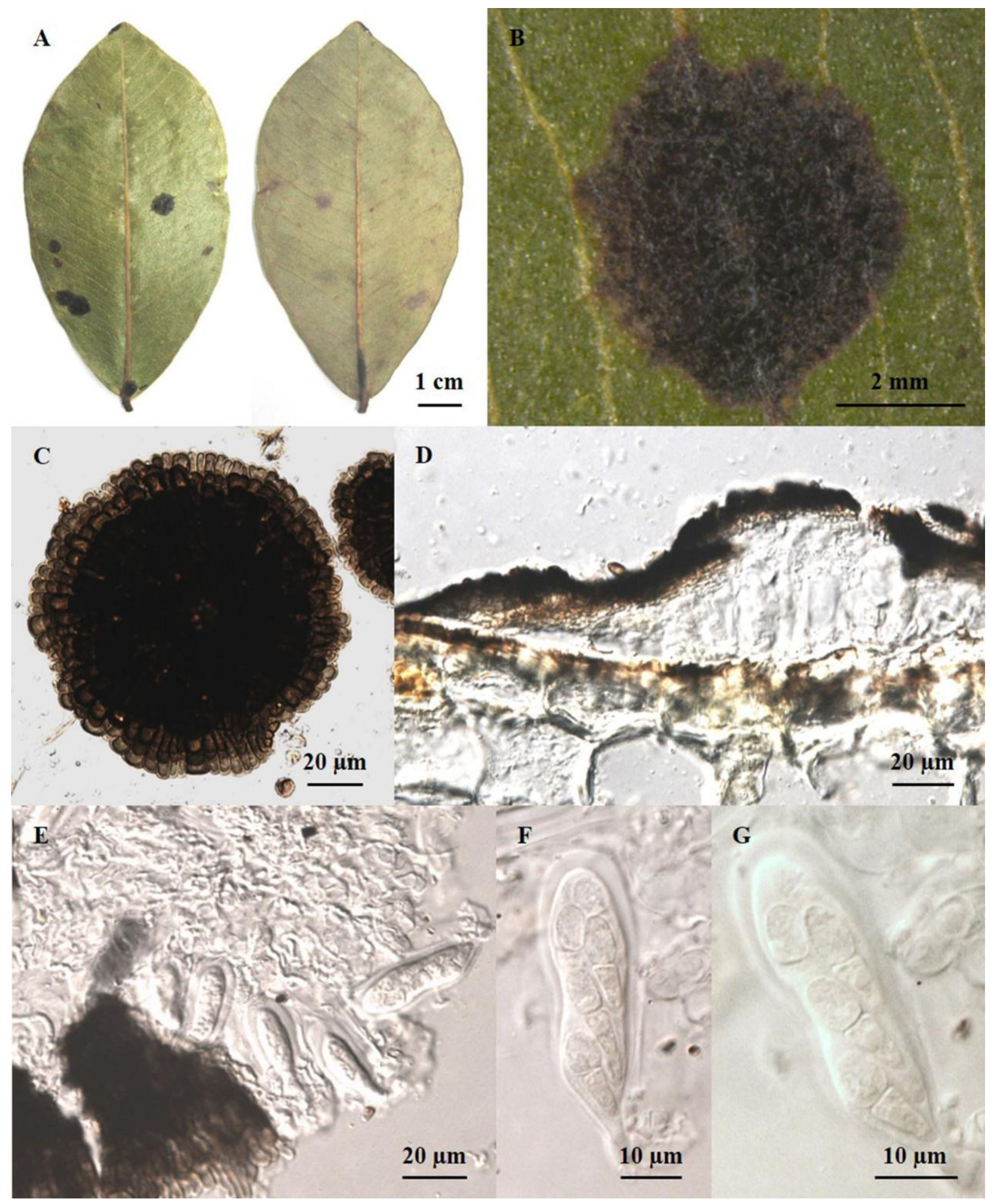

Figura 17. A-G. Dothidasteroma psidii em folhas de Psidium laruotteanum. (Myrtaceae) (UB-Micol. Col. 23390). A. Folha com lesões na face adaxial e abaxial. B. Detalhe da lesão. C. ascoma. D. Corte transversal mostrando colonização do fungo nas células foliares. E. Ascos imaturos. F-G. Ascos e ascósporos. 
3.5.2. Parmularia styracis Lév., Annls Sci. Nat., Bot., sér. 3 5: 286 (1846). Figura $18(\mathrm{~A}-\mathrm{F})$

Colônias superficiais, 1,5-3 mm, discoide, na face adaxial das folhas, não associada a necrose. Micélio externo ausente e interno presente. Estroma externo epifilo, discoide, franjado nas bordas, 1,5-3 mm de diâmetro. Estroma interno globular, 60-60 × 73-172 $\mu \mathrm{m}$. Haustórios coraloides. Pseudoparáfises hialinas 1,5-3 $\mu \mathrm{m}$ de largura, septadas. Ascos bitunicados, truncados na base, cilíndricos a clavados, 45-63,5 × 7,5-10 $\mu \mathrm{m}$, contendo oito ascósporos. Ascósporos elípticos a clavados, hialinos quando imaturos e oliváceos a marrom quando maduros, bicelulares, com a célula superior mais arredondada, 12-14,6 × 3-3,9 $\mu \mathrm{m}$. Forma assexuada ausente.

Espécime examinado: em folhas de Styrax ferrugineus (Stiracaceae), BRASIL, Distrito Federal, Planaltina, Reserva do Mirante, EMBRAPA CPAC; 03/03/2016, Bruno Cézar Pereira de Souza \#128, UB (Col. Micol.) 23396.

O gênero Parmularia tem $P$. styracis Lév. como espécie tipo, possui 55 nomes registrados, sendo alguns variações subespecíficas (Index Fungorum, 2017). A família Parmulariaceae inclui fungos formando colônias folícolas ou liquenícolicas, superficiais, castanho-escuras a pretas; haustórios coraloides, hialinos, numerosos em cada célula hospedeira; ascomas solitários a gregários, superficiais (ou raramente imersos), escudados, estelares, elipsoidais ou em forma de barco, fortemente aplanados, membranáceos a carbonáceos, originários de hifas emergentes ou de um hipostroma eruptivo, cobertos por uma parede escura composta muitas vezes de fileiras de células radiantes e aberturas por fissura ou por deliquescência, marrom-escuros a pretos; ascos contendo oito ascósporo, paredes espessas, fissitunicados, de formas variadas, pedicelos curtos, com uma câmara ocular distinta, ascósporos oblongos, elipsoidais ou ovoides, terminam arredondados, uniseptados, constrito ou não no septo, hialinos a castanho-escuros, lisos à verrugosos (Léveillé, 1846; 
Inácio e Cannon, 2008; Hyde et al., 2013). A espécie tipo apresenta as seguintes sinonímias: Schneepia guaranitica Speg, Parmularia guaranitica (Speg.) Henn., Schneepia arechavaletae Speg., Parmularia arechavaletae (Speg.) G. Arnaud, Parmularia styracis var. minor Henn.(Index Fungorum, 2017).

Para comparação da espécie estudada foram utilizadas espécies de Parmularia relatadas no Brasil (Tabela 16). A espécie com a hospedeira em comum, P. styracis, foi a que mais se assemelhou à espécie em estudo. Verificou-se que a espécie em estudo estava, todavia, imatura, por isso as medidas se apresentaram menores em relação à espécie de $P$. styracis. Mesmo assim pode-se concluir que se trata da espécie Parmularia styracis Lév.

Tabela 16. Características morfométricas de espécies de Parmularia relatadas no Brasil.

\begin{tabular}{|c|c|c|c|c|c|}
\hline $\begin{array}{l}\text { Espécies de } \\
\text { Parmularia }\end{array}$ & $\begin{array}{c}\text { Ascoma } \\
(\mathbf{m m})\end{array}$ & $\begin{array}{c}\text { Estroma } \\
\text { interno }(\mu \mathrm{m})\end{array}$ & $\begin{array}{c}\text { Ascos } \\
(\mu \mathrm{m})\end{array}$ & $\begin{array}{c}\text { Ascósporos } \\
(\boldsymbol{\mu m})\end{array}$ & Hospedeiro \\
\hline P. miconiae ${ }^{1}$ & $0,5-1,25$ & $45-80 \times 75-200$ & $43-70 \times 17-26$ & $16-21 \times 7-9$ & Miconia sp. \\
\hline P. porteae ${ }^{1}$ & - & $\begin{array}{c}55-145 \times 110- \\
600\end{array}$ & $45-90 \times 11-35$ & $\begin{array}{c}23-32 \times 8- \\
13\end{array}$ & Portea sp \\
\hline P. radians $^{1}$ & $1-2$ & $\begin{array}{c}45-115 \times 90- \\
330\end{array}$ & $42-77 \times 12-16$ & $15-19 \times 5-8$ & Xylopia sp. \\
\hline P. styracis ${ }^{2 *}$ & $2-3$ & $\begin{array}{c}76-365 \times 100- \\
320\end{array}$ & $47-81 \times 9-18$ & $14-20 \times 5-7$ & $\begin{array}{c}\text { Styrax } \\
\text { ferrugineus }\end{array}$ \\
\hline P. uleana ${ }^{1}$ & $0,4-3$ & $\begin{array}{c}53-135 \times 70- \\
400(-945)\end{array}$ & $50-95 \times 20-35$ & $\begin{array}{c}21-30 \times 8- \\
12\end{array}$ & $\begin{array}{l}\text { Aechmea } \\
\text { pectinata }\end{array}$ \\
\hline $\begin{array}{l}\text { P. styracis } \\
\text { UB } 23396\end{array}$ & $1,5-3[2,5]$ & $\begin{array}{c}50-60[55] \times 73- \\
172[131]\end{array}$ & $\begin{array}{c}45-63,5[55] \times \\
7,5-9,5[8,5]\end{array}$ & $\begin{array}{c}12- \\
14,5[13,5] \times \\
3-4[3,5]\end{array}$ & $\begin{array}{c}\text { Styrax } \\
\text { ferrugineus }\end{array}$ \\
\hline
\end{tabular}




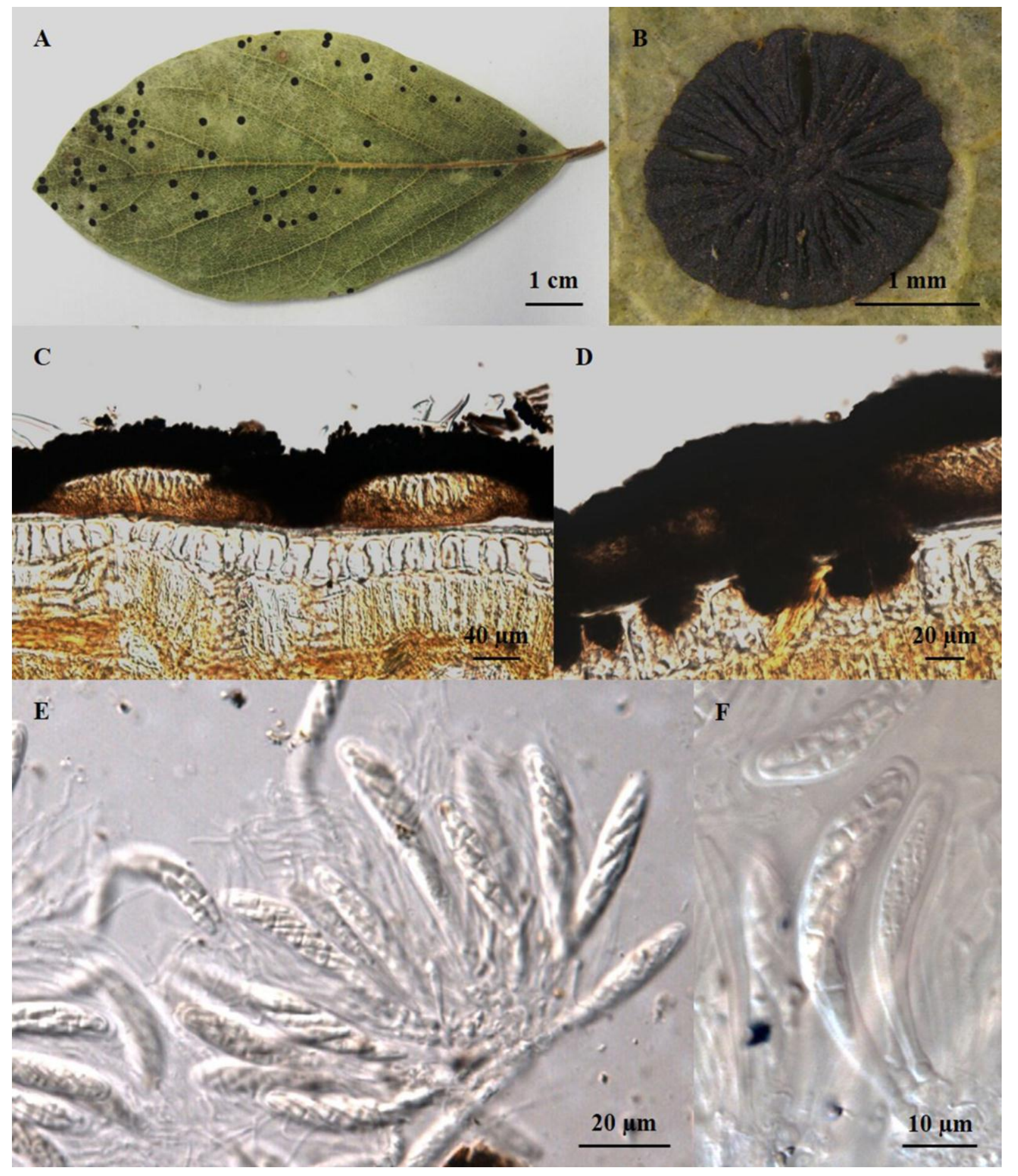

Figura 18. A-F. Parmularia styracis em folhas de Styrax ferrugineus (Stiracaceae) (UBMicol. Col. 23396). A. Lesões foliares. B. Ascoma. C. Corte transversal mostrando lóculos. D. Haustórios. E. Ascos parafisados. F. Ascósporos. 


\subsection{Membros da família Phyllachoraceae}

3.6.1. Apiosphaeria guaranitica (Speg.) Höhn., Sber. Akad. Wiss. Wien, Math.naturw. Kl., Abt. 1 118: 1218 [62 repr.] (1909). Figura 19 (A-E)

Pseudostromas espessos, de coloração laranja a marrom escuro, superficiais, epifilos, multiloculares, chegando a medir mais de $1 \mathrm{~cm}$ de diâmetro e mais de $360 \mu \mathrm{m}$ de espessura, podendo ocupar grande parte do limbo foliar. Ascomas peritecióides, rostrados, arredondados

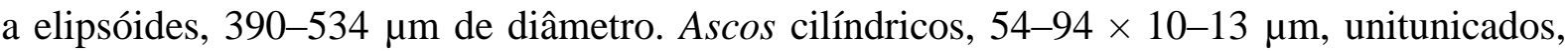
contendo oito ascósporos ordenados de forma unisseriada. Ascósporos hialinos, elípticos, bicelulares, com a parte inferior papilada, 10-13 × 5-7 $\mu \mathrm{m}$. Estado anamorfo ausente.

Espécime examinado: em folhas de Handroanthus ochraceus (Bignoniaceae), BRASIL, Distrito Federal, Planaltina, Reserva do Mirante, EMBRAPA CPAC; 03/03/2016, Bruno Cézar Pereira de Souza \#124, UB (Col. Micol.) 23393.

Trata-se de uma espécie do gênero Apiosphaeria, que tem como espécie tipo A. guaranitica (Speg.) Höhn (Höhnel, 1909b). Spegazzini havia alocado o mesmo fungo em Munkiella guaranitica, gênero de sua autoria, que atualmente é basiônimo de A. guaranitica (Speggazini, 1885; Viégas, 1943). As características do gênero são: Ausência de estroma; peritécios rostrados, claros, carnosos, inseridos no pseudoestroma; paráfises ausentes; ascos cilíndricos; ascósporos elípticos, hialinos, compostos por duas células desiguais em tamanho. Atualmente o gênero contém seis registros, sendo eles: Apiosphaeria controversa (Starbäck) Arx, que foi realocada para Stigmochora controversa; A. guaranitica (Speg.) Höhn.; A. indica S.K. Bose; A. nipponica I. Hino \& Katum.; A ospinae (Chardón) Petr. e A. topographica (Speg.) Arx (Index Fungorum, 2017).

A espécie em estudo apresenta similaridade com uma espécie muito comum relatada em espécies de Handroanthus, ou Ypê, A. guaranitica (Speg.) Höhn. Suas medidas e o 
hospedeiro em comum auxiliam na constatação de que se trata da mesma espécie (Höhnel, 1909b).
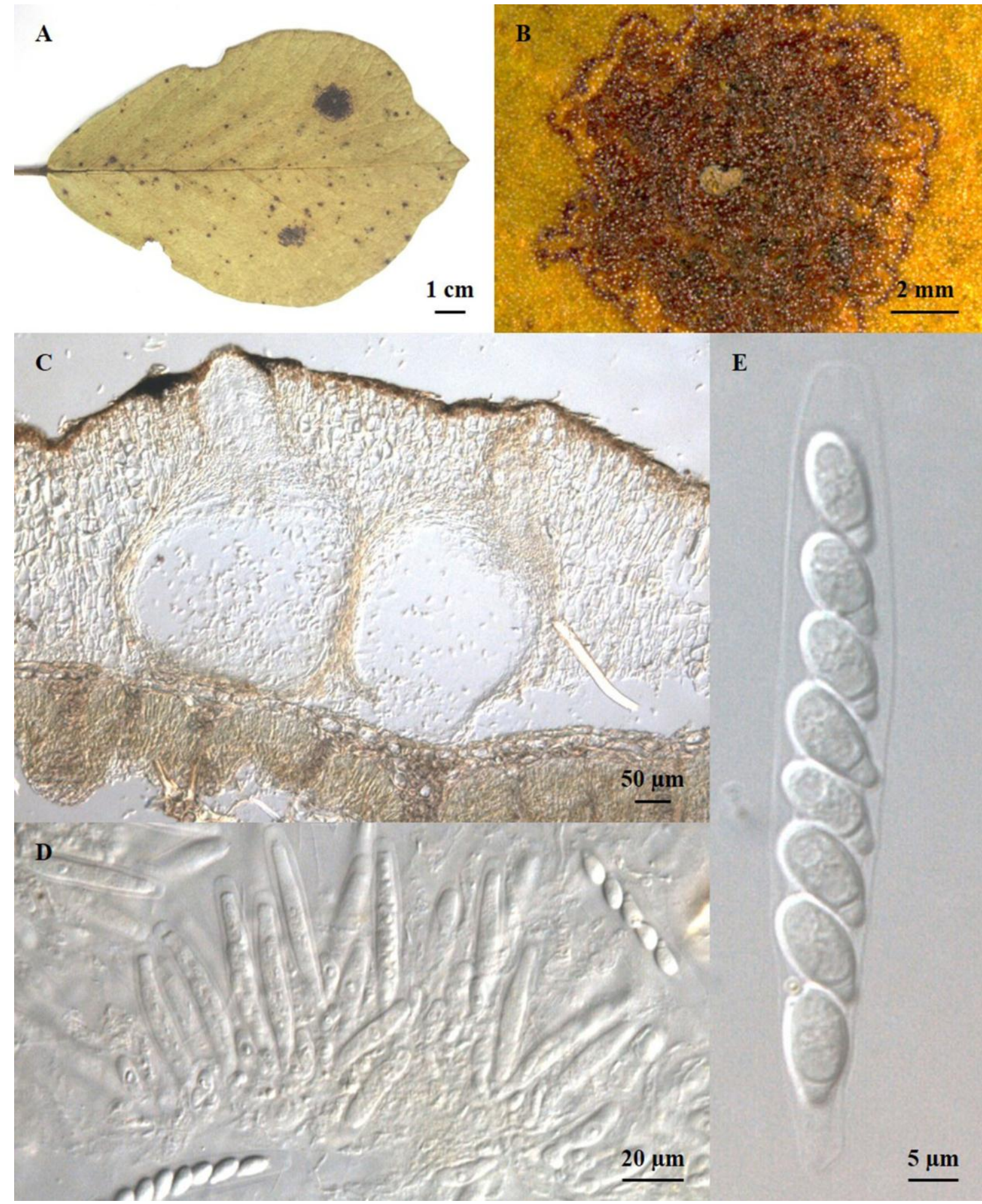

Figura 19. A-E. Apiosphaeria guaranitica em folhas de Handroanthus ochraceus (Bignoniaceae) (UB-Micol. Col. 23393). A. Folha com lesões. B. Pseudoestorma. C. Corte transversal contendo peritécios. D. Ascos. E. Ascósporos. 
3.6.2. Phaeochorella parinari (Henn.) Theiss. \& Syd. , Annls mycol. 13(3/4): 405 (1915) Figura 20 (A-I)

Pseudostroma epifilo, com formato irregular, gregário ou isolado, $2,5-3 \mathrm{~mm}$ de diâmetro, negro, pouco brilhante, subepidérmico, clipeado, multiloculado. Ascomas circulares a elipsóides, 148-335 $\mu \mathrm{m}$ de diâmetro. Ascos cilíndricos a clavados, arredondados no ápice, unitunicados, 77-90 × 10-13 $\mu \mathrm{m}$, contendo oito ascósporos dispotos de forma unisseriada em sua maioria, raramente bisseriados, parafisados. Paráfises hialinas, com $1,5-4 \mu \mathrm{m}$ de espessura. Ascósporos elípticos a oblongos, arredondado nas extremidades, marrons, unicelulares, com uma banda hialina no meio, $11-13 \times 5,5-7 \mu \mathrm{m}$.

Espécime examinado: em folhas de Parinari obtusifolia (Chrysobalanaceae), BRASIL, Distrito Federal, Planaltina, Reserva do Mirante, EMBRAPA CPAC; 03/03/2016, Bruno Cézar Pereira de Souza \#129, UB (Col. Micol.) 23397.

O gênero Phaeochorella tem P. parinarii (Henn.) Theiss. \& Syd. (Basiônimo: Cocconia parinarii Henn.) como espécie tipo e apresentas as seguintes características: Estroma entre epiderme e tecido paliçádico, coberto por epiderme estromatizada, formada por hifas dispostas verticalmente; lóculos imersos; ascos parafisados; ascósporos marrons, unicelulares (Theissen e Sydow, 1915a).

Atualmente há sete nomes registrados, no entanto, Phaeochorella sphaerospora Chardón, foi renomeada como Phyllachora conica (Chardón) Petr (Index Fungorum, 2017). A espécie em estudo foi comparada com cinco espécies atualmente denominadas como Phaeochorella (Tabela 17), já que não foram encontrados os dados da espécie $P$. artocarpi T.S. Ramakr. \& K. Ramakr. para fazer a comparação. A espécie em estudo apresenta estreita relação com P. parinarii (Henn.) Theiss. \& Syd., pois apresenta medidas estruturais semelhantes e parasitam a mesma espécie de planta. Logo, pode-se concluir que se trata de uma espécie de $P$. parinarii. 
Tabela 17. Características morfométricas das espécies de Phaeochorella.

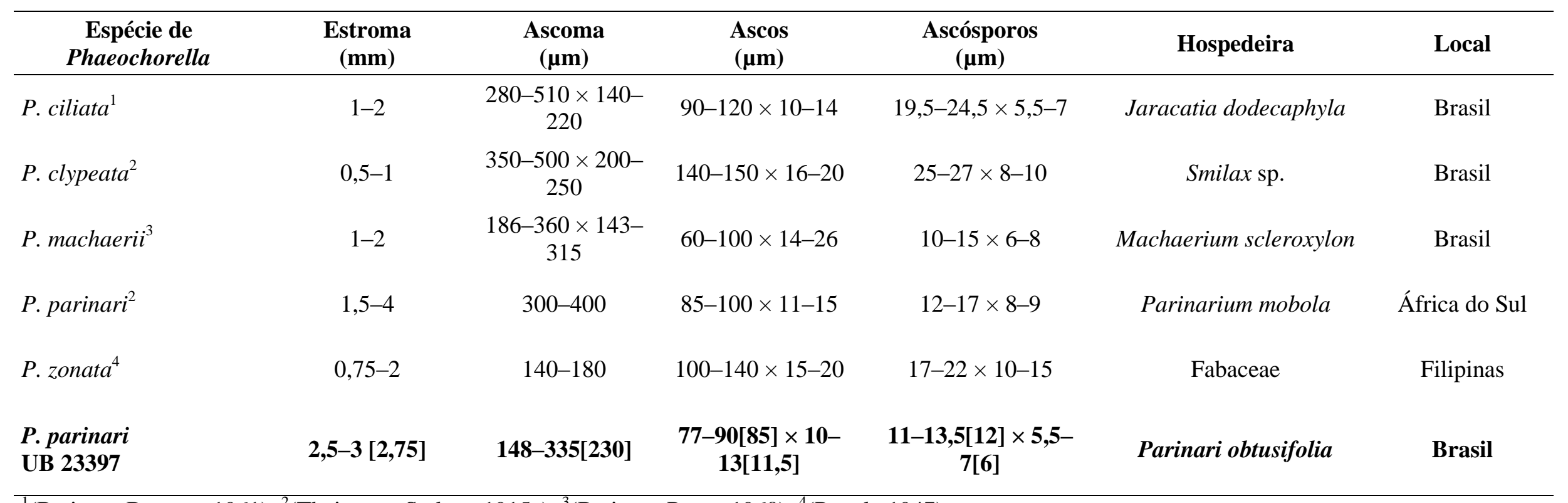

${ }^{1}$ (Batista e Bezerra, 1961); ${ }^{2}$ (Theissen e Sydow, 1915a); ${ }^{3}$ (Batista e Peres, 1960); ${ }^{4}$ (Petrak, 1947). 


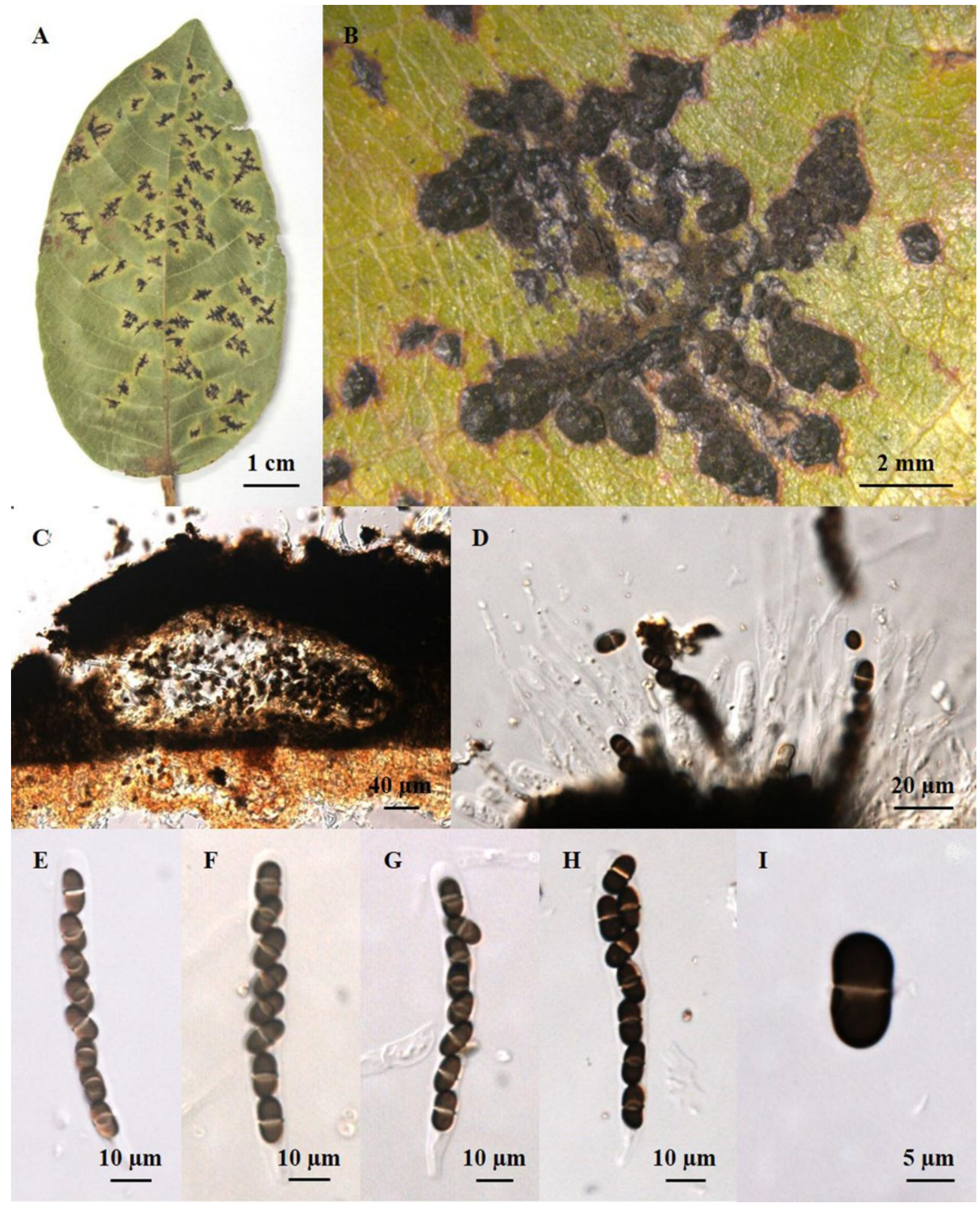

Figura 20. A-I. Phaeochorella parinari em folhas de Parinari obtusifolia (Chrysobalanaceae) (UB-Micol. Col. 23397). A. Lesões foliares. B. Estroma na folha. C. Corte transversal contendo lóculo. D. Ascos parafisados. E-H. Ascos. I. Ascósporo. 


\subsubsection{Phyllachora (provável espécie nova $\mathrm{n}^{\circ}$ 7). Figura $21(\mathrm{~A}-\mathrm{G})$}

Pseudoestromas proeminentes, brilhantes, anfígenos, negros, confluentes ou isolados, de formato irregular, associados a manchas marrom-escuras nas bordas, medindo 1-5 mm de diâmetro. Ascomas piriformes, a elipsoides, multiloculados, perifisados, 145-300 × 187-442

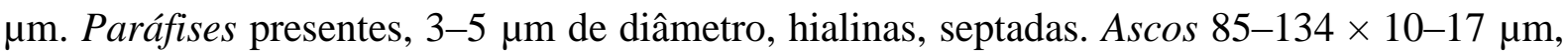
cilíndricos a clavados, com ápice truncado, contendo oito ascósporos. Ascósporos 14-19 × 6$10 \mu \mathrm{m}$, hialinos, unicelulares, em forma de lua ou elipsoides. Forma assexuada ausente.

Espécime examinado: em folhas de Roupala montana (Proteaceae), BRASIL, Distrito Federal, Planaltina, Reserva do Mirante, EMBRAPA CPAC; 21/06/2015, Bruno Cézar Pereira de Souza \#16, UB (Col. Micol.) 23375.

O gênero Phyllachora foi descrito inicialmente por Nitshke e confirmado por Fuckel no ano de 1867 com uma só espécie, P. agrostis Fuckel, esta, foi erroneamente descrita e incluída dentro da ordem Dothideales, sendo assim, foi realizada uma nova descrição do gênero sendo nominado como Scirrihia bentgrass (Dothideaceae). Após isso, P. graminis (Pers.) Fuckel foi designada como nova espécie tipo (Fuckel, 1870). Atualmente o gênero possui 1501 nomes registrados (Index Fungorum, 2017).

O gênero Phyllachora é caracterizado por formar pseudostromas escuros, negros, brilhantes, geralmente clipeados, que podem ser subcuticulares, subepidérmicos ou imersos, atingindo profundamente o mesófilo. Os pseudostromas possuem de um a vários lóculos. Ascomas periteciais, de paredes finas, perídios constituídos por tecido marrom-escuro a marrom-claro, ostiolados, em geral irrompentes, conspícuos ou não, perifisados. Hamatécio constituído por paráfises, que podem se tornar deliquescentes na maturidade dos ascos e ascósporos. Ascos cilíndricos, clavados ou elipsóides, em geral sem aparelho apical conspícuo. Ascósporos variáveis na forma, unicelulares, hialinos que podem se tornar marrom-claros, repetidamente envoltos em camada gelatinosa, poucas vezes ornamentados. A 
fase assexual apresenta conidiomas de formas variadas, embora sejam geralmente picnidiais, imersos em estroma com parede do conidioma frequentemente não diferenciadas. Células conidiogênicas cilíndricas, fialídicas com frequência formando conídios espermaciais pequenos, asseptados, hialinos, filiformes, geralmente curvados (Cannon, 1991).

O espécime estudado foi comparado com espécies da família Phyllachoraceae relatados em plantas da família Proteaceae (Tabela 18). A espécie em questão apresenta uma relação estreita com a espécie $P$. roupalina var. macrospora (Batista, Peres e Maia, 1967), mas difere da espécie em estudo pela forma dos ascósporos, que são elipsoides a lunados na mesma. Sendo assim, pode-se concluir que a espécie em estudo é provavelmente uma variação de $P$. roupalina.

Tabela 18. Características morfométricas de espécies da família Phyllachoraceae presentes em plantas da família Proteaceae.

\begin{tabular}{|c|c|c|c|c|c|c|}
\hline Espécie & $\begin{array}{c}\text { Estroma } \\
\emptyset(\mathbf{m m})\end{array}$ & $\begin{array}{c}\text { Ascoma } \\
(\mu \mathrm{m})\end{array}$ & $\begin{array}{l}\text { Asco } \\
(\mu \mathrm{m})\end{array}$ & $\begin{array}{l}\text { Ascósporo } \\
(\mu \mathrm{m})\end{array}$ & Hospedeira & Local \\
\hline P. roupalae ${ }^{1}$ & 2 & - & - & $21 \times 9-10$ & Roupala sp. & Brasil \\
\hline $\begin{array}{l}\text { Catacauma } \\
\text { roupalinum }\end{array}$ & $2-4$ & $\begin{array}{c}300-500 \times \\
250-350\end{array}$ & $\begin{array}{c}70-100 \times \\
10-14\end{array}$ & $15-20 \times 6-9$ & $\begin{array}{l}\text { Roupala } \\
\text { guyanensis }\end{array}$ & Brasil \\
\hline $\begin{array}{l}\text { P. roupalina var. } \\
\text { macrospora }^{3}\end{array}$ & $1-5$ & $\begin{array}{c}157-315 \times \\
215-745\end{array}$ & $\begin{array}{c}61-114 \times \\
11-13\end{array}$ & $\begin{array}{c}17-28 \times 11- \\
13\end{array}$ & $\begin{array}{c}\text { Roupala } \\
\text { brasiliensis }\end{array}$ & Brasil \\
\hline Phyllachora sp. ${ }^{4}$ & $0,6-10$ & $\begin{array}{c}350-450 \times \\
450-650\end{array}$ & $\begin{array}{c}86-140 \times 9- \\
17\end{array}$ & $15-19 \times 7-8$ & $\begin{array}{l}\text { Roupala } \\
\text { montana }\end{array}$ & Brasil \\
\hline $\begin{array}{l}\text { Phylachora sp. } \\
\text { UB } 23375\end{array}$ & $1-4,7[2,6]$ & $\begin{array}{c}145-300[202] \\
\times 187-442[275]\end{array}$ & $\begin{array}{r}85-134[110] \\
\times 10-17[13]\end{array}$ & $\begin{array}{c}14-19[16,7] \\
\times 6-10[7]\end{array}$ & $\begin{array}{l}\text { Roupala } \\
\text { montana }\end{array}$ & Brasil \\
\hline
\end{tabular}




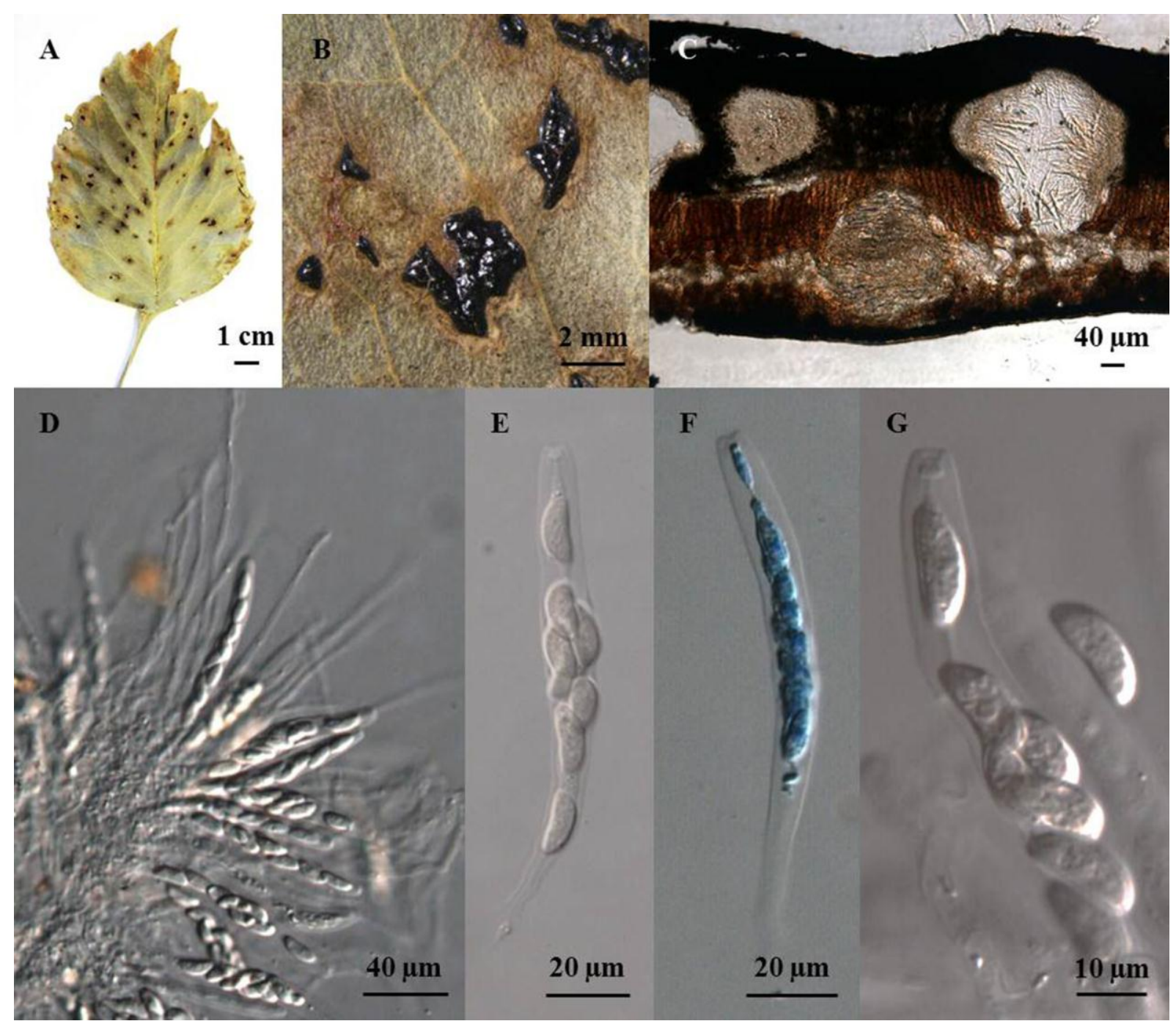

Figura 21. A-G. Phyllachora sp. em folhas de Roupala montana (Proteaceae) (UB-Micol. Col. 23375). A. Lesões foliares. B. Estromas. C. Corte transversal contendo lóculos. D. Ascos parafisados. E-F. Ascos. G. Ascósporos. 
3.6.4. Phyllachora (provável espécie nova $n^{\circ}$ 8). Figura $22(A-G)$

Pseudostromas epifilos, 1,5-5 $\mathrm{mm}$ de diâmetro, grandes, negros, com paredes brilhantes, com formato irregular, isolados ou gregários. Clípeo com 17-28 $\mu \mathrm{m}$ de espessura. Ascomas peritecióides, 157-317 × 211-376 $\mu \mathrm{m}$, circulares, subepidérmicos. Ascos clavados, com ápices arredondados, unitunicados, 53-73 × 11-18 $\mu \mathrm{m}$, possuindo oito ascósporos, distribuídos de forma bi a unisseriada. Ascósporos unicelulares, hialinos, elipsóides, 9-13 × 5-8 $\mu \mathrm{m}$. Apresenta cirros de ascósporos, proveniente de alguns peritécios. Estado anamorfo ausente. Está associada à Lasmeniella sp.

Espécime examinado: em folhas de Machaerium sp. (Fabaceae), BRASIL, Distrito Federal, Planaltina, Reserva do Mirante, EMBRAPA CPAC; 21/06/2015, Bruno Cézar Pereira de Souza \#22, UB (Col. Micol.) 23378.

Três espécies de Phyllachora foram descritas parasitando espécies de Machaerium, são elas: P. conica (Chardón) Petr., P. machaeriicola (Henn.) Theiss. \& Syd. e P. manaosensis Henn. As mesmas, juntamente com uma espécie relatada em Machaerium villosum, foram comparadas com a espécie encontrada neste trabalho (Tabela 19). O espécime em estudo possui estromas maiores e ascomas menores que as espécies comparadas. Seus ascos também são maiores, no entanto seus ascósporos se assemelham em tamanho com o descrito em Machaerium villosum e está associado com outro fungo, Pseudothis coccodes (Beserra Júnior e Pfenning, 2006). O fungo em estudo está associado a Lasmeniela sp., anamorfo de Pseudothis coccodes, e ainda outro celomiceto. Tendo em vista a diferença de dimensões dos fungos descritos como espécies de Phyllachora em Machaerium, pode-se inferir que se trata de uma provável nova espécie de Phyllachora. 
Tabela 19. Características morfométricas das espécies de Phyllachora reportadas em Machaerium spp.

\begin{tabular}{|c|c|c|c|c|c|c|}
\hline Espécies de Phyllachora & $\begin{array}{c}\text { Estroma } \\
\emptyset(\mathbf{m m})\end{array}$ & $\begin{array}{c}\text { Clípeo } \\
(\mu \mathrm{m})\end{array}$ & $\begin{array}{c}\text { Ascomas } \\
\emptyset(\mu \mathrm{m})\end{array}$ & $\begin{array}{c}\text { Ascos } \\
(\mu \mathrm{m})\end{array}$ & $\begin{array}{c}\text { Ascósporos } \\
(\mu \mathrm{m})\end{array}$ & Hospedeira \\
\hline P. conica $^{1}$ & $0,3-0,75$ & $18-40$ & $280-680$ & $46-55 \times 18-24$ & $10-13 \varnothing$ & Machaerium sp. \\
\hline P. manaosensis ${ }^{3}$ & $0,2-0,25$ & - & - & $45-60 \times 12-18$ & $7-9 \times 5-6$ & Machaerium sp. \\
\hline Phyllachora sp. ${ }^{4}$ & $2-3$ & - & $\begin{array}{c}314-480 \times 242- \\
338\end{array}$ & $41-53 \times 13-21$ & $12-14 \times 7-9$ & Machaerium villosum \\
\hline $\begin{array}{l}\text { Phyllachora sp. } \\
\text { UB } 23378\end{array}$ & $1,5-5[3]$ & $17-28[23]$ & $\begin{array}{c}104-165[136] \times \\
69-95[84]\end{array}$ & $\begin{array}{c}53-73[63] \times \\
11-18[14]\end{array}$ & $\begin{array}{c}9-13[10,5] \times 5- \\
8[6,5]\end{array}$ & Machaerium sp. \\
\hline
\end{tabular}

${ }^{1}$ (Petrak, 1931); ${ }^{2}$ (Theissen e Sydow, 1915b); ${ }^{3}$ (Hennings, 1904a); ${ }^{4}$ (Beserra Júnior e Pfenning, 2006). 

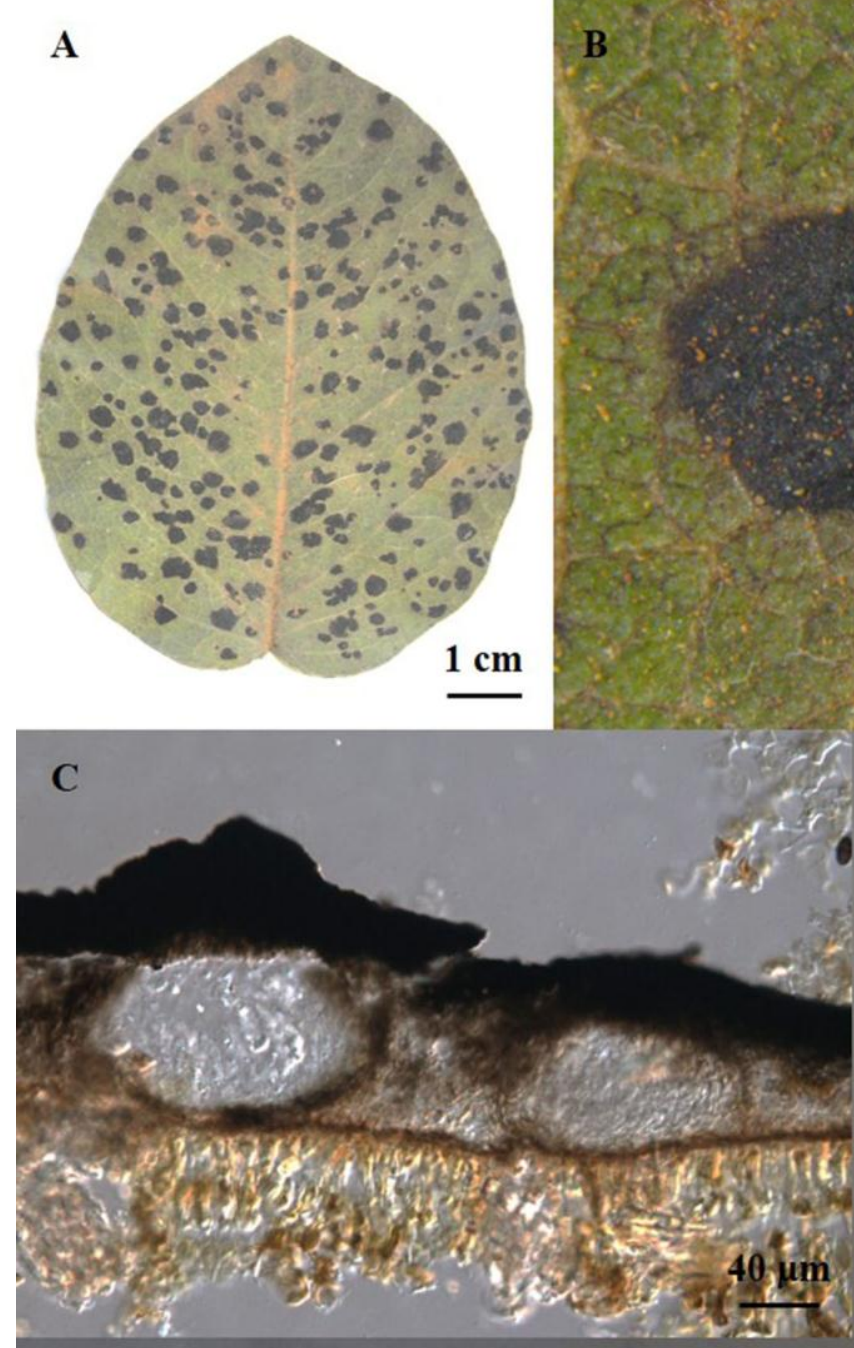

E

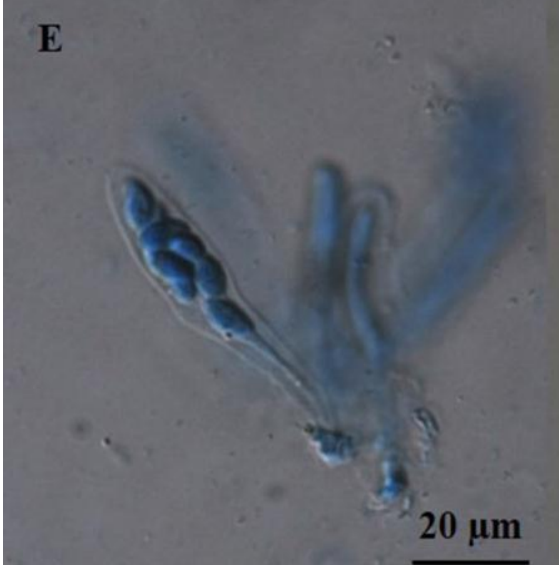

F

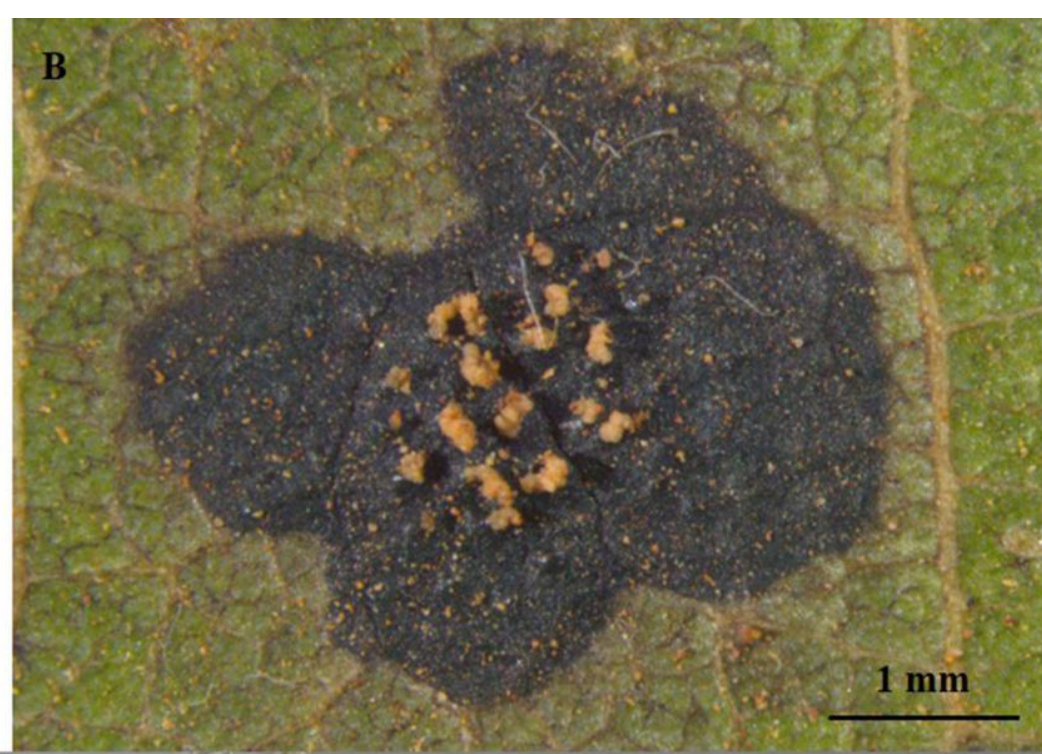

D

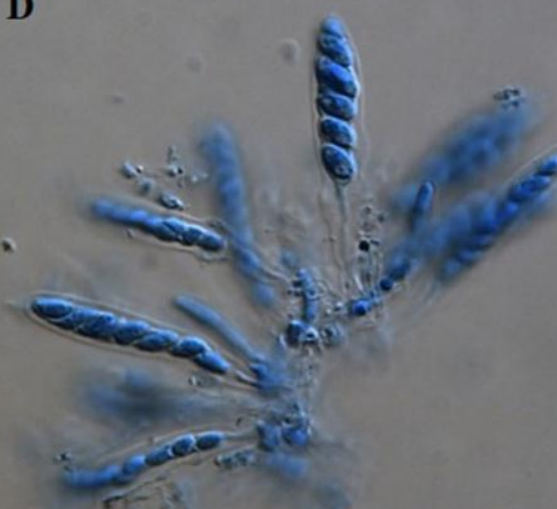

$\mathbf{G}$
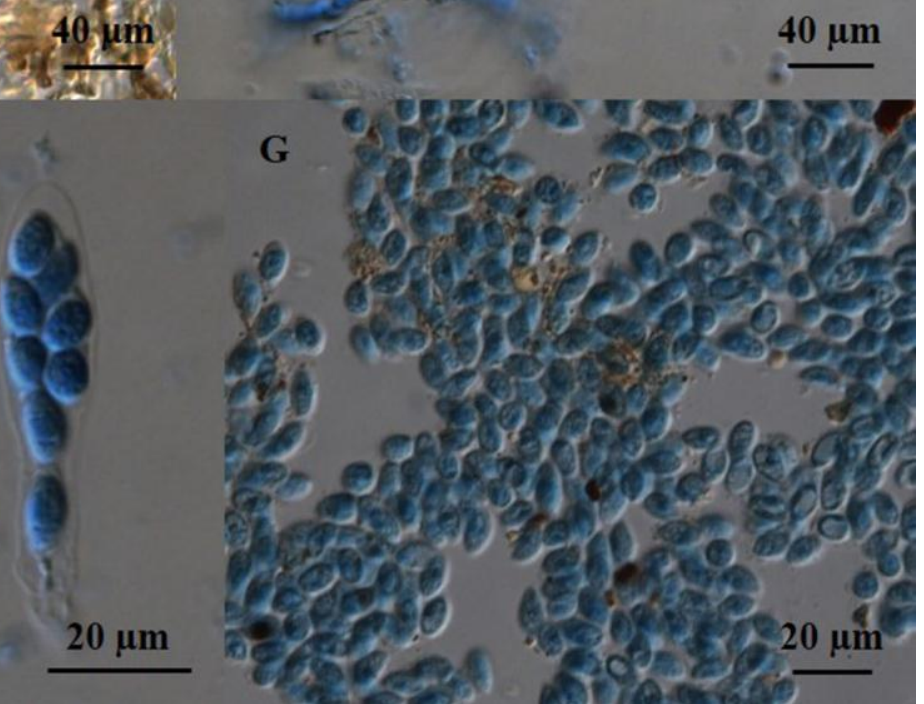

Figura 22. A-G. Phyllachora sp. em folhas de Machaerium sp. (Fabaceae) (UB-Micol. Col. 23378). A. Lesões foliares. B. Estroma com cirros. C. Corte transversal contendo lóculos. DF. Ascos e ascósporos. G. Ascósporos provenientes dos cirros. 


\subsubsection{Phyllachora (provável espécie nova $n^{\circ}$ 9). Figura $23(\mathrm{~A}-\mathrm{F})$}

Pseudostromas epifilos, 170-250 $\mu \mathrm{m}$ de diâmetro, negros, redondos, pulvinados, isolados, uniloculares. Ascomas circulares, 219-288 $\mu \mathrm{m}$ de diâmetro, subepidérmicos, imersos no mesófilo do hospedeiro. Clípeo 13-26 $\mu \mathrm{m}$, negro, rígido. Ascos unitunicados, cilíndricos a clavados, com o ápice truncado, 70-115 × 10-20 $\mu \mathrm{m}$, possuindo oito esporos distribuídos de forma unisseriada, ás vezes bisseriada. Paráfises hialinas, filiformes, com 1,84,5 $\mu \mathrm{m}$ de espessura. Ascósporos 8-14,5 × 5-7 $\mu \mathrm{m}$, elipsoides, hialinos, unicelulares, gutulados.

Espécime examinado: em folhas de Mimosa sp. (Fabaceae), BRASIL, Distrito Federal, Planaltina, Reserva do Mirante, EMBRAPA CPAC; 03/03/2016, Bruno Cézar Pereira de Souza \#123, UB (Col. Micol.) 23392.

Três espécies de Phyllachora foram relatadas sobre espécies de Mimosa, as quais foram comparadas com a espécie encontrada neste trabalho (Tabela 20). A espécie em estudo apresenta relação mais próxima com $P$. michelii Speg., diferenciando-se apenas pelo tamanho dos ascos e ascóporos. Já a espécie P. ekmaniana Petr. \& Cif. apresenta ascósporos semelhantes às da espécie estudada. No entanto, apesar das semelhanças pontuais, as diferenças encontradas permitem concluir que se trata de uma provável nova espécie de Phyllachora encontrada em uma espécie ainda não identificada de Mimosa. 
Tabela 20. Características morfométricas de espécies de Phyllachora relatadas em espécies de Mimosa.

\begin{tabular}{|c|c|c|c|c|c|}
\hline $\begin{array}{l}\text { Espécies de } \\
\text { Phyllachora }\end{array}$ & $\begin{array}{c}\text { Estroma } \\
\emptyset(\mu \mathrm{m})\end{array}$ & $\begin{array}{c}\text { Ascoma } \\
(\mu \mathrm{m})\end{array}$ & $\begin{array}{c}\text { Ascos } \\
(\mu \mathrm{m})\end{array}$ & Ascósporos $(\mu \mathrm{m})$ & Hospedeira \\
\hline P. acaciae $^{1}$ & - & $140-200$ & $45-52 \times 14-17$ & $12-15 \times 4-5$ & Acacia farnesiana \\
\hline P. michelii ${ }^{3}$ & - & $200-250$ & $90-100 \times 9-10$ & $10 \times 8-9$ & Mimosa procurrentis \\
\hline $\begin{array}{l}\text { Phyllachora } \\
\text { UB } 23392\end{array}$ & $170-250[200]$ & 219-288[257] & $70-115[94] \times 10-20[15]$ & $8-14,5[12] \times 5-7[6]$ & Mimosa sp. \\
\hline
\end{tabular}

${ }^{1}$ (Hennings, 1984); ${ }^{2}$ (Petrak e Ciferri, 1930); ${ }^{3}$ (Spegazzini, 1888). 

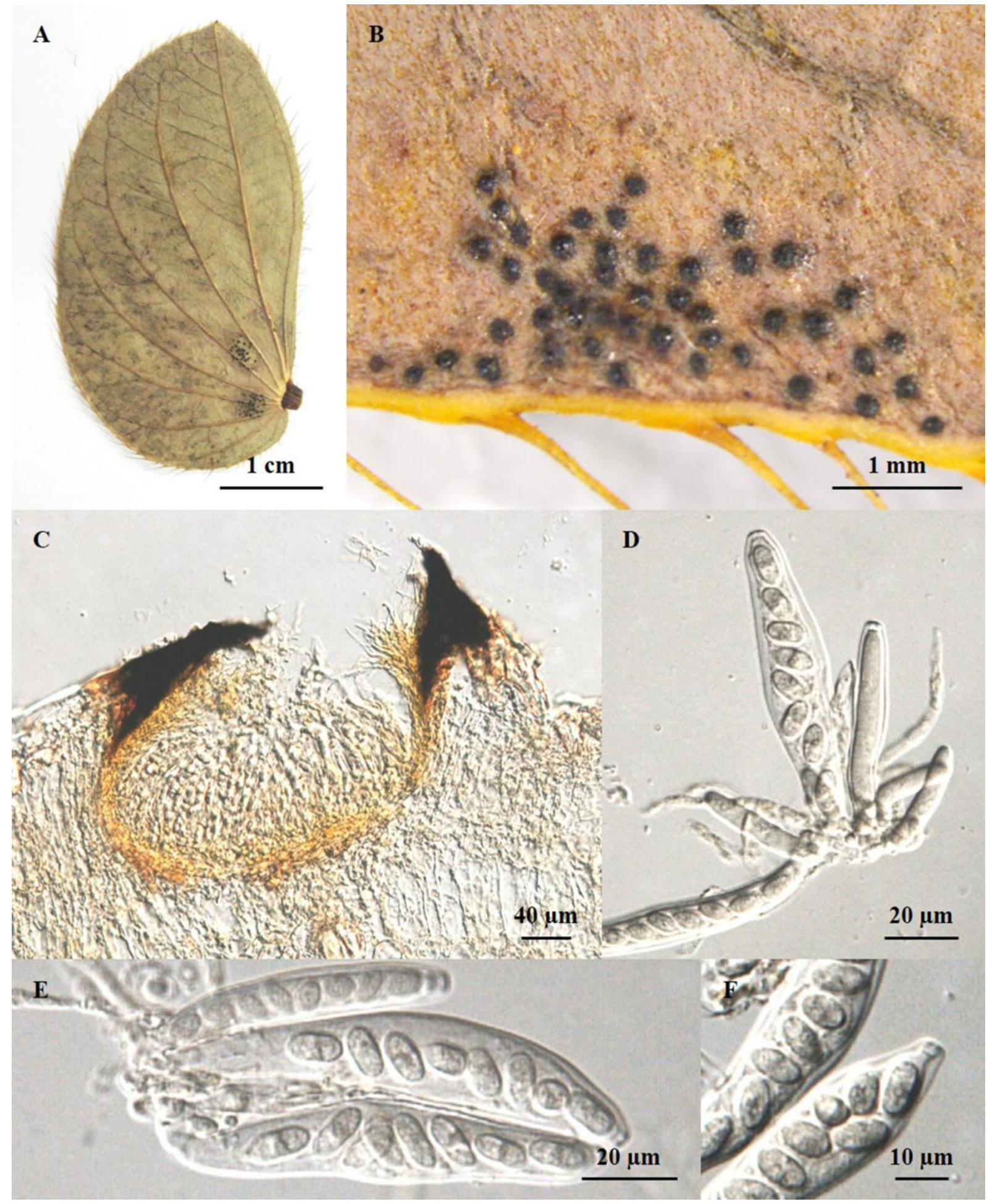

Figura 23. A-F. Phyllachora sp. em folhas de Mimosa sp. (Fabaceae) (UB-Micol. Col. 23392). A-B. Lesões foliares. C. Corte transversal contendo peritécio. D. Ascos parafisados. E-F. Ascos e ascósporos. 
3.6.6. Phyllachora qualeae (Viégas) Bat. \& Peres, Atas Inst. Micol. Univ. Recife 4: 66 (1967). (Nova hospedeira $\mathrm{n}^{\circ}$ 2). Figura 24 (A-F)

Pseudoestromas epifilos, 1-8,5 mm de diâmetro, negros, com paredes brilhantes, de formato irregular, isolados ou gregários. Ascomas 198-383 × 140-321 $\mu \mathrm{m}$, peritecióides, circulares, subepidérmicos, imersos no mesófilo do hospedeiro, com ostíolos conspícuos e perifisados. Ascos cilíndricos a clavados, unitunicados, $84-130 \times 7-8,5 \mu \mathrm{m}$, possuindo oito ascósporos, distribuídos de forma unisseriada. Paráfises filiformes, com 1-2 $\mu$ m de diâmetro, hialinas, ramificadas. Ascósporos unicelulares, hialinos, gutulados, reniformes, 8-11 $\times 3-4,5$ $\mu \mathrm{m}$. Espermácias presentes, no lado oposto aos peritécios, 7-12 × 1-1,5. $\mu \mathrm{m}$, hialinos, fusóides.

Espécime examinado: em folhas de Qualea grandiflora (Vochysiaceae), BRASIL, Distrito Federal, Planaltina, Reserva do Mirante, EMBRAPA CPAC; 21/06/2015, Bruno Cézar Pereira de Souza \#18, UB (Col. Micol.) 23376.

Dentre das espécies de Phyllachora, as seguintes estão relatadas em membros da família Vochysiaceae: P. congregata Theiss. \& Syd. em folhas de Vochysia elliptica Mart.; P. qualeae (Viégas) Bat. \& Peres sobre Qualea parviflora Mart.; P. vochysiae Henn. em Vochysia haenkana Mart. e P. lehmanniana Henn. em Vochysia lehmanni Hieron. Dentre elas, a que apresenta maior semelhança taxonômica e morfológica com o fungo estudado é $P$. qualeae (Tabela 21). Essa espécie foi inicialmente descrita como Catacauma qualeae, posteriormente foi denominada P. qualae (Viégas, 1944; Batista, Peres e Maia, 1967). Os ascos e ascósporos da espécie em estudo são maiores, mas não o suficiente para considerar que se seja uma nova espécie, razão pela qual o fungo estudado pode ser considerado o primeiro relato de $P$. qualeae em folhas de Qualea grandiflora. 
Tabela 21. Características morfométricas das espécies do gênero Phyllachora associadas a hospedeiras da família Vochysiaceae.

\begin{tabular}{|c|c|c|c|c|c|c|}
\hline Espécie & $\begin{array}{c}\text { Pseudostroma } \\
\varnothing(\mathbf{m m})\end{array}$ & $\begin{array}{c}\text { Ascoma } \\
(\mu \mathrm{m})\end{array}$ & $\begin{array}{c}\text { Ascos } \\
(\mu \mathrm{m})\end{array}$ & $\begin{array}{c}\text { Ascósporos } \\
(\mu \mathrm{m})\end{array}$ & Hospedeira & Local \\
\hline P. lehmanniana ${ }^{1}$ & $3-4$ & - & $95-120 \times 12-16$ & $17-22 \times 5-6$ & $\begin{array}{l}\text { Vochysia } \\
\text { lehmanni }\end{array}$ & Colômbia \\
\hline P. congregata ${ }^{3}$ & $2-4$ & 200-280Ø & $70-90 \times 12-15$ & $15-181 \times 5-6$ & $\begin{array}{l}\text { Vochysia } \\
\text { elliptica }\end{array}$ & Brasil \\
\hline $\begin{array}{l}\text { Phyllachora sp. } \\
\text { UB } 23376\end{array}$ & $1-9[3]$ & $\begin{array}{c}198-383[277] \times \\
140-321[230]\end{array}$ & $\begin{array}{c}84-130[115] \times 7- \\
8,5[7,5]\end{array}$ & $\begin{array}{c}8-11[9,5] \times 3- \\
4,5[4]\end{array}$ & $\begin{array}{c}\text { Qualea } \\
\text { grandiflora }\end{array}$ & Brasil \\
\hline $\begin{array}{l}\text { Phyllachora sp. } \\
\text { UB } 23377\end{array}$ & $1-4[3]$ & $\begin{array}{c}157-317[243] \times \\
211-376[296]\end{array}$ & $\begin{array}{c}88-155[117] \times 7,5- \\
9[8,5]\end{array}$ & $\begin{array}{c}9,5-13[11] \times 5- \\
6[5,5]\end{array}$ & $\begin{array}{c}\text { Qualea } \\
\text { parviflora }\end{array}$ & Brasil \\
\hline
\end{tabular}

${ }^{\mathrm{T}}$ (Hennings, 1897); ${ }^{2}$ (Hennings, 1905); ${ }^{3}$ (Theissen e Sydow, 1915b); ${ }^{4}$ (Batista, Peres e Maia, 1967). 


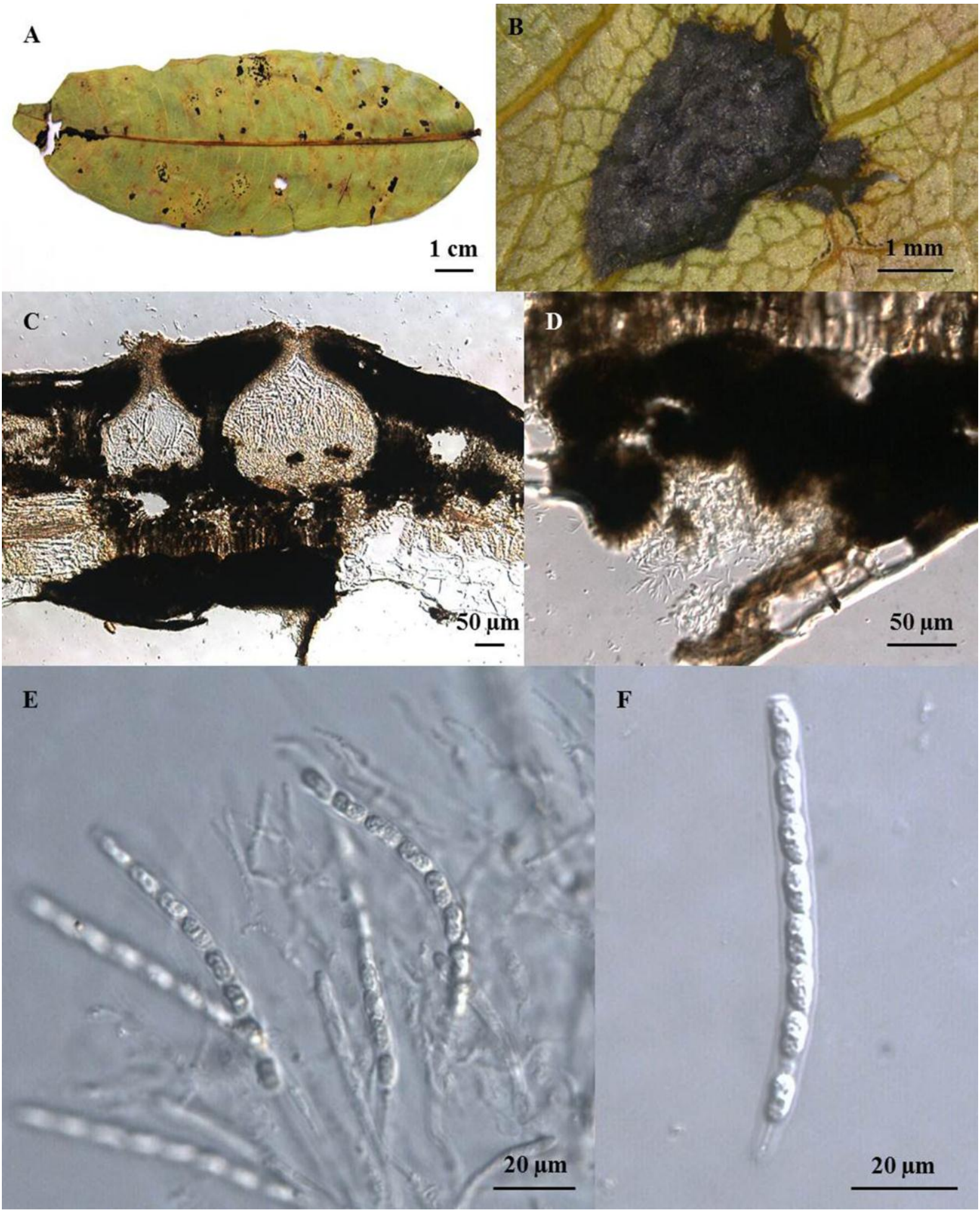

Figura 24. A-F. Phyllachora qualae em folhas de Qualea grandiflora (Vochysiaceae) (UBMicol. Col. 23376). A. Lesões foliares. B. Estroma na parte abaxial da folha. C. Corte transversal da folha contendo peritécios. D. Fase espermacial. E. Ascos parafisados. F. Asco e ascósporos. 
3.6.7. Phyllachora qualeae (Viégas) Bat. \& Peres, Atas Inst. Micol. Univ. Recife 4: 66 (1967). Figura $25($ A-G)

Pseudoestromas epifilos, 1-4 mm de diâmetro, pequenos, negros, com paredes brilhantes, arredondados, isolados ou gregários. Ascomas 157-317 × 211-376 $\mu \mathrm{m}$, peritecióides, circulares, subepidérmicos, imersos no mesófilo do hospedeiro, com ostíolos conspícuos e perifisados. Ascos cilíndricos a clavados, com ápices arredondados, unitunicados, $88-155 \times 7,5-9 \mu \mathrm{m}$, possuindo oito ascósporos, distribuídos de forma unisseriada. Paráfises filiformes, com 1-3 $\mu \mathrm{m}$ de diâmetro, hialinas, ramificadas. Ascósporos unicelulares, hialinos, gutulado, reniformes, 9,5-13 × 5-6 $\mu \mathrm{m}$. Estado anamorfo ausente.

Espécime examinado: em folhas de Qualea parviflora (Vochysiaceae), BRASIL, Distrito Federal, Planaltina, Reserva do Mirante, EMBRAPA CPAC; 21/06/2015, Bruno Cézar Pereira de Souza \#19, UB (Col. Micol.) 23377.

O espécime em estudo foi comparado com outras espécies de Phyllachora encontradas em plantas da família Vochysiaceae (Tabela 21). Constatou-se que, assim como o fungo anterior, se trata de $P$. qualae (Viégas) Bat. \& Peres, já que as dimensões das estruturas fúngicas são semelhantes e a hospedeira é a mesma já relatada (Batista, Peres e Maia, 1967). 


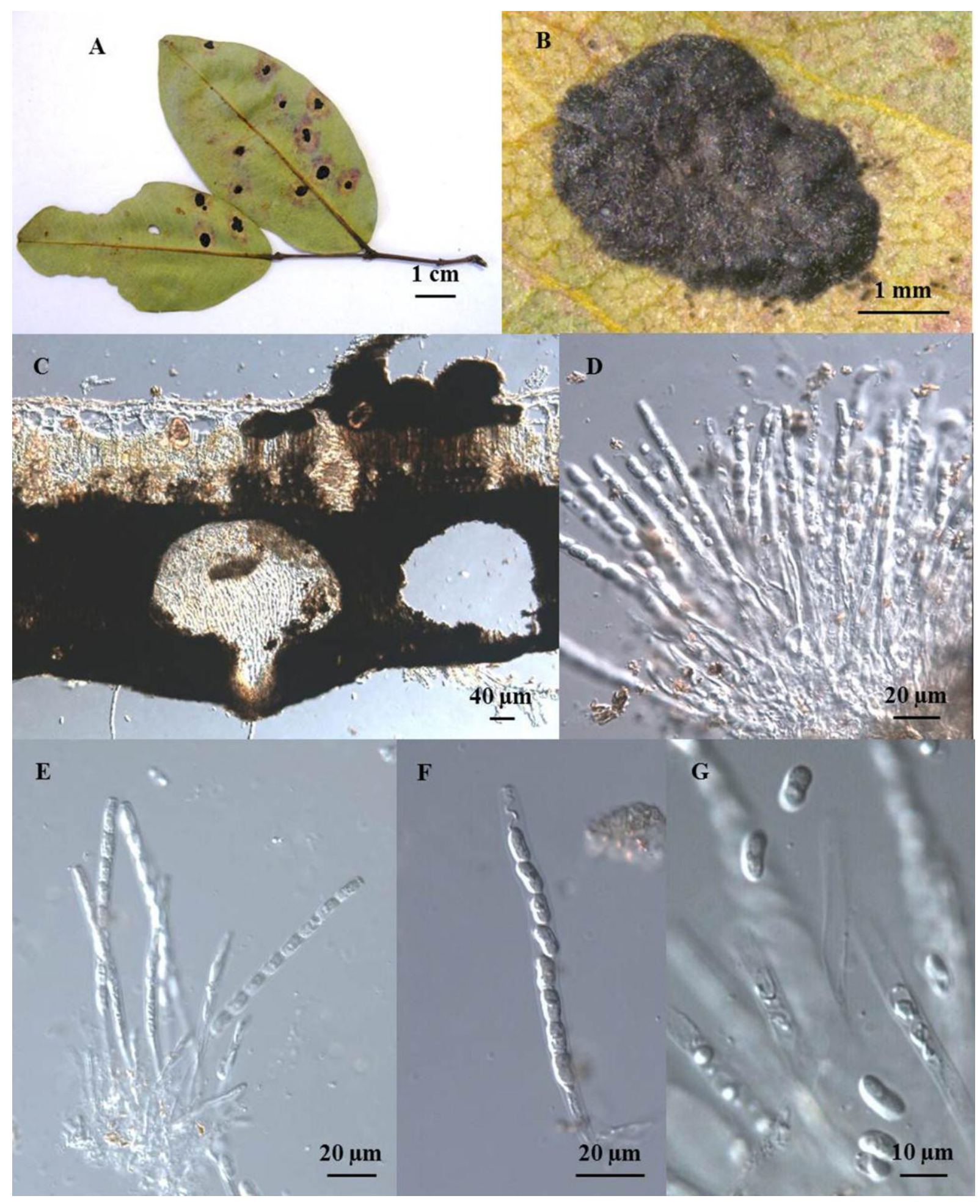

Figura 25 A-G. Phyllachora qualeae em folhas de Qualea parviflora (Vochysiaceae) (UBMicol. Col. 23377). A. Lesões foliares. B. Estroma na parte abaxial da folha. C. Corte transversal da folha mostrando o estroma multilocular. D-E. Ascos parafisados. F. Asco. G. Ascósporos. 
3.6.8. Phyllachora subcircinans Speg., Revista Argent. Hist. Nat. 1(6): 413 (1891). Figura $26($ A-G)

Pseudostromas epifilos, de 1-2,5 $\mathrm{mm}$ de diâmetro, subcuticulares, às vezes intraepidérmicos, circulares a irregulares, negros, brilhantes, isolados ou gregários, multiloculares, epífelos, esparsos, cobrindo grande parte do limbo foliar. Ascomas periteciais, 72-174 × 143-291 $\mu \mathrm{m}$, subepidérmicos, clipeados, com ostíolos conspícuos, perifisados. Ascos cilíndricos a clavados, com ápice obtuso, unitunicados, 64,5-85 × 9-17,5 $\mu \mathrm{m}$, com oito ascósporos, dispostos uni ou bisseriadamente. Paráfises filiformes, hialinas, septadas, numerosas, com 1-2 $\mu \mathrm{m}$ de diâmetro, não ramificadas. Ascósporos 12-14,5 × 6-8 $\mu \mathrm{m}$, unicelulares, hialinos, elipsóides a oblongos, envoltos por uma camada mucilaginosa e gutulados na porção central.

Espécime examinado: em folhas de Psidium sp. (Myrtaceae), BRASIL, Distrito Federal, Planaltina, Reserva do Mirante, EMBRAPA CPAC; 21/06/2015, Bruno Cézar Pereira de Souza \#29, UB (Col. Micol.) 23380.

Dentro da família Myrtaceae estão registradas 36 espécies de Phyllachora. Em um trabalho recente, onde se relatam espécies de Phyllachora encontradas infectando plantas da família Myrtaceae do Cerrado, foram propostas quatro novas espécies (Santos et al., 2016). Essas espécies novas e outras encontradas no Brasil foram comparadas com a espécie estudada neste trabalho (Tabela 22). Verificou-se uma proximidade morfológica com $P$. subcircinans Speg., quanto o tamanho de ascos e ascósporos, além de ambos apresentarem um ascósporo envolto por mucilagem, gutulados na porção central e estarem parasitando a mesma hospedeira. Sendo assim, pode-se concluir que se trata da mesma espécie. 
Tabela 22. Características morfométricas de espécies de Phyllachora reportadas no Brasil em plantas da família Myrtaceae.

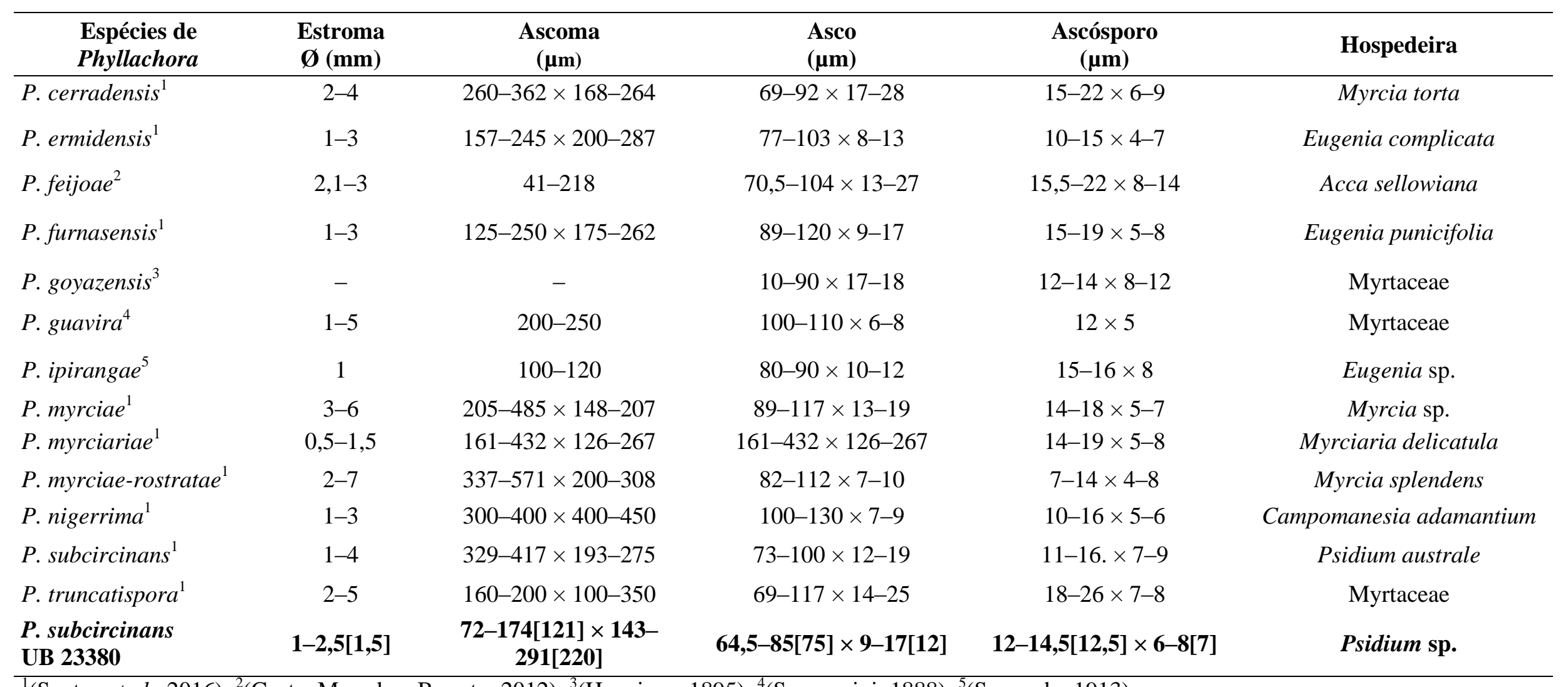

${ }^{1}$ (Santos et al., 2016); ${ }^{2}$ (Costa, Macedo e Barreto, 2012); ${ }^{3}$ (Hennings, 1895); ${ }^{4}$ (Spegazzini, 1888); ${ }^{5}$ Saccardo, 1913). 


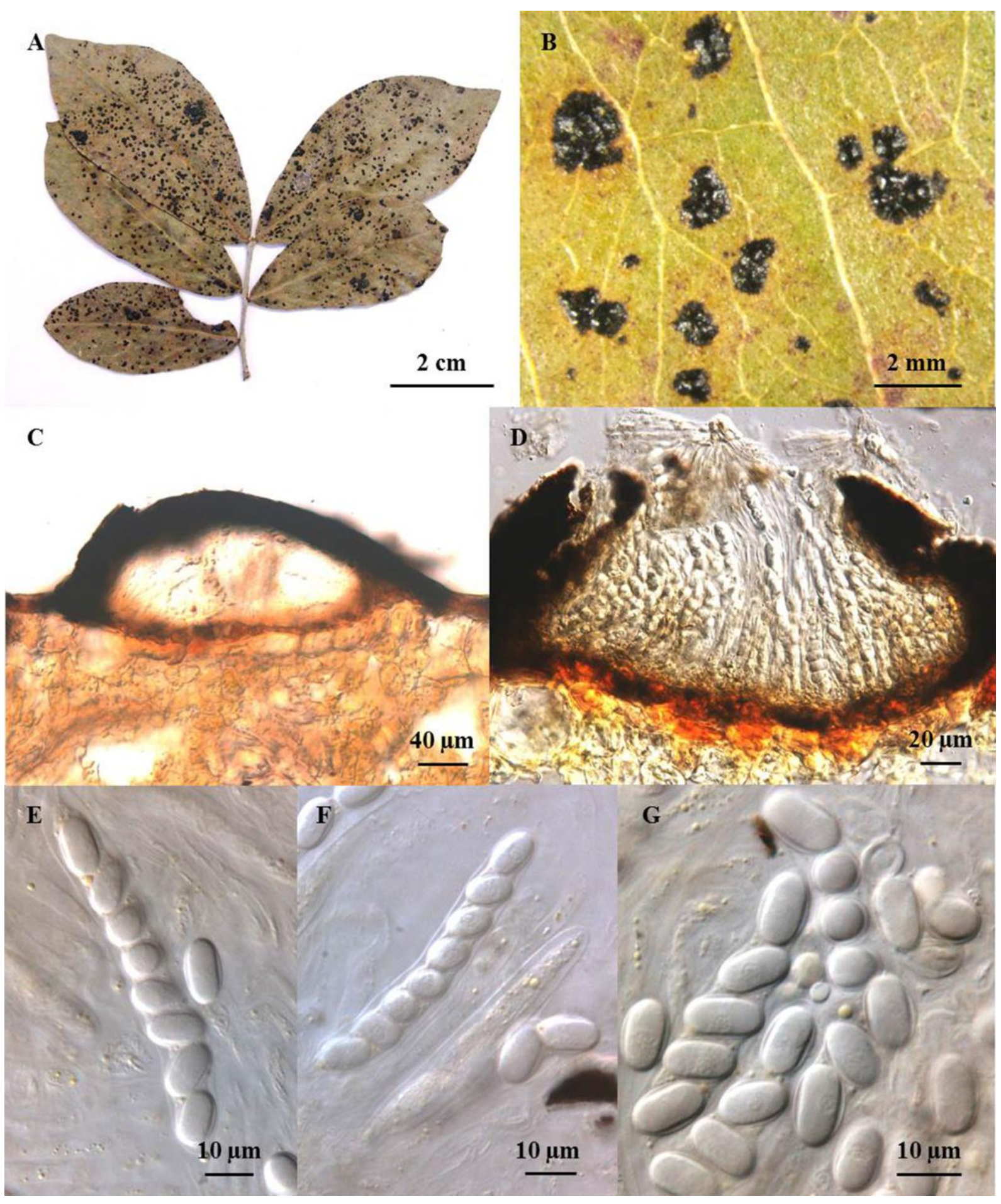

Figura 26. A-G. Phyllachora subcircinans em folhas de Psidium sp. (Myrtaceae) (UBMicol. Col. 23380). A. Lesões foliares. B. Pseudoestromas. C-D. Corte transversal mostrando inserção do pseudoestroma e disposição de ascos parafisados. E-F. Ascos. G. Ascósporos gutulados. 
3.6.9. Phyllachoraceae (provável gênero novo $\mathrm{n}^{\circ}$ 1). Figura 27 (A-E)

Lesões anfígenas, negras, medindo até $5 \mathrm{~cm}$ de diâmetro, chegando a cobrir grande parte do limbo foliar. Pseudostromas marrom-escuros a negros, ocupando todo o mesófilo. Micélio interno presente, inter e intracelular, composto de hifas melanizadas, ás vezes de aspecto torulóide, septadas, formando um tecido não muito compacto. Ascomas peritecióides, subglobosos, perifisados, ostiolados, 114-195 $\mu \mathrm{m}$ de diâmetro. Paráfises hialinas, septadas, 3-4,5 $\mu \mathrm{m}$ de espessura. Ascos unitunicados, cilíndricos a clavados, 69-89 × 10-15,5 $\mu \mathrm{m}$, com ápice truncado, contendo oito ascósporos dispostos de forma unisseriada, ás vezes bisseriada. Ascósporos 9-13 × 3-5 $\mu \mathrm{m}$, hialinos, elipsoides, unicelulares, gutulados.

Espécime examinado: em folhas de Salacia crassifolia (Clelastraceae), BRASIL, Distrito Federal, Planaltina, Reserva do Mirante, EMBRAPA CPAC; 03/03/2016, Bruno Cézar Pereira de Souza \#127, UB (Col. Micol.) 23399.

O espécime aparenta ser da família Phyllachoraceae devido às características de seu centrum, a presença de perífises abundantes, formato de ascos, ascósporos e paráfises (SilvaHanlin e Halin, 1998).

Há três registros de Phyllachora em plantas da família Celastraceae, são elas: $P$. amphididyma Penz. \& Sacc. em Salacia brunneriana, P. celastri R.K. Verma \& Kamal em Celastri peniculata e P. punctifaciens Petr em Salacia sp. A espécie P. celastri R.K. Verma \& Kamal, não pode ser comparada com o espécieme em estudo, pois não foi possível acessar suas medidas. As demais espécies relatadas na família Celastraceae foram comparadas com a espécie em estudo (Tabela 23). Uma característica marcante em ambas espécies de Phyllachora é a presença de um clípeo em torno dos ostíolos, o que não se dá na espécie em estudo. A amostra coletada apresenta material estromático composto de tecido fúngico e o tecido do hospedeiro foi modificado no local da lesão onde foram encontrados os peritécios, o 
que pode excluir a mesma do gênero Phyllachora, apesar das similaridades citadas acima (Cannon, 1991).

O espécime em estudo apresenta características distintas das espécies conhecidas da família Phyllachoraceae, apesar de apresentar características em comum, por isso, sugere-se que esta espécie seja alocada em um novo gênero, assim como foi sugerido em uma dissertação de mestrado na UnB, e cuja amostra também foi comparada com a espécie estudada neste trabalho, constatando-se que se trata da mesma espécie (Santos, 2011).

Tabela 23. Características morfométricas de espécies de Phyllachora em plantas do gênero Salacia.

\begin{tabular}{|c|c|c|c|c|c|}
\hline Espécies & $\begin{array}{c}\text { Estroma } \\
\emptyset(\mathbf{m m})\end{array}$ & $\begin{array}{c}\text { Ascoma } \\
(\mu \mathrm{m})\end{array}$ & $\begin{array}{l}\text { Asco } \\
(\mu \mathrm{m})\end{array}$ & $\begin{array}{c}\text { Ascósporos } \\
(\mu \mathrm{m})\end{array}$ & Hospedeira \\
\hline Phyllachora amphididyma ${ }^{1}$ & 1 & 300 & $\begin{array}{c}100-125 \times 7- \\
8\end{array}$ & $14-16 \times 6$ & $\begin{array}{c}\text { Salacia } \\
\text { brunneriana }\end{array}$ \\
\hline Phyllachora punctifaciens ${ }^{2}$ & $1-2,5$ & $350-500$ & $\begin{array}{c}38-50 \times 12- \\
20\end{array}$ & $\begin{array}{c}16-10 \times \\
4,5-6\end{array}$ & Salacia sp. \\
\hline $\begin{array}{l}\text { Phylalchoraceae sp. } \\
\text { UB } 10234\end{array}$ & - & $110-180$ & $\begin{array}{c}53-88 \times 7- \\
13,5\end{array}$ & $12-17 \times 4-7$ & $\begin{array}{c}\text { Salacia } \\
\text { crassifolia }\end{array}$ \\
\hline $\begin{array}{l}\text { Phylalchoraceae sp. } \\
\text { UB } 23399\end{array}$ & - & $\begin{array}{c}114- \\
195[156]\end{array}$ & $\begin{array}{c}69-89[77] \times \\
10-15[12]\end{array}$ & $\begin{array}{l}9-13[11] \times \\
3-5[4]\end{array}$ & $\begin{array}{c}\text { Salacia } \\
\text { crassifolia }\end{array}$ \\
\hline
\end{tabular}




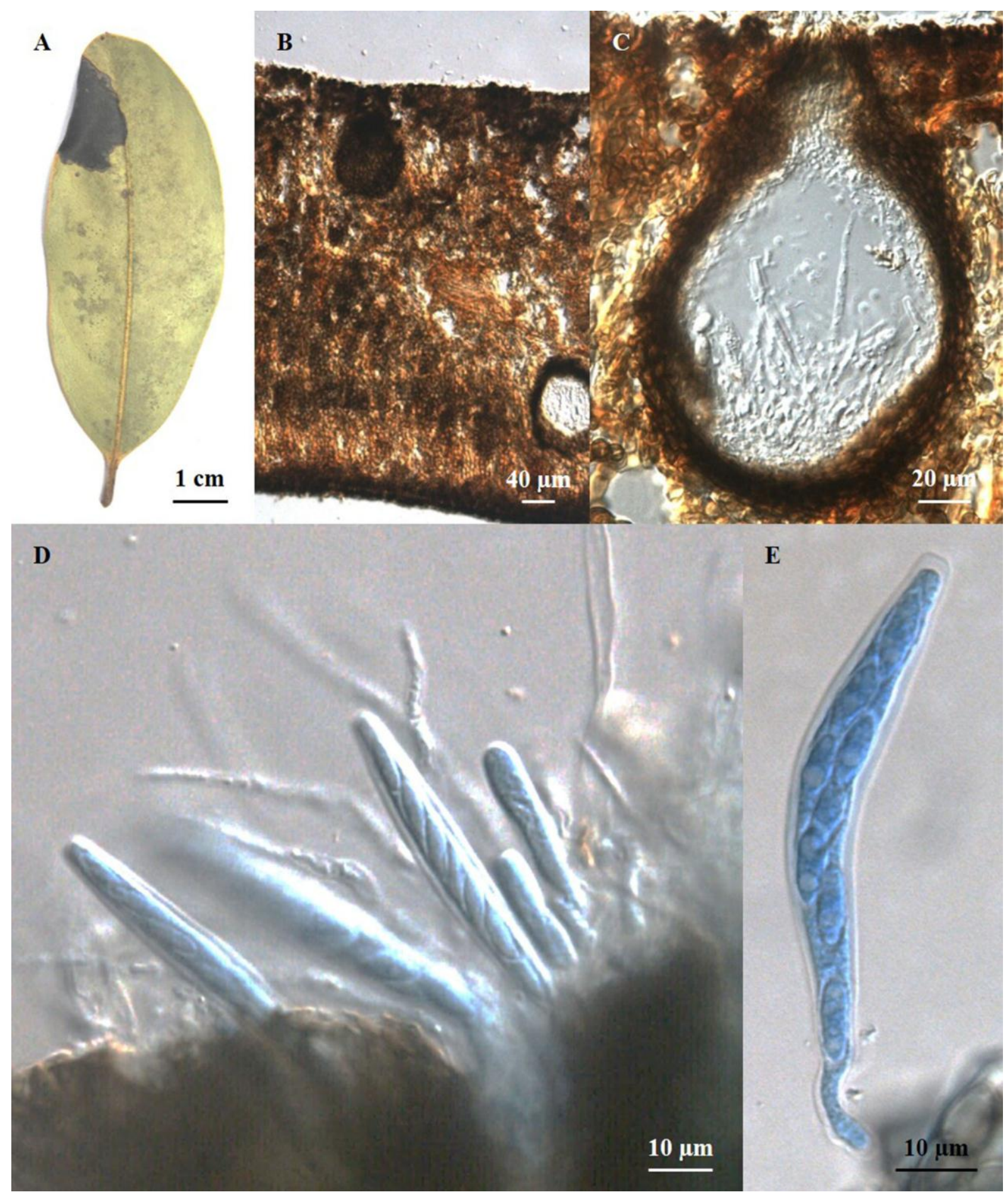

Figura 27. A-E. Phyllachoraceae em folhas de Salacia crassifolia (Clelastraceae) (UBMicol. Col. 23399). A. Lesões foliares. B-C. Corte transversal contendo lóculos anfígenos e tecido foliar modificado. D. Ascos parafisados. E. Asco e ascósporos. 


\subsection{Membros da família Pseudoperisporiaceae}

\subsubsection{Nematostoma (provável espécie nova $\left.\mathrm{n}^{\circ} 10\right)$. Figura $28(\mathrm{~A}-\mathrm{G})$}

Ascomas periteciais, globosos, setosos, isolados, ostiolados, 86-120 $\mu \mathrm{m}$ de diâmetro. Setas periteciais simples, direitas, marrons, asseptadas, dispostas na metade superior das frutificações, 32-42 por ascoma, 167-277 × 4-6 $\mu \mathrm{m}$. Subiculum composto de hifas oliváceas. Ascos clavados a elipsoides, bitunicados, contendo oito ascósporos, 29,5-44 × 19-28 $\mu \mathrm{m}$. Ascósporos elipsóides a oblongos, hialinos, 1 a 5 septos transversais, $13-27 \times 4-6 \mu \mathrm{m}$.

Espécime examinado: em folhas de Clusia sp. (Clusiaceae), BRASIL, Distrito Federal, Planaltina, Reserva do Mirante, EMBRAPA CPAC; 21/06/2015, Bruno Cézar Pereira de Souza \#6, UB (Col. Micol.) 23372.

A família Pseudoperisporiaceae pertence à classe Dothideomycetes, com subclasse e ordem Incertae sedis, foi introduzida por Toro (Toro, 1926) e tem como possível sinônimo a família Epipolaeaceae (Theissen e Sydow, 1918; Hyde et al., 2013). As características da família são as seguintes: Parasitas ou saprófitas em folhas ou outros fungos, principalmente em regiões tropicais; ascoma superficial, solitário a gregário, disperso, globoso a subgloboso, colapsando quando seco, rodeada por micélio castanho na base, ostiolo central com diâmetro de 14-20 $\mu \mathrm{m}$ e rodeado por setas marrons; setas afilando para ápice subagudo; perídio composto de textura angularis, castanho a marrom avermelhado, de paredes finas, colapsando quando seco; hamatécio composto por pseudoparáfises cilíndricas, filiformes, hialinas, ramificadas, septadas, em matriz gelatinosa; ascos bitunicados, fissitunicados, contendo oito ascósporos, oblongos a clavados, ligeiramente curvados, maior no ápice, séssil, ou com pedicelo parecendo um botão, com câmara ocular pequena; ascósporos biseriados, fusóides a elipsoides, com as extremidades arredondadas e subagudas, uniseptados, ligeiramente constrito no septo, hialinos, tornando-se castanhos na maturidade, parede com detalhe verrucoso. Estado assexuado: Chaetosticta (celomiceto) (Hyde et al., 2013). 
O gênero Nematostoma tem como espécie tipo N. artemisiae Syd. \& P. Syd., possui atualmente 21 registros e apresenta as seguintes características: peritécios superficiais, pequenos, membranáceos, negros, com setas longas e escuras perto do ostíolo; ascos clavados, parafisados, contendo oito ascósporos; ascósporos clavados, pluriseptados, hialinos a coloridos (Sydow e Sydow, 1914; Index Fungorum, 2017).

Foram comparadas 14 espécies de Nematostoma com a espécie em estudo (Tabela 24). Constatou-se que o espécime em estudo apresenta ascomas menores em comparação ás outras espécies e setas maiores, similares apenas com as da espécie $N$. artemisiae Syd. \& P. Syd. Quanto o tamanho dos ascos, não há semelhança com nenhuma das espécies comparadas, e quanto os ascósporos, há uma similaridade com os da espécie N. hoehnelii (Rehm) Rossman, mas a quantidade de septos é diferenciada na espécie em estudo. Devido às diferenças morfométricas e por ser o primeiro relato do fungo em uma planta da família Clusiaceae, sugere-se que esta seja uma provável nova espécie de Nematostoma. 
Tabela 24. Características morfométricas de espécies de Nematostoma.

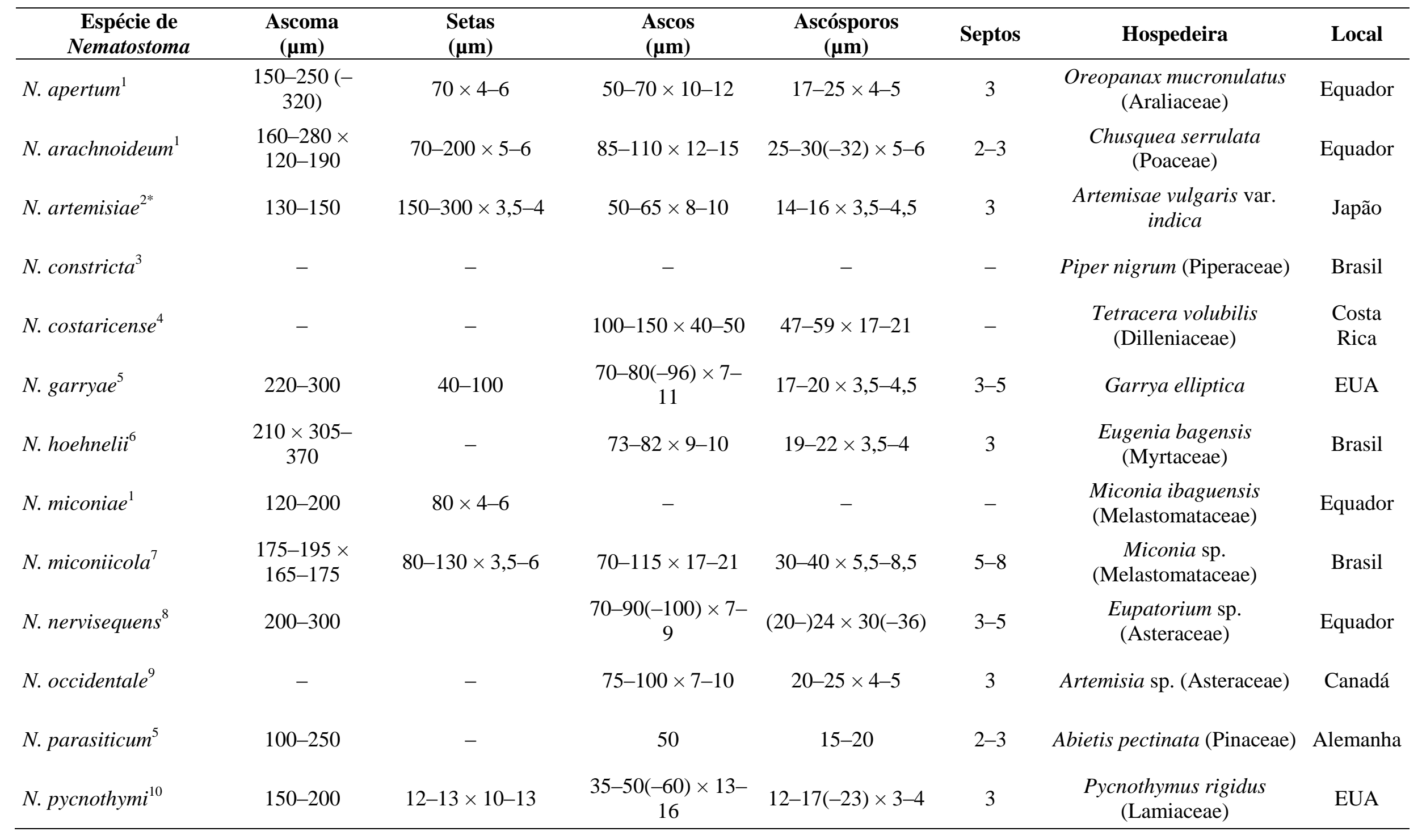


Continuação

\begin{tabular}{lcccccc}
\hline N. singeri ${ }^{11}$ & $180-320$ & - & $70-90(-115) \times$ & $28-43 \times 9-11,5$ & $3(4-5)$ & $\begin{array}{c}\text { Dryopteris lillois } \\
\text { (Dryopteridaceae) }\end{array}$ \\
$\begin{array}{l}\text { Nematostoma } \text { Sp.nv } \\
\text { UB 23372 }\end{array}$ & $\mathbf{8 6 -}$ & $\mathbf{1 6 7 - 2 7 7}[\mathbf{2 1 9}] \times \mathbf{4}-$ & $\begin{array}{c}\mathbf{2 9 , 5 - 4 3 , 5}[\mathbf{3 7}] \times \\
\mathbf{1 9 - 2 8}[\mathbf{2 3}]\end{array}$ & $\begin{array}{c}\mathbf{1 3 - 2 7}[\mathbf{1 9}] \times \mathbf{4}- \\
\mathbf{6}[\mathbf{5}]\end{array}$ & $\mathbf{1 - 5}$ & $\begin{array}{c}\text { Clusia } \mathbf{s p} \text { (Clusiaceae) } \\
\text { Brasília }\end{array}$ \\
\hline
\end{tabular}

${ }^{1}$ (Petrak, 1949); ${ }^{2}$ (Sydow e Sydow, 1914); ${ }^{3}$ (Batista e Vital, 1955); ${ }^{4}$ (Hansford, 1946); ${ }^{5}$ (Barr, 1997); ${ }^{6}$ (Rossman, 1987); ${ }^{7}$ (Batista et al., 1967); ${ }^{8}($ Petrak, 1950); ${ }^{9}$ (Barr, 1968); ${ }^{10}$ (Petrak, 1952); ${ }^{11}$ (Petrak, 1955); *Espécie tipo. 


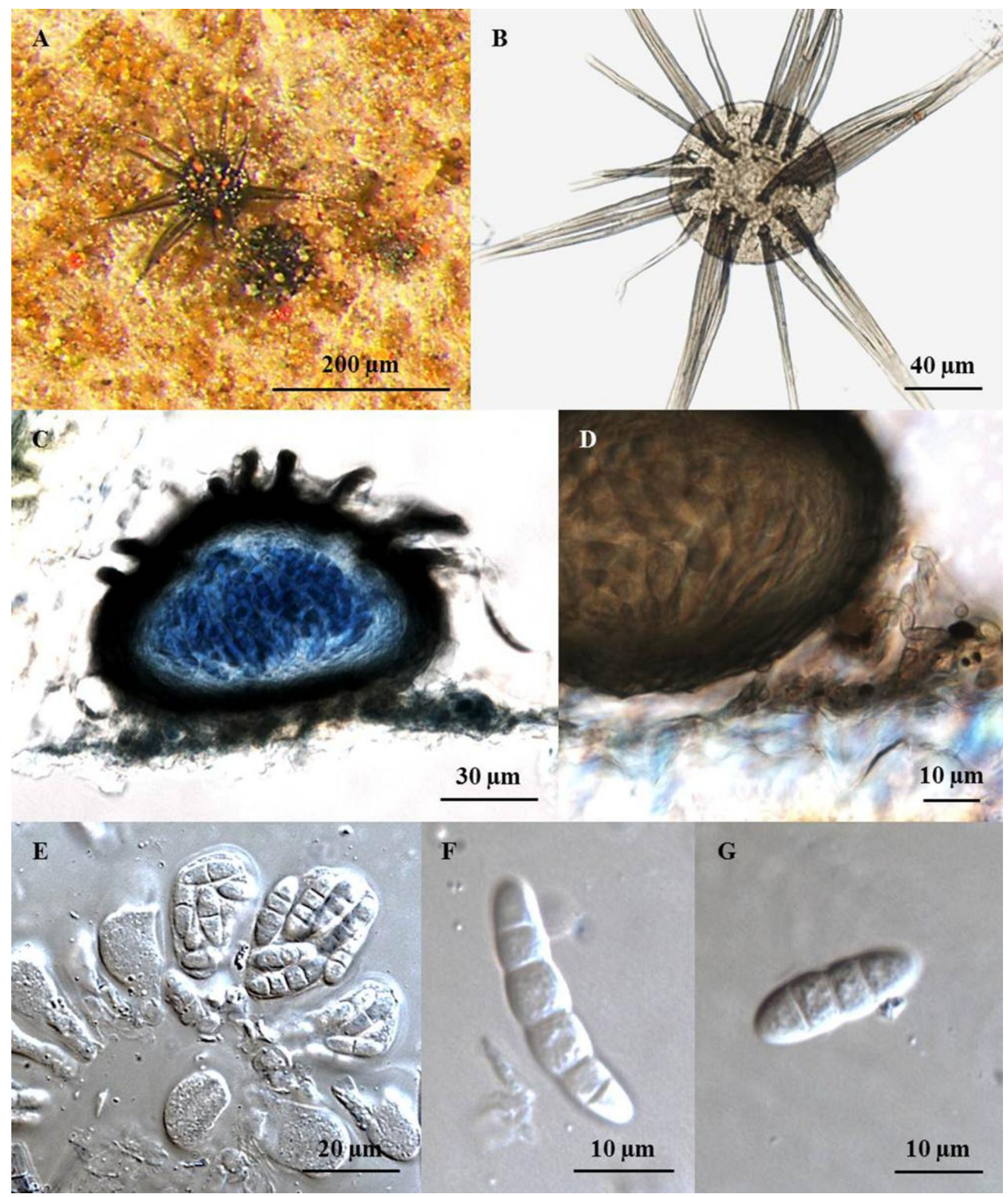

Figura 28. A-G. Nematostoma sp. em folhas de Clusia sp. (Clusiaceae) (UB-Micol. Col. 23372). A. Ascoma na folha. B. Ascoma com setas. C. Corte transversal mostrando himênio e posição das setas. D. Subiculum. E. Ascos. F-G. Ascósporos. 


\subsection{Membros da família Saccardiaceae}

3.8.1. Johansonia amadelpha (Syd.) Arx, Müller \& von Arx, Beitr. Kryptfl. Schweiz 11(no. 2): 212 (1962). (Nova hospedeira no 3). Figura 29 (A-F)

Colônias hipófilas, dispersas, setosas, acinzentadas. Micélio superficial, setoso. Setas miceliais $104-474 \times 4-7 \mu \mathrm{m}$, eretas, septadas, marrom-escuras, filiformes. Hifas ramificadas, septadas, hialinas a marrom-claras, setosas. Ascomas superficiais, $148-292,5 \times 45-81 \mu \mathrm{m}$, discoides, marrom-escuros a negros. Ascos 33,5-42,5 × 13-19 $\mu \mathrm{m}$, numerosos, cilíndricos a elipsóides, bitunicados, contendo oito ascósporos. Ascósporos 7-13,5 × 4-5 $\mu \mathrm{m}$, hialinos, bicelulares, clavados, sem constrição nos septos.

Espécime examinado: em folhas de Qualea grandiflora (Vochysiaceae), BRASIL, Distrito Federal, Planaltina, Reserva do Mirante, EMBRAPA CPAC; 21/06/2015, Bruno Cézar Pereira de Souza \#10 e 23, UB (Col. Micol.) 23374 e 23379.

O gênero Johansonia tem como espécie tipo J. setosa (Basiônimo: Ravenelula setosa G. Winter) (Saccardo, 1889). Devido o seu ascoma superficial discoide, ascos bitunicados e ascósporos hialinos uniseptados, foi alocada inicialmente na família Schizothyriaceae (Müller e Von Arx, 1962). Posteriormente, foi colocada na família Saccardiaceae, subordem Dothideaceae em Dothideales, baseado em um epitécio de hifas ramificadas no ascoma (Von Arx e Müller, 1975). Após isso, a alocaram em Phillipsiellaceae em Loculoascomycetes, e finalmente concluíram que era um membro de Saccardiaceae, uma família que consideravam Incertae sedis em Ascomycota (Barr, 1993; Lumbsch e Huhndorf, 2007). Em estudo mais recente, Johansonia chapadiensis Crous, R.W. Barreto, Alfenas \& R.F. Alfenas, foi a primeira espécie a ter dados de sequências de DNA no GenBank, esse estudo revelou que Johansonia pertence à classe Dothideomycetes, ordem Capnodiales, e está intimamente relacionada com Schizothyriaceae e Mycosphaerellaceae, no entanto, não define se é um membro da família Saccardiaceae, já que atualmente não há culturas conhecidas desta família 
disponíveis para comparação. Alguns gêneros da família Saccardiaceae foram transferidas para Schizothyriaceae e, portanto, sua relação próxima com o Schizothyriaceae sugere Saccardiaceae como uma provável família para este gênero (Crous et al., 2010).

O gênero é caracterizado por ter ascoma frouxo, superficial, discoidal, situado em um estroma hifal, e ascos bitunicados cobertos por um excípulo; paráfises entremeadas entre os ascos, hialinas, septadas, tornando-se um pouco escurecidas e ramificadas quando em direção ao epitécio apical; ascósporos hialinos e bicelulares; ascomas cercados por setas marrons, eretas, retas a curvas (Müller e Von Arx, 1962).

O espécime foi comparado com as espécies de Johansonia presentes na literatura acessível, assim como em trabalhos realizados pelo Departamento de Fitopatologia da UnB (Tabela 25). Trabalhos realizados no Cerrado já tinham detectado este fungo em Qualea grandiflora (Dornelo-Silva, 1999). O espécime é similar a J. setosa quanto o tamanho e formato de setas, que são obtusas e grandes, diferindo quanto o tamanho de ascos e ascósporos. As espécies J. amadelfa e $J$. chapadensis possuem ascos similares à espécie em estudo. Quanto os ascósporos, o espécime estudado é similar a J. amadelfa. A diferença em relação às setas pode ser devido à diferença de hospedeira, que é indédita. No entanto, sugerese que o espécime em estudo seja descrito como sendo J. amadelfa. 
Tabela 25. Características morfométricas das espécies de Johansonia.

\begin{tabular}{|c|c|c|c|c|c|c|}
\hline Espécies de Johansonia & $\begin{array}{c}\text { Setas } \\
(\mu \mathrm{m})\end{array}$ & $\begin{array}{c}\text { Ascomas } \\
(\mu \mathrm{m})\end{array}$ & $\begin{array}{c}\operatorname{Ascos} \\
(\mu \mathrm{m})\end{array}$ & $\begin{array}{c}\text { Ascósporos } \\
(\mu \mathrm{m})\end{array}$ & Hospedeira & Local \\
\hline J. amadelfa ${ }^{1}$ & $170 \times 3-5$ & $250-400 \times 25$ & $25-33 \times 11-16$ & $9-12 \times 3-4$ & $\begin{array}{l}\text { Roupalae veraguensis } \\
\text { (Proteaceae) }\end{array}$ & Costa Rica \\
\hline J. brasliensis ${ }^{2}$ & $200-300 \times 7-9$ & $151-208 \times 65-80$ & $40-54 \times 18-23$ & $19-24 \times 6-7,5$ & Inga sp. (Fabaceae) & Brasil \\
\hline J. chapadiensis $^{3}$ & $130-260 \times 4-5$ & $\begin{array}{c}\text { Até } 300 \times \text { até } \\
200\end{array}$ & $32-45 \times 11-19$ & $\begin{array}{c}(13-) 15-19(-44) \times \\
(5-) 6-7\end{array}$ & $\begin{array}{l}\text { Dimorphandra mollis } \\
\text { (Fabaceae) }\end{array}$ & Brasil \\
\hline J. consociata ${ }^{1}$ & - & $180-220$ & - & $10-13 \times 3,5-4,5$ & $\begin{array}{l}\text { Roupalae veraguensis } \\
\text { (Proteaceae) }\end{array}$ & Costa Rica \\
\hline J. cupulata ${ }^{4}$ & $210 \times 6$ & 300 & $48 \times 12$ & $12-13 \times 4-4,5$ & $\begin{array}{c}\text { Quercus laurifolie } \\
\text { (Fagaceae) }\end{array}$ & EUA \\
\hline J. formosa $a^{5}$ & $160-300$ & $\begin{array}{l}180-280 \times \\
80-100\end{array}$ & $33-60 \times 14,5-28$ & $21-25,5 \times 7-5,9$ & Olea americana (Oleaceae) & EUA \\
\hline J. guazumae 6 & - & 250 & $40-50 \times 5-6$ & $6-8 \times 3-3,5$ & $\begin{array}{l}\text { Guazuma rosea } \\
\text { (Sterculiaceae) }\end{array}$ & Brasil \\
\hline J. microglossae $e^{1}$ & 140 & $\begin{array}{c}120-180 \times 60- \\
80\end{array}$ & - & $17-20 \times 6-8$ & $\begin{array}{l}\text { Microgolssa volubilis } \\
\quad \text { (Asteraceae) }\end{array}$ & África \\
\hline J. nigro-capitata ${ }^{7}$ & - & 83-128 & $25-27 \times 12,5-16$ & $11-13 \times 4$ & Solanaceae & Brasil \\
\hline$J$. pandani $^{8}$ & 100 & $\begin{array}{c}150-200 \times 50- \\
60\end{array}$ & $27-36 \times 11-13$ & $11-13 \times 3,5-5$ & Pandani sp. (Pandanaceae) & Indonésia \\
\hline$J . \operatorname{setos}^{7} *$ & Até 500 & - & $40-52 \times 12-14$ & $11-14 \times 3-4$ & Sapindaceae & $\begin{array}{c}\text { América do } \\
\text { Sul }\end{array}$ \\
\hline $\begin{array}{l}\text { Johansonia sp. } \\
\text { UB10041 }\end{array}$ & $135-620 \times 4-6[5]$ & $\begin{array}{c}230-450 \times 45- \\
60\end{array}$ & $\begin{array}{c}30-57[45] \times 10- \\
18[15]\end{array}$ & $10-22[17] \times 4-6[5]$ & $\begin{array}{c}\text { Qualea grandiflora } \\
\text { (Vochysiaceae) }\end{array}$ & Brasil \\
\hline $\begin{array}{l}\text { Johansonia sp. } \\
\text { UB7744 }\end{array}$ & $77-130 \times 1-3[1]$ & $\begin{array}{c}60-139[80] \times \\
50-57\end{array}$ & $\begin{array}{c}35-45[39] \times 8- \\
13[10]\end{array}$ & $8-14[11] \times 2-4[3]$ & $\begin{array}{c}\text { Eugenia dysenterica } \\
\text { (Myrtaceae) }\end{array}$ & Brasil \\
\hline $\begin{array}{l}\text { Johansonia sp. } \\
\text { CMEPH M39 823B }\end{array}$ & $\begin{array}{c}77,5-157,5[143,5] \times \\
3-6[6]\end{array}$ & $156-360[218,5]$ & $\begin{array}{c}27-38[30] \times 7- \\
11,5[9]\end{array}$ & $5,5-11[7] \times 1-3,5[3]$ & $\begin{array}{c}\text { Ocotea paniculata } \\
\text { (Laureaceae) }\end{array}$ & Brasil \\
\hline $\begin{array}{l}\text { Johansonia } \text { sp. }^{12} \\
\text { UB } 23248\end{array}$ & $225-365 \times 4-6$ & $\begin{array}{c}230-360 \times 60- \\
80\end{array}$ & $36-55 \times 21-25$ & $11-17 \times 4-5,5$ & Pouteria torta (Sapotaceae) & Brasil \\
\hline $\begin{array}{l}\text { J. chapadiensis } \\
\text { UB } 23373\end{array}$ & $\begin{array}{c}172-247[190] \times 3,5- \\
5,5[4,5]\end{array}$ & $\begin{array}{c}181-292[213] \times \\
43-66[52]\end{array}$ & $\begin{array}{c}33-42,5[37] \times 12- \\
16[14]\end{array}$ & $9-16[12] \times 3-5[4]$ & Byrsonima (Malpighiaceae) & Brasil \\
\hline
\end{tabular}


Continuação.

Johansonia sp.

UB 23374

\section{4-474[274}

[6]

167-324[250]

$[4,5]$

$267-440[350] \times 5$

6,5[5]

Johansonia sp.

UB 23382
148-292 [220] × 33,5-42,5[39] $\times$

$$
\text { 45-89[64] }
$$

13-19[16]

$7-14[11,5] \times 4-$
$5[4,5]$

$265-464[325] \times 35-41[37,5] \times 12$

$265-464[325] \times$
$60,5-82[66,5]$

14,5 [13]

9-12 [11] $\times$ 3-5 [4]

187-377[239,5]

$\times$ 52-71,5[62]

$32-43,5[38] \times 10-\quad 11-14[12,5] \times 4-$

15[13]

$5,5[5]$

${ }^{9}$ (Dornelo-Silva, 1999); ${ }^{10}$ (Pereira-Carvalho, 2004); ${ }^{11}$ (Souza, 2011). ${ }^{12}$ (Vélez Zambrano, 2016); *Espécie tipo. 

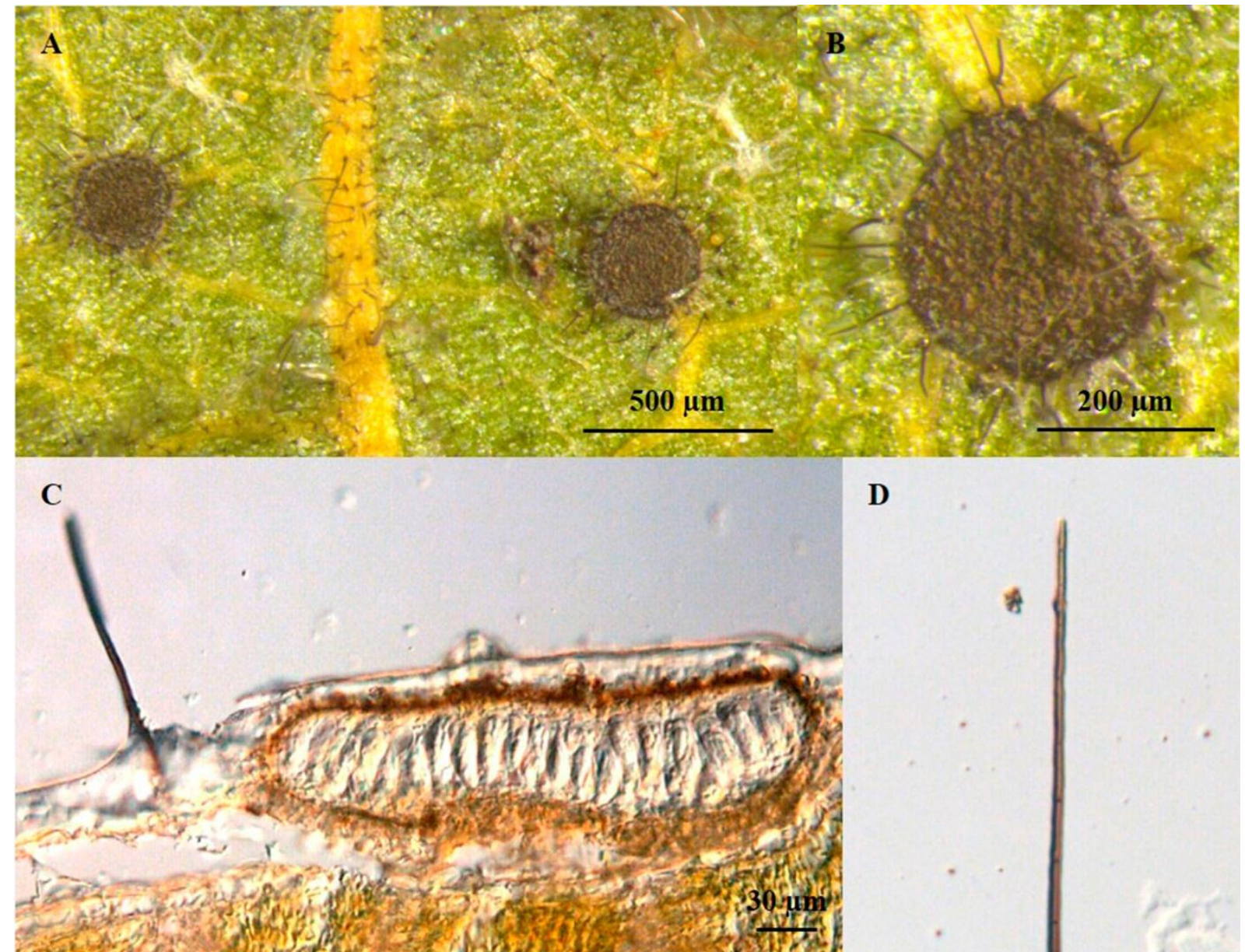

D

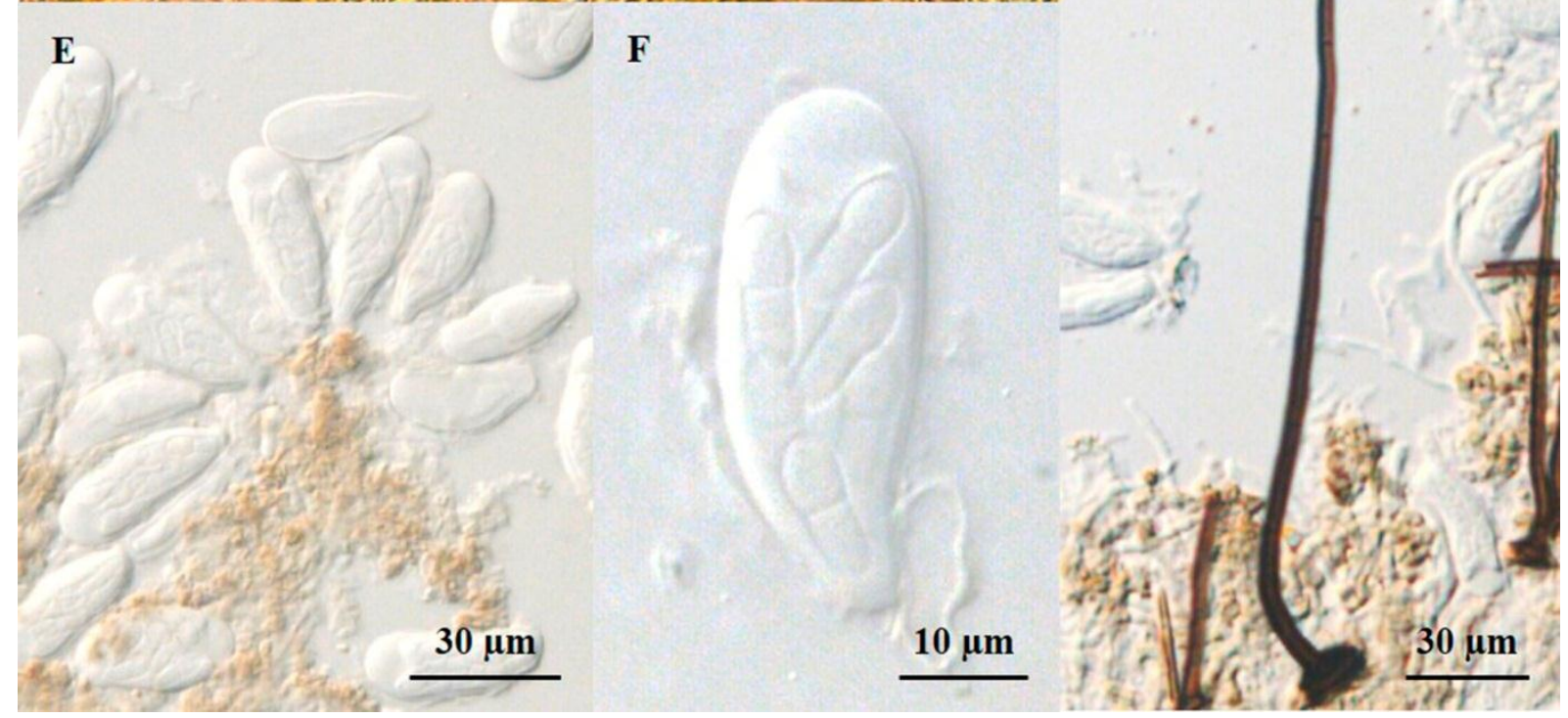

Figura 29. A-F. Johansonia amadelpha. em folhas de Qualea grandiflora (Vochysiaceae) (UB-Micol. Col. 23374). A-B. Ascomas e setas na face abaxial da folha. C. Corte transversal mostrando a disposição dos ascos em paliçada. D. Seta. E. Ascos. F. Ascósporos. 
3.8.2. Johansonia chapadensis Crous, R.W. Barreto, Alfenas \& R.F. Alfenas, IMA Fungus 1(2): 119 (2010). (Nova hospedeira n 4). Figura 30 (A-F)

Colônias hipófilas, dispersas, setosas, acinzentadas. Micélio superficial setoso. Setas miceliais $172-247 \times 3,5-6 \mu \mathrm{m}$, eretas, septadas, marrom escuras, filiformes, arrendondadas no ápice. Hifas ramificadas, septadas, hialinas a marrom-claras, setosas. Ascomas superficiais, $181-292 \times 43-66 \mu \mathrm{m}$, discoides, marrom-escuras a negras. Ascos 33-42,5 × 12$16 \mu \mathrm{m}$, numerosos, cilíndricos a elipsóides, bitunicados, contendo oito ascósporos. Ascósporos 9-16 × 3-5 $\mu \mathrm{m}$, hialinos, bicelulares, clavados, sem constrição nos septos.

Espécime examinado: em folhas de Byrsonima sp. (Malpighiaceae), BRASIL, Distrito Federal, Planaltina, Reserva do Mirante, EMBRAPA CPAC; 21/06/2015, Bruno Cézar Pereira de Souza \#8, UB (Col. Micol.) 23373.

O espécime em estudo foi comparado com as espécies de Johansonia presentes em literatura acessível, assim como com espécies relatadas em trabalhos realizados no Departamento de Fitopatologia da UnB (Tabela 25). A espécie encontrada em Byrsonima sp., possui características morfométricas semelhantes a $J$. chapadiensis quanto o tamanho e formato de setas (arredondadas no ápice), ascos e ascósporos, mas se diferencia quanto a altura dos ascomas. Trata-se do primeiro registro deste fungo em uma planta da família Malpighiaceae. 


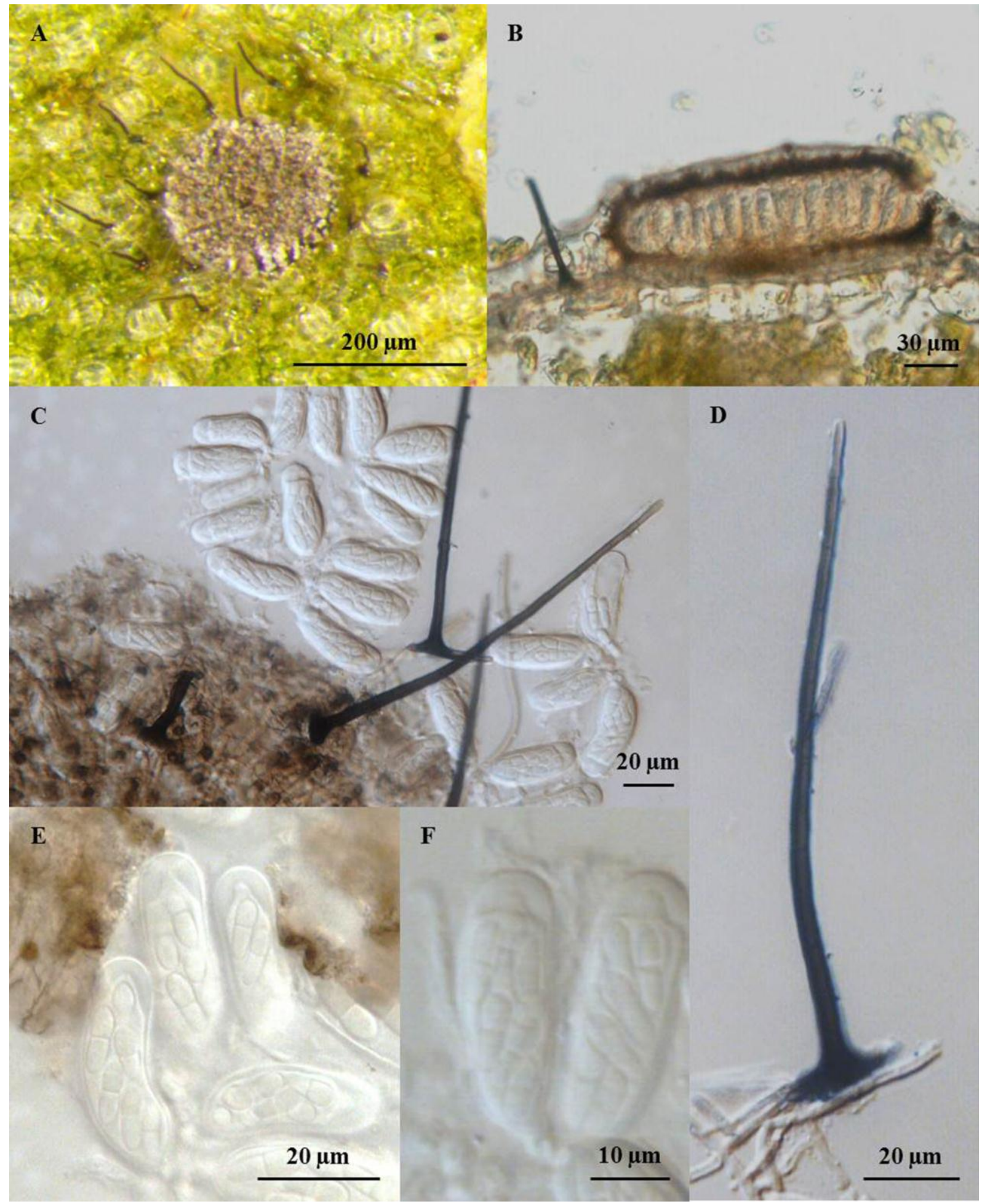

Figura 30. A-F. Johansonia chapadiensis. em folhas de Byrsonima sp. (Malpighiaceae) (UB-Micol. Col. 23373). A. Ascoma com setas ao redor. B. Corte transversal mostrando ascos em paliçada. C. Ascoma e ascos. D. Seta. E-F. Ascos e ascósporos. 
3.8.3. Johansonia setosa (G. Winter) Sacc., Syll. fung. (Abellini) 8: 785 (1889). (Nova hospedeira $\left.\mathrm{n}^{\mathrm{o}} 5\right)$. Figura $31(\mathrm{~A}-\mathrm{F})$

Colônias hipófilas, dispersas, setosas, acinzentadas. Micélio superficial, setoso. Setas miceliais $266,5-440 \times 5-6,5 \mu \mathrm{m}$, eretas, septadas, marrom-escuras, filiformes, obtusas. Hifas ramificadas, septadas, hialinas a marrom-claras, setosas. Ascomas superficiais, 187-377 × 52-71,5 $\mu \mathrm{m}$, discoides, marrom-escuros a negros. Ascos 32-43,5 $\times 9,5-14,5 \mu \mathrm{m}$, numerosos, cilíndricos a elipsóides, bitunicados, contendo oito ascósporos. Ascósporos 11,5-13,5 × 4-5,5 $\mu \mathrm{m}$, hialinos, bicelulares, clavados, sem constrição nos septos.

Espécime examinado: em folhas de Siagrus flexuosa (Arecaceae), BRASIL, Distrito Federal, Planaltina, Reserva do Mirante, EMBRAPA CPAC; 21/06/2015, Bruno Cézar Pereira de Souza \#31, UB (Col. Micol.) 23382.

O espécime foi comparado com as espécies de Johansonia presentes em literatura acessível, assim como em trabalhos realizados pelo Departamento de Fitopatologia da UnB (Tabela 25). A espécie em estudo é similar a J. setosa quanto o tamanho de ascos e ascósporos, além de possuir setas miceliais agudas e grandes. Trata-se do primeiro relato deste fungo em Siagrus flexuosa. 

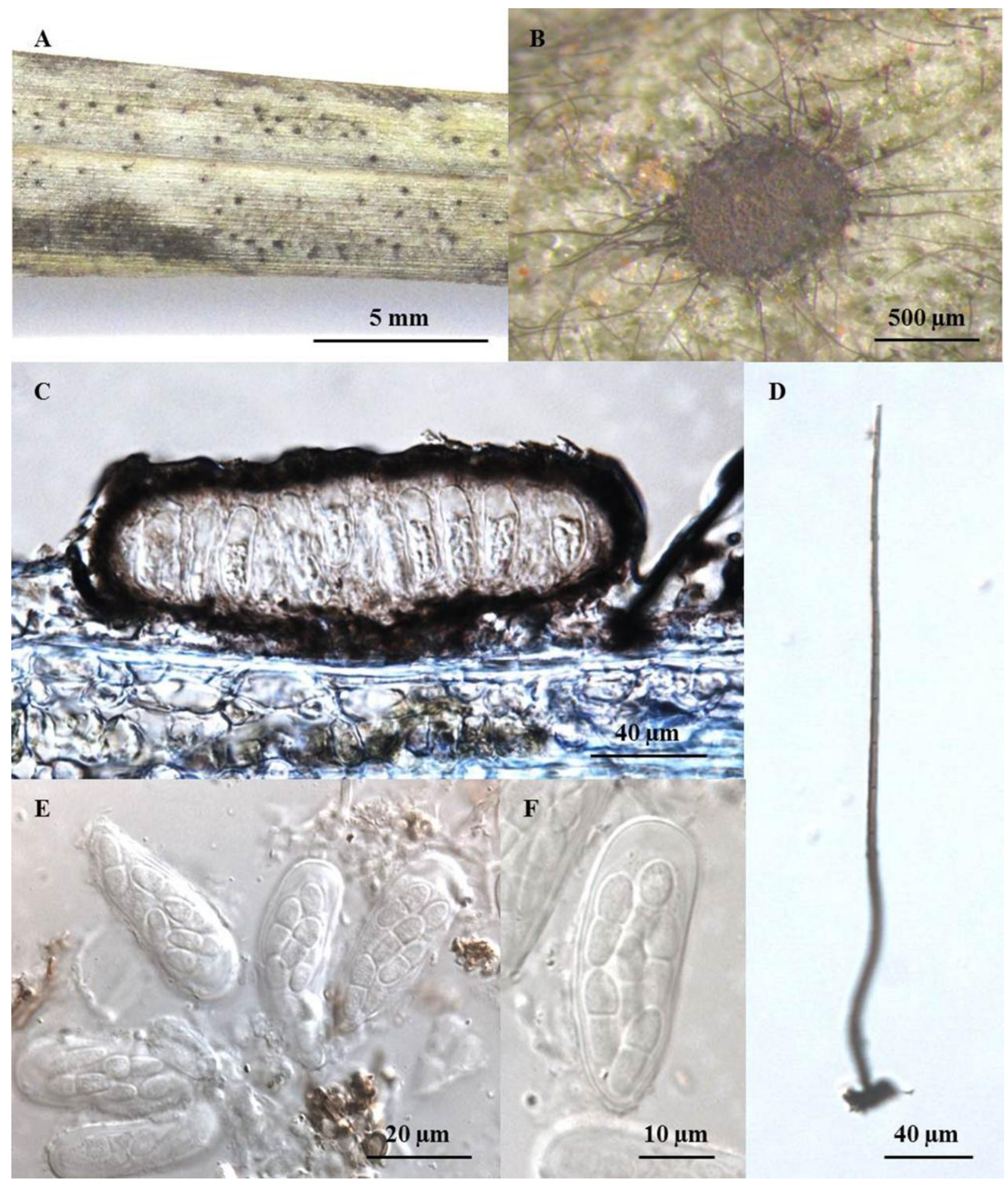

Figura 31. A-F. Johansonia setosa. em folhas de Siagrus flexuosa (Arecaceae) (UB-Micol. Col. 23382). A. Face abaxial da folha parasitada pelo fungo. B. Detalhe do ascoma com numerosas setas ao redor. C. Corte transversal mostrando diposição dos ascos em paliçada. D. Seta. E. Ascos. F. Ascósporos. 
3.8.4. Phillipsiella atra Cooke, Grevillea 7(no. 42): 48 (1878). (Nova hospedeira $\left.n^{\circ} 6\right)$. Figura $32(A-F)$

Colônias hipófilas, efuso, acinzentadas a escuras, dispersas. Micélio superficial, septado, com hifas de 2-4 $\mu \mathrm{m}$ de largura, marrons, flexuosas, setas ausentes. Ascomas 214$323 \times 73-85 \mu \mathrm{m}$, superficiais, sésseis, escuros, discoides e glabros. Ascos bitunicados, 34-45 $\times$ 8-15 $\mu \mathrm{m}$, sésseis, cilíndricos a clavados, contendo oito esporos. Ascósporos elipsóides, 8,9$12 \times 3,4-5 \mu \mathrm{m}$, hialinos, didimospóros, lisos, com uma leve constrição no septo.

Espécime examinado: em folhas de Byrsonima (Malpighiaceae), BRASIL, Distrito Federal, Planaltina, Reserva do Mirante, EMBRAPA CPAC; 21/06/2015, Bruno Cézar Pereira de Souza \#8, UB (Col. Micol.) 23373.

O gênero Phillipsiella (Espécie tipo: P. atra) foi proposto por Cooke, sendo caracterizada por conter ascomas discoides, ascos numerosos, bitunicados e ascósporos bicelulares e hialinos (Cooke, 1878). Mais tarde o gênero foi alocado em Schyzothyriaceae (Müller e Von Arx, 1962) e posteriormente em Saccardiaceae (Von Arx e Müller, 1975), no entanto, Barr reinstalou o gênero em Phillipsiellaceae (Von Höhnel, 1909; Barr, 1979), que foi aceito em seguida (Eriksson, 1981; Katumoto, 1986). Em um trabalho mais atual, utilizando o sequenciamento da região LSU do rDNA, o gênero Phillipsiella foi alocado na ordem Capnodiales, classe Dothideomycetes, mas a situação da família segue indefinida (Silva et al., 2016).

O gênero Phillipsiella possui as seguintes características: não apresentam estroma, formam ascomas escudados a pulvinados, semi-apoteciais, verde-escuros a negros, às vezes rodeado por micélio pouco desenvolvido, perídio pouco desenvolvido com células parenquimáticas, tecido interascal constando de pseudoparafíses que se alargam na parte apical para formar um epitécio; ascos em forma de sacos, sésseis, com parede grossa ao 
menos no ápice, com uma ampla câmara ocular, não fissitunicados; ascósporos hialinos a escuros, simples, com septos transversais ou muriformes (Kirk et al., 2008).

Atualmente há 12 registros de espécies no gênero Phillipsiella, no entanto, três registros foram renomeados, sobrando então nove espécies (Index Fungorum, 2017). As espécies em literatura acessível foram comparadas com o espécime em estudo, juntamente com outras espécies de Phillipsiella relatadas em trabalhos realizados no Cerrado (Tabela 26). A espécie em estudo apresenta similaridades com as espécies $P$. atra e $P$. caseariae. $\mathrm{O}$ espécime em estudo difere de $P$. atra apenas em relação a altura dos ascomas, já em relação a $P$. caseariae a diferença se dá quanto o comprimento dos ascomas, largura dos ascos e dimensão dos ascósporos, sendo que os ascos da espécie em estudo são mais estreitos e os ascósporos menores que os de $P$. caseariae. Assim sendo, pode-se inferir que se trata de uma espécie de P. atra em uma nova hospedeira da família Malpighiaceae. 
Tabela 26. Características morfométricas das espécies de Phillipsiella.

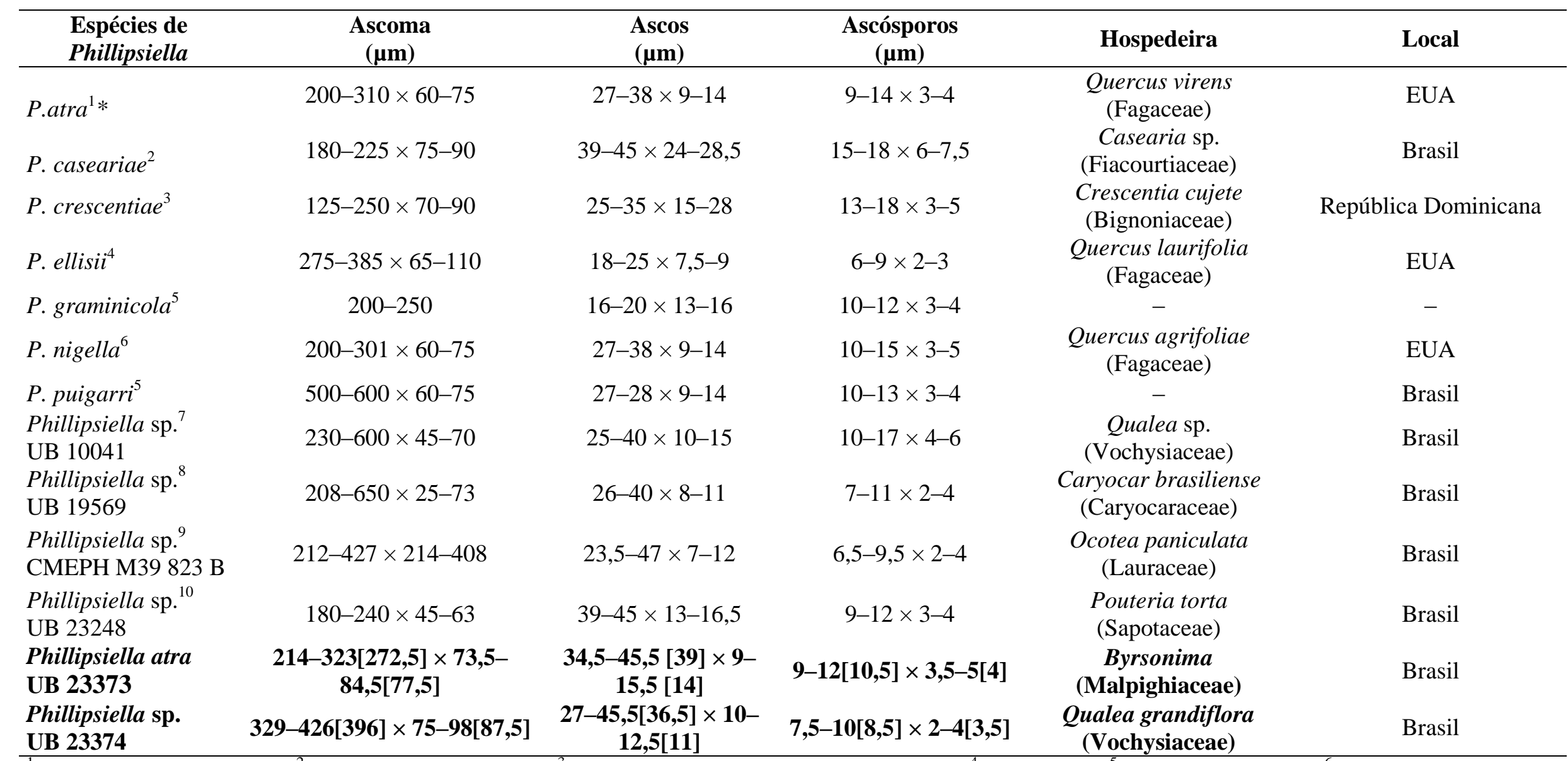

${ }^{1}$ (Müller e Von Arx, 1962); ${ }^{2}$ (Bezerra e Poroca, 1969); ${ }^{3}$ (Rossman, Mouchacca e Samuels, 1994); ${ }^{4}$ (Barr, 1993); ${ }^{5}$ (Von Höhnel, 1909); ${ }^{6}($ Phillips e Harkness, 1884); ${ }^{7}$ (Dornelo-Silva, 1999); ${ }^{8}$ (Armando, 2015); ${ }^{9}$ (Souza, 2011); ${ }^{10}$ (Vélez Zambrano, 2016); *Espécie tipo. 


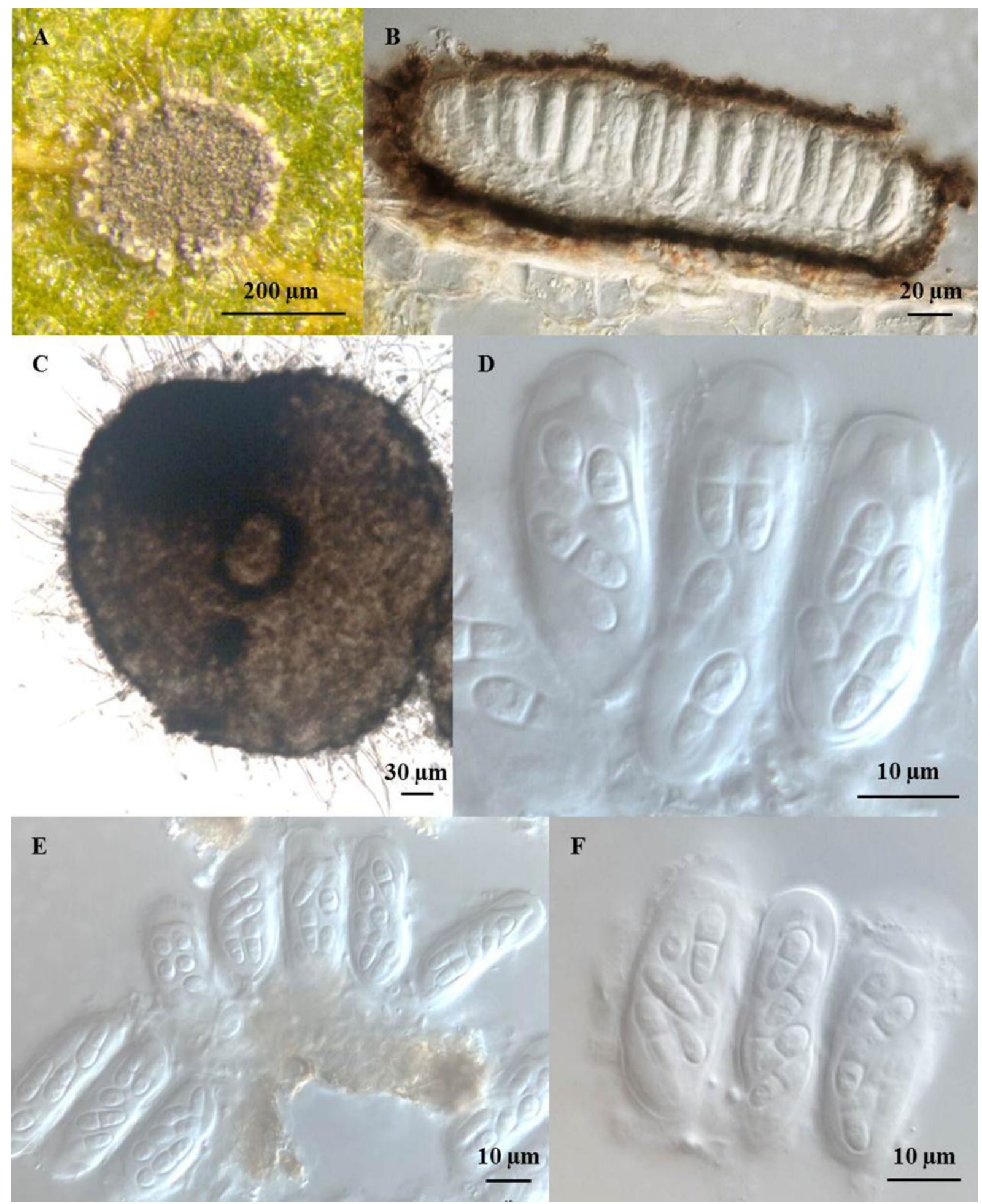

Figura 32. A-F. Phillipsiella atra em folhas de Byrsonima (Malpighiaceae) (UB-Micol. Col. 23373). A. Ascoma sobre a folha. B. Corte transversal mostrando disposição dos ascos em paliçada. C. Ascoma rodeado de micélio. D-E. Ascos. F. Ascósporos. 
3.8.5. Phillipsiella nigella W. Phillips \& Harkn., Bull. Calif. Acad. Sci. 1(no. 1): 23 (1884). (Nova hospedeira no 7). Figura 33 (A-F)

Colônias hipófilas, efusas, acinzentadas a escuras, dispersas. Micélio superficial, septado, com hifas de 2-4 $\mu \mathrm{m}$ de largura, marrons, flexuosas, setas ausentes. Ascomas medindo 329-426 × 75-98 $\mu \mathrm{m}$, superficiais, sésseis, escuros, discoides e glabros. Ascos bitunicados, medindo $26,5-45,5 \times 10-12,5 \mu \mathrm{m}$, sésseis, cilíndricos a clavados, contendo oito esporos. Ascósporos elipsóides, 7,5-10 × 2-4 $\mu \mathrm{m}$, hialinos, bicelulares, lisos, com uma leve constrição no septo.

Espécime examinado: em folhas de Qualea grandiflora (Vochysiaceae), BRASIL, Distrito Federal, Planaltina, Reserva do Mirante, EMBRAPA CPAC; 21/06/2015, Bruno Cézar Pereira de Souza \#10, UB (Col. Micol.) 23374.

As espécies em literatura acessível foram comparadas com o espécime em estudo, juntamente com outras espécies de Phillipsiella relatadas em trabalhos realizados no Cerrado (Tabela 26). Os ascósporos da espécie estudada asemlha-se a P. ellisii, já os ascos a P.atra e $P$. nigella. No entanto, o ascoma é maior que todas as espécies conhecidas, excluindo $P$. puigarri, que apresenta ascomas maiores. Espécies de Phillipsiella relatadas em Qualea sp. e Caryocar brasiliense em uma dissertação de mestrado, são similares à estudada neste trabalho, as mesmas porém não foram publicadas (Dornelo-Silva, 1999). Dentre as espécies descritas em literatura, o espécime em questão é similar a $P$. nigella e $P$. pugarri, sendo mais próxima de P. nigella. Trata-se do primeiro relato da espécie em Qualea grandiflora. 


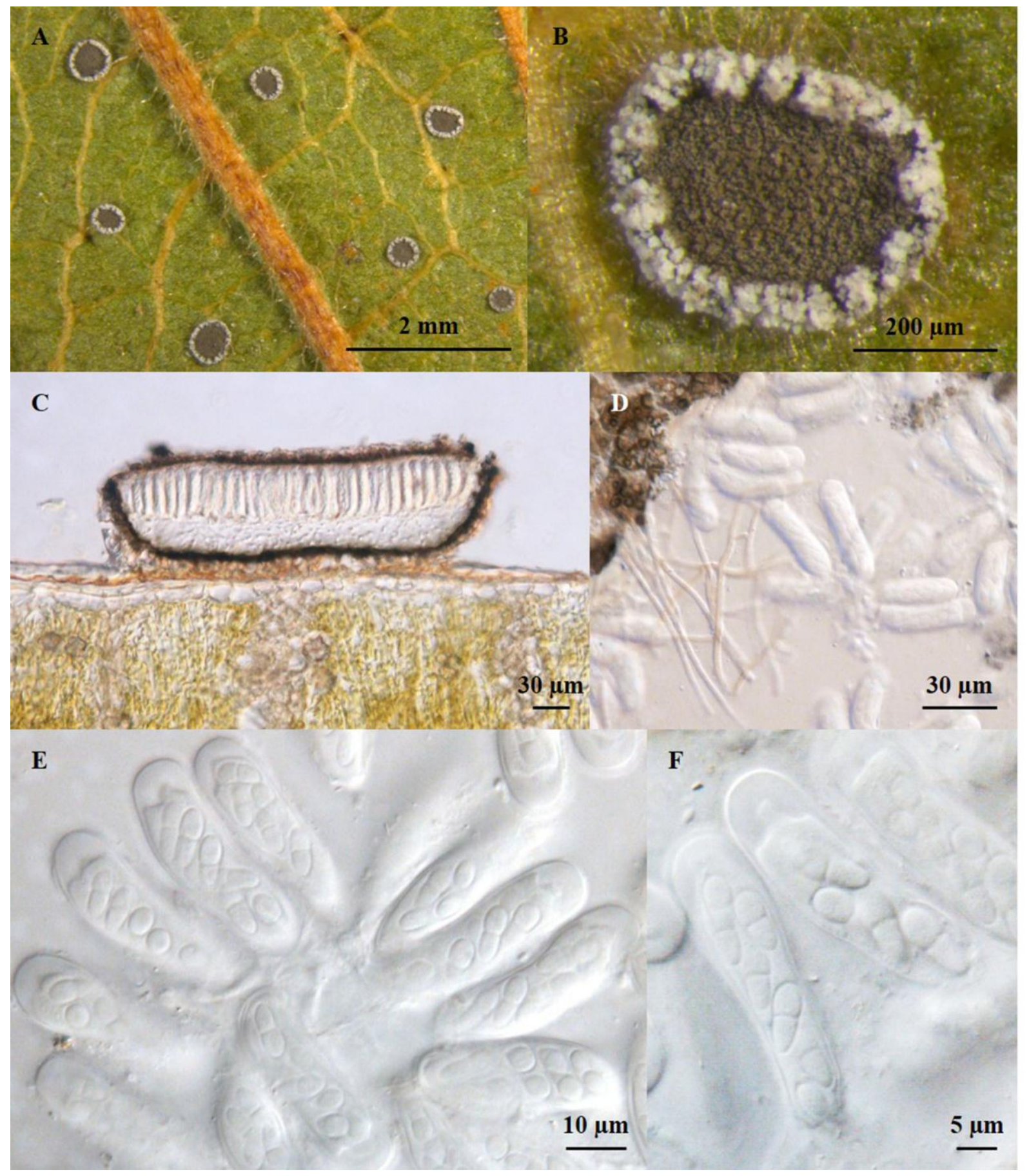

Figura 33. A-F. Phillipsiella nigella em folhas de Qualea grandiflora (Vochysiaceae) (UBMicol. Col. 23374). A. Colônia na parte abaxial da folha. B. Ascoma sobre a folha. C. Corte transversal mostrando disposição dos ascos em paliçada. D. Micélio. E. Ascos. F. Ascósporos. 


\subsubsection{Vonarxella (provável espécie nova $\left.\mathrm{n}^{\circ} 11\right)$. Figura $34(\mathrm{~A}-\mathrm{F})$}

Colônias hipófilas, escuras, dispersas. Micélio superficial, oliváceo, com hifas de 2-4 $\mu \mathrm{m}$ de largura, sob o ascoma. Ascomas 203-413 × 27-44 $\mu \mathrm{m}$, superficiais, escuros, discoides e glabros. Ascos bitunicados, 17-25,5 × 9-13,5 $\mu \mathrm{m}$, sésseis, cilíndricos a clavados, contendo quatro ascósporos. Ascósporos elipsóides, 8-10 × 2,5-3,5 $\mu \mathrm{m}$, hialinos a oliváceos, bicelulares, lisos, com uma leve constrição no septo.

Espécime examinado: em folhas de Qualea grandiflora (Vochysiaceae), BRASIL, Distrito Federal, Planaltina, Reserva do Mirante, EMBRAPA CPAC; 21/06/2015, Bruno Cézar Pereira de Souza \#23, UB (Col. Micol.) 23.379.

O gênero Vonarxella tem apenas um registro atualmente, V. dypterygis Bat., J.L. Bezerra \& Peres relatada em Dypterix alata (Fabaceae) e é caracterizado por apresentar subículo peliculoso, marrom, com hifas pouco ramificadas, septadas; apotécios elevados sobre o subículo, superficiais, plano-orbiculares, glabros, marrom-escuros, membranosos, discoides, planos, com excípula prosenquimática, epitécio marrom, hipotécio marrom e himênio hialino; ascos bitunicados, inoperculados, contendo oito ascósporos, subsésseis, parafisados; ascósporos oblongos, bicelulares e hialinos (Batista, Bezerrra e Peres, 1965).

A espécie encontrada neste trabalho foi comparada com a espécie monotípica e uma encontrada em trabalho realizado no Cerrado (Tabela 27). A espécie encontrada neste trabalho apresenta ascomas semelhantes à $V$. diptergys, no entanto, possui ascos menores e ascósporos oliváceos também menores, além de produzir apenas quatro ascósporos por asco. Sendo assim, pode-se deduzir que se trata de uma provável nova espécie de Vonarxella. 
Tabela 27. Características morfométricas das espécies de Vonarxella.

\begin{tabular}{|c|c|c|c|c|c|}
\hline $\begin{array}{l}\text { Espécies de } \\
\text { Vonarxella }\end{array}$ & $\begin{array}{l}\text { Ascoma } \\
(\mu \mathrm{m})\end{array}$ & $\begin{array}{l}\text { Hifas } \\
(\mu \mathrm{m})\end{array}$ & $\begin{array}{c}\text { Ascos } \\
(\mu \mathrm{m})\end{array}$ & $\begin{array}{l}\text { Ascósporos } \\
(\mu \mathrm{m})\end{array}$ & Hospedeira \\
\hline V. dipterygis ${ }^{1} *$ & $\begin{array}{c}185-420 \times 63- \\
77\end{array}$ & - & $\begin{array}{c}28-43 \times 10- \\
13\end{array}$ & $10-13 \times 3,5-4$ & $\begin{array}{l}\text { Dipterix } \\
\text { alata }\end{array}$ \\
\hline $\begin{array}{l}\text { Vonarxella sp. } \\
\text { UB } 06902\end{array}$ & $\begin{array}{c}183-248[215] \\
\times 160- \\
290[186]\end{array}$ & - & $\begin{array}{l}28-53[50] \times \\
11-25[11,5]\end{array}$ & $\begin{array}{c}12-21[16,5] \times \\
4-6,5[5]\end{array}$ & Ocotea sp. \\
\hline $\begin{array}{l}\text { Vonarxella sp. } \\
\text { UB } 23379\end{array}$ & $\begin{array}{c}203-413[295] \\
\times 27-44[37]\end{array}$ & $1,5-2$ & $\begin{array}{c}17-25,5[21] \\
\times 9-13,5 \\
{[11,5]}\end{array}$ & $\begin{array}{c}7,5-10[8,5] \times \\
2,5-3,5[3]\end{array}$ & $\begin{array}{c}\text { Qualea } \\
\text { grandiflora }\end{array}$ \\
\hline
\end{tabular}

${ }^{\top}$ (Batista, Bezerrra e Peres, 1965), ${ }^{2}$ (Souza, 2011); *Espécie tipo. 


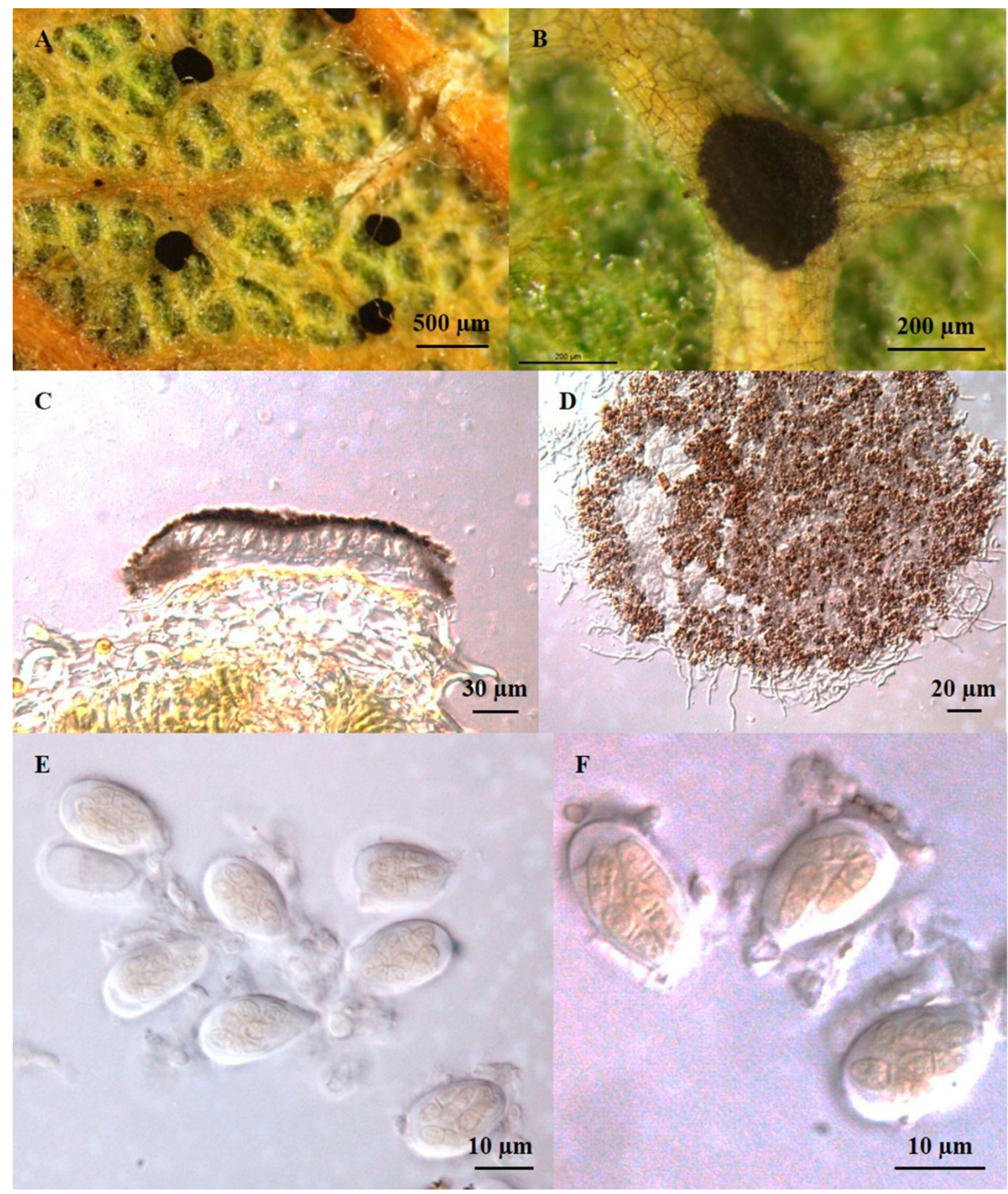

Figura 34. A-F. Vonarxella sp. em folhas de Qualea grandiflora (Vochysiaceae) (UBMicol. Col. 23379). A. Colônia na face abaxial da folha. B. Ascoma e micélio. C. Corte transversal mostrando disposição dos ascos em paliçada. D. Ascoma rodeado por micélio. E. Ascos. F. Ascósporos. 


\section{CONCLUSÃO}

De um total de 136 amostras analisadas provenientes da reserva ecológica Mirante, na Embrapa Cerrados em Planaltina-DF, foram documentados e descritos aqui neste trabalho 34 fungos, sendo que as demais amostras foram analisadas previamente e, juntamente com as apresentadas neste trabalho, depositadas na Coleção Micológica do Herbário da Universidade de Brasília (CMHUB).

As plantas foram provenientes de 15 famílias botânicas, sendo elas: Arecaceae, Asteraceae, Bignoniaceae, Celastraceae, Chrysobalanaceae, Clusiaceae, Fabaceae, Icacinaceae, Loranthaceae, Malpighiaceae, Myrtaceae, Proteaceae, Rubiaceae, Stiracaceae e Vochysiaceae.

Foram descritos seis ascomicetos assexuados, sendo três celomicetos e três hifomicetos, além de 28 ascomicetos sexuados, totalizando 34 ascomicetos. Dentre estes há uma provável espécie nova de hifomiceto (Zasmidium), um provável gênero novo de ascomiceto sexuado (Phyllachoraceae), dez prováveis espécies novas de ascomicetos sexuados (Ophiociliomyces, Dothidasteromella, Lembosia, Stomiopeltis, Nematostoma, Dyctyopeltis, três espécies de Phyllachora e uma de Vonarxella), além do registro de seis novos hospedeiro para fungos já conhecidos.

A riqueza de espécies de fungos presentes no bioma Cerrado é muito grande, porém a mão de obra para identificação e descrição dos mesmos é ainda escassa. O trabalho de identificação deve passar também para o âmbito molecular, com extração de DNA e sequenciamento, para assim vir ao encontro da modernidade e facilitar a comparação com espécies descritas. 


\section{REFERÊNCIAS BIBLIOGRÁFICAS}

Alexopoulos, C J; Mins, C W; Blackwell, M. Introductory Mycology. New York: John Wiley and Sons: 869 p. 1996.

Armando, E a S. Fungos epifíticos e fitopatogênicos associados a plantas do Cerrado. 2015. Tese de doutorado. Universidade de Brasília, Brasília, Brasil.

Barr, M E. The Venturiaceae in North America. Canadian Journal of Botany, v. 46, n. 6, p. 799-864, 1968.

. A classification of Loculoascomycetes. Mycologia, v. 71, p. 935-957, 1979.

$505,1987$.

New taxa and combinations in the Loculoascomycetes. Mycotaxon, v. 29, p. 501Redisposition of some taxa described by JB Ellis. Mycotaxon, v. 46, p. 45-76, 1993.

. Notes on some 'dimeriaceous' fungi. Mycotaxon, v. 64, p. 149-171, 1997.

Batalha, M A. O cerrado não é um bioma. Biota Neotropica, v. 11, n. 1, p. 1-4, 2011.

Batista, A C. Alguns fungos de fumagina de Pernambuco. Mycopathologia Applicata, v. 5, n. 2, p. 147-172, 1951.

Monografia dos fungos Micropeltaceae. Universidade do Recife, 1959.

Batista, A C; Bezerra, J L. Discomycetidae e pyrenomycetidae novos ou vulgares. Instituto de Micologia, Universidade do Recife (Memórias da Sociedade Broteriana 14: 29-47), v. $271,1961$.

Batista, A C; Bezerra, J L; Castro, J E W. Sphaeropsidaceae antigos e novos. Anais do XIII Congresso da Sociedade Botânica do Brasil, v. 363, 1964.

Batista, A C; Bezerra, J L; Poroca, D J; Moura, N R. Espécies novas e antigas de Ascomycetes epifíticos da flora brasílica. Atas do Instituto de Micologia. Universidade Federal de Pernambuco, Recife, v. 3, p. 122-138, 1966.

Batista, A C; Bezerrra, J L; Peres, G E P. Vonarxella e outros novos Ascomycetes. Rivista di Patologia Vegetale, v. 1, p. 61-69, 1965.

Batista, A C; Peres, G E P. Ascomycetes fitoparasitas. Instituto de Micologia, Universidade do Recife, v. 277, 1960.

Batista, A C; Peres, G E P; Maia, H S. Alguns Phyllachora dos "Cerrados" e de outras áreas fisiográficas brasileiras. Atas do Instituto de Micologia. Universidade Federal de Pernambuco, Recife, v. 443, p. 63-81, 1967. 
Batista, A C; Peres, G E P; Poroca, D J M; Bezerra, J L. Três interessantes Ascomycotina de peritécios setosos. Instituto de Micologia, Universidade do Recife (Atas do Instituto de Micologia. Universidade Federal de Pernambuco, Recife 5: 235-243). v. 582, 1967.

Batista, A C; Vital, A F. Novos elementos para a taxonomia dos fungos de fumagina. Instituto de Micologia, Universidade do Recife (Anais da Sociedade de Biologia de Pernambuco 13 (2): 108-124). v. 321955.

A redescription of a few species of Dothidasteromella, Hysterostomella Speg., Inocyclus Theiss. \& Syd. and Leptodothis Theiss. \& Syd. Atas Inst Micol Univ Recife, v. 1, n. 122, p. 205-219, 1960.

Batista, A C; Vital, A F; Maia, H S; Lima, I H. Coletânea de novas espécies de fungos. Instituto de Micologia, Universidade do Recife (Anais da Sociedade de Biologia de Pernambuco 13 (1): 185-195), v. 20, 1955.

Beserra Júnior, J E A; Pfenning, L H. Associação de Pseudothis coccodes e seu anamorfo com Machaerium villosum (Papilionoideae). Fitopatologia brasileira, v. 31, n. 1, 2006.

Blackwell, M. The Fungi: 1, 2, 3... 5.1 million species? American Journal of Botany, v. 98, n. 3, p. 426-438, 2011.

Braun, U. Taxonomic notes on some species of the Cercospora complex (VII). Fungal Diversity, v. 8, p. 41-71, 2001.

Braun, U; Crous, P W; Schubert, K; Shin, H. Some reallocations of Stenella species to Zasmidium. Schlechtendalia, v. 20, p. 99-104, 2013.

Braun, U; Delhey, R; Dianese, J C; Hosagoudar, V B. Miscellaneous notes on biotrophic micromycetes. Schlechtendalia, v. 14, p. 85-97, 2006.

Braun, U; Nakashima, C; Crous, P W. Cercosporoid fungi (Mycosphaerellaceae) 1. Species on other fungi, Pteridophyta and Gymnospermae. IMA fungus, v. 4, n. 2, p. 265-345, 2013.

Braun, U; Takamatsu, S. Phylogeny of Erysiphe, Microsphaera, Uncinula (Erysipheae) and Cystotheca, Podosphaera, Sphaerotheca (Cystotheceae) inferred from rDNA ITS sequencessome taxonomic consequences. Schlechtendalia, v. 4, p. 1-33, 2013.

Braun, U; Urtiaga, R. New species and new records of cercosporoid hyphomycetes from Cuba and Venezuela (Part 2). Mycosphere, v. 4, n. 2, p. 174-214, 2013.

Cannon, P F. A revision of Phyllachora and some similar genera on the host family Leguminosae. Mycological Papers, 1991. 302 ISBN 0851987354.

Cantrell, S A; Dianese, J C; Fell, J; Gunde-Cimerman, N; Zalar, P. Unusual fungal niches. Mycologia, v. 103, n. 6, p. 1161-74, 2011.

Castellani, E. Micromiceti dell'africa orientali italiana. Nuovo Giornale Botanico Italiano, v. 49, n. 1, p. 1-31, 1942. 
Chaudhary, S; Sharma, N. Three new species of Stenella. Indian Phytopathology, v. 55, n. 1, p. 57-60, 2002.

Cochrane, T T; Sánchez, L G; Azevedo, L G; Porras, J A; Garver, C L. Land in Tropical America. CIAT/Planaltina: EMBRAPA-CPAC, 1985. ISBN 8489206392.

Cooke, M C. Ravenel's American fungi. Grevillea, v. 7, p. 32-35, 1878.

Cooke, M C; Harkness, H W. Californian fungi (cont. from p. 9). Grevillea, v. 9, n. 51, p. 81$87,1881$.

Costa, L C; Macedo, D M; Barreto, R W. Reappraisal and neotypification of Phyllachora feijoae. IMA fungus, v. 3, n. 1, p. 9-14, 2012.

Crous, P W. Impact of molecular phylogenetics on the taxonomy and diagnostics of fungi. EPPO Bulletin, v. 35, n. 1, p. 47-51, 2005.

Crous, P W; Barreto, R W; Alfenas, A C; Alfenas, R F; Groenewald, J Z. what is Johansonia? IMA Fungus: The Global Mycological Journal, v. 1, n. 2, p. 117, 2010.

Crous, P W; Shivas, R G; Quaedvlieg, W; Van Der Bank, M; Zhang, Y; Summerell, B A; Guarro, J; Wingfield, M J; Wood, A R; Alfenas, A C. Fungal Planet description sheets: 214280. Persoonia-Molecular Phylogeny and Evolution of Fungi, v. 32, n. 1, p. 184-306, 2014.

Crous, P W; Summerell, B A; Carnegie, A J; Wingfield, M J; Hunter, G C; Burgess, T I; Andjic, V; Barber, P A; Groenewald, J Z. Unravelling Mycosphaerella: do you believe in genera? Persoonia-Molecular Phylogeny and Evolution of Fungi, v. 23, n. 1, p. 99-118, 2009.

Crous, P W; Summerell, B A; Shivas, R G; Carnegie, A J; Groenewald, J Z. A re-appraisal of Harknessia (Diaporthales), and the introduction of Harknessiaceae fam. nov. PersooniaMolecular Phylogeny and Evolution of Fungi, v. 28, n. 1, p. 49-65, 2012.

Dianese, A C; Costa, A M; Dianese, J C. A new Pseudocercospora species on Passiflora setacea. Mycotaxon, v. 105, p. 1-5, 2008.

Dianese, A C; Helson, M; Vale, M; Érica, S; Souza, C; Pereira-Carvalho, R C; Chaves, Z M; Paulo, E; Câmara, S; Dianese, J C. New Cercospora species on Jatropha curcas in central Brazil. Mycological Progress, v. 13, n. 4, p. 1069, 2014.

Dianese, A C; Sutton, B C; Tessman, D J. Two deutromycetes, Phloeosporella flavio-moralis sp. nov. and Pseudocercospora punctata comb. nov. causing leaf lesions on Eugenia spp. Mycological Research, v. 97, n. 1, p. 123-126, 1993.

Dianese, J C. Micodiversidade associada a plantas nativas do Cerrado. Tópicos Atuais em Botânica. Brasília: Sociedade Brasileira de Botânica/Embrapa-Cenargen. p, p. 109-115, 2000. 
Dianese, J C; Buriticá, P; Hennen, J F. The rust of" Jatobá": a new Crossopsora species from Neotropica on Hymenaea (Leguminosae). Fitopatologia brasileira, v. 19, n. 4, p. 588-591, 1994.

Dianese, J C; Câmara, M P S. Pseudocercospora aspidospermatis-a new combination for Bactrodesmiella aspidospermatis. Sydowia, v. 46, p. 225-232, 1994.

Dianese, J C; Dianese, A C. Three Uncinula species from the Brazilian cerrado and a key to South American Uncinula species. Mycological Research, v. 99, n. 7, p. 821-824, 1995.

Dianese, J C; Hasan, S; Sobhian, R. Ramularia cuprinae sp. nov., a leaf pathogen of Cuprina vulgaris. Fitopatologia brasileira, v. 21, p. 115-119, 1996.

Dianese, J C; Inácio, C A; Dornelo-Silva, D. Wilmia, a new genus of phaeosphaeriaceous ascomycetes on Memora pedunculata in central Brazil. Mycologia, v. 93, n. 5, p. 1014-1018, 2001.

Dianese, J C; Medeiros, R B; Santos, L T P. Biodiversity of microfungi found on native plants of the Brazilian Cerrado. In: Hyde, K D (Ed.). Biodiversity of Tropical Microfungi. Hong Kong: Hong Kong University Press, 1997. p.367-417.

Dianese, J C; Medeiros, R B; Santos, L T P; Furlanetto, C. Batistopsora gen. nov. and new Phakopsora, Ravenelia, Cerotelium e Skierka species from the Brazilian Cerrado. Fitopatologia Brasileira, v. 18, p. 436-436, 1993a.

Dianese, J C; Medeiros, R B; Santos, L T P; Sutton, B C. Coniella costae sp. nov. on leaves of Myrcia tomentosa from Brazilian cerrado. Mycological Research, v. 97, n. 10, p. 12341236, $1993 \mathrm{~b}$.

Dianese, J C; Santos, L T P. Aplopsora hennenii sp. nov., the first rust fungus recorded from Vochysiaceae. Mycological Research, v. 99, n. 8, p. 914-916, 1995.

Dianese, J C; Santos, L T P; Medeiros, R B; Furlanetto, C. Kimuromyces cerradensis Gen. et sp. nov., the rust fungus of Gonçalo Alves (Astronium fraxinifolium-Anacardiaceae) from the Brazilian Cerrado. Fitopatologia Brasileira, v. 20, p. 251-255, 1995.

Dianese, J C; Tessmann, D J; Furlanetto, C. Reinstating Oswaldina icarahyensis as the name of the anamorph of Apiosphaeria guaranitica. Sydowia, v. 46, n. 2, p. 233-237, 1994.

Diogo, E L F; Santos, J M; Phillips, A J L. Phylogeny, morphology and pathogenicity of Diaporthe and Phomopsis species on almond in Portugal. Fungal Diversity, v. 44, n. 1, p. 107-115, 2010.

Dornelo-Silva, D; Dianese, J C. Hyphomycetes on the Vochysiaceae from the Brazilian cerrado. Mycologia, v. 95, n. 6, p. 1239-51, 2003.

New hyphomycete genera on Qualea species from the Brazilian cerrado. Mycologia, v. 96, n. 4 , p. 879-884, 2004. 
Dornelo-Silva, D; Pereira-Carvalho, R C; Dianese, J C. New Stenella and Parastenella species from the Brazilian cerrado. Mycologia, v. 99, n. 5, p. 753-64, 2007.

Dornelo-Silva, D. Fungos associados a plantas da família Vochysiaceae presentes no Cerrado. 1999. Dissertação de Mestrado. Universidade de Brasília, Brasília, Brasil.

Early, M P; Punithalingam, E. Phomopsis anacardii sp. nov. on Anacardium occidentale. Transactions of the British Mycological Society, v. 59, n. 2, p. 345-347, 1972.

Ellis, J B; Kellerman, W A. New Kansas fungi. Journal of Mycology, v. 1, n. 1, p. 2-3, 1887.

Eriksson, O. The families of bitunicate ascomycetes. Nordic Journal of Botany, v. 1, n. 60, p. 1-220, 1981.

Farr, D F; Rossman, A Y. Harknessia lythri, a new species on purple loosestrife. Mycologia, v. 93, n. 5, p. 997-1001, 2001.

Fungal Databases, Syst. Mycol. Microbiol. Lab., ARS, USDA 2016.

Firmino, A L; Inácio, C A; Pereira, O L; Dianese, J C. Additions to the genera Asterolibertia and Cirsosia (Asterinaceae, Asterinales), with particular reference to species from the Brazilian Cerrado. IMA fungus, v. 7, n. 1, p. 9-28, 2016.

Firmino, A L; Pereira, O L. Lembosia bezerrae, a new asterinaceous fungus associated with a terrestrial orchid from Bahia, Brazil. Mycotaxon, v. 127, n. 1, p. 199-205, 2014.

Fuckel, K W G L. Symbolae mycologicae: Beiträge zur Kenntniss der rheinischen Pilze. Jahrbücher des Nassauischen Vereins für Naturkunde, v. 23-24, p. 1-459, 1870.

Furlanetto, C; Dianese, J C. Rhinocladium pulchrum, a new record for Brazil and new combinations in Rhinocladium. Mycological research, v. 100, n. 2, p. 244-246, 1996.

29, 1998.

Some coelomycetes from central Brazil. Mycological Research, v. 102, n. 01, p. 19-

Some Pseudocercospora species and a new Prathigada species from the Brazilian cerrado. Mycological research, v. 103, n. 09, p. 1203-1209, 1999.

Guatimosim, E; Firmino, A L; Bezerra, J L; Pereira, O L; Barreto, R W; Crous, P W. Towards a phylogenetic reappraisal of Parmulariaceae and Asterinaceae (Dothideomycetes). Persoonia: Molecular Phylogeny and Evolution of Fungi, v. 35, p. 230, 2015.

Hanlin, R T. Combined keys to illustrated genera of ascomycetes: Volumes I \& II. St. Paul, Minnesota: American Phytopathological Society (APS Press), 1998. ISBN 089054199X.

Hansford, C G. The foliicolous ascomycetes, their parasites and associated fungi. Mycological Papers, v. 15, n. 1, p. 1-240, 1946. 
Hawksworth, D; Rossman, A. Where are all the undescribed fungi? Phytopathology, v. 87, n. 9, p. 888-891, 1997.

Hawksworth, D L. Naming Aspergillus species: progress towards one name for each species. Medical Mycology, v. 49, n. sup1, p. S70-S76, 2011.

Global species numbers of fungi: are tropical studies and molecular approaches contributing to a more robust estimate? Biodiversity and Conservation, v. 21, n. 9, p. 24252433, 2012.

Hennings, P. Fungi goyazenses. Hedwigia, v. 34, n. 2-3, p. 88-116, 1895. 1904a.

Fungi Amazonici II. a cl. Ernesto Ule collecti. Hedwigia, v. 43, n. 4, p. 242-273, . Fungi fluminenses a. cl. E. Ule collecti. Hedwigia, v. 43, n. 2, p. 78-95, 1904 b. 57-71, 1905.

Fungi Amazonici IV. a cl. Ernesto Ule collecti (Appendix). Hedwigia, v. 44, n. 2, p. . Neue und interessante Pilze aus dem Königl. botanischen Museum in Berlin II. Hedwigia, v. 33, p. 228-233, 1984.

Hennings, P C. Beiträge zur Pilzflora Südamerikas II. Hedwigia, v. 36, n. 4, p. 193-246, 1897.

Fungi S. Paulenses a cl. Puttemans collecti. Hedwigia, v. 41, n. 6, p. 295-311, 1902a.

1902b.

Fungi S. Paulenses I a cl. Puttemans collecti. Hedwigia, v. 41, n. 3, p. 104-118,

Hernández-Gutiérrez, A; Braun, U; Dianese, J C. Cercosporoid hyphomycetes on malpighiaceous hosts from the Brazilian Cerrado: species of Pseudocercospora on hosts belonging to Byrsonima. Mycological progress, v. 13, n. 2, p. 193-210, 2014.

Hernandéz-Gutiérrez, A; Chaves, Z M; Dornelo-Silva, D; Dianese, J C. Additions to the cercosporoid fungi from the Brazilian Cerrado: 1 . New species on hosts belonging in family Fabaceae, and reallocations of four Stenella species into Zasmidium. Mycobiota, v. 5, p. 3364, 2015.

Hernandéz-Gutiérrez, A; Dianese, J C. New cercosporoid fungi from the Brazilian Cerrado 1. Species on hosts of the families Anacardiaceae, Araliaceae, Bombacaceae, Burseraceae and Celastraceae. Mycotaxon, v. 106, p. 41-63, 2008.

Hernández-Gutiérrez, A; Dianese, J C. New cercosporoid fungi from the Brazilian Cerrado 2. Species on hosts of the subfamilies Caesalpinioideae, Faboideae and Mimosoideae (Leguminosae s. lat.). Mycotaxon, v. 107, n. 1, p. 1-24, 2009. 
. Cercosporoid hyphomycetes on malpighiaceous hosts from the Brazilian Cerrado: New Passalora and Pseudocercospora species on hosts of the genus Banisteriopsis. Mycological progress, v. 13, n. 2, p. 365-371, 2014a.

New Passalora species on Peixotoa (Malpighiaceae) from the Brazilian Cerrado. Mycological progress, v. 13, n. 1, p. 75-79, 2014 b.

Hobbs, T W; Schmitthenner, A F; Kuter, G A. A new Phomopsis species from soybean. Mycologia, v. 77, n. 4, p. 535-544, 1985.

Höhnel, F X R V. Fragmente zur Mykologie (IX. Mitteilung, Nr. 407 bis 467). Sitzungsberichte der Kaiserlichen Akademie der Wissenschaften in Wien Mathematisch-Naturwissenschaftliche Classe, v. 1, n. 118, p. 1461-1552, 1909a.

. Fragmente zur Mykologie VIII. Sitzungsber. Kaiserl. Akad. Wiss., Math.Naturwiss. Cl., Abt, v. 1, n. 118, p. 1157-1246, 1909 b.

Fragmente zur Mykologie X. Sitzungsber. Kaiserl. Akad. Wiss., Math.-Naturwiss. Cl., Abt, v. 1, n. 119, p. 420, 1910.

Hongsanan, S; Li, Y; Liu, J; Hofmann, T; Piepenbring, M; Bhat, J D; Boonmee, S; Doilom, M; Singtripop, C; Tian, Q; Mapook, A; Zeng, X; Bahkali, A H; Xu, J; Mortimer, P E; Wu, X; Yang, J; Hyde, K D. Revision of genera in Asterinales. Fungal diversity, v. 68, n. 1, p. 1-68, 2014.

Hongsanan, S; Tian, Q; Peršoh, D; Zeng, X; Hyde, K D; Chomnunti, P; Boonmee, S; Bahkali, A H; Wen, T. Meliolales. Fungal Diversity, v. 74, n. 1, p. 91-141, 2015.

Hosagoudar, V B; Abraham, T K; Biju, C K. Re-evaluation of the family Asterinaceae. Journal of Mycopathological Research, v. 39, n. 1, p. 61-64, 2001.

Hosagoudar, V B; Balakrishnan, N P; Goos, R D. Some Asterina species from Southern India. Mycotaxon, v. 59, p. 167-187, 1996.

Hosagoudar, V B; Goos, R D. Some Asterina, Asteromstomella and Lembosia species from Southern India. Mycotaxon, v. 52, n. 2, p. 467-473, 1994.

. Some foliicolous fungi from Southern India. Mycotaxon, v. 59, p. 149-166, 1996.

Hyde, K D; Jones, E B G; Liu, J; Ariyawansa, H; Boehm, E; Boonmee, S; Braun, U; Chomnunti, P; Crous, P W; Dai, D. Families of Dothideomycetes. Fungal Diversity, v. 63, n. 1, p. 1-313, 2013.

Inácio, C A; Cannon, P F. The genera of the 'Parmulariaceae'. CBS Fungal Biodiversity Centre, 2008. ISBN 9070351722.

Inácio, C A; Dianese, J C. Some foliicolous fungi on Tabebuia species. Mycological Research, v. 102, n. 06, p. 695-708, 1998. 
A new Mycovellosiella species on Myracrodruon urundeuva. Mycotaxon, v. 72, p. 251-263, 1999.

Foliicolous fungi on Tabebuia species from the cerrado. Mycological Progress, v. 5, n. 2, p. 120-127, 2006.

Inácio, C A; Furlanetto, C; Hernández-Gutiérrez, A; Dianese, J C. Some Cercospora species originally described by Ahmés Pinto Viégas. Fitopatologia Brasileira, v. 21, p. 405-409, 1996.

Inácio, C A; Pereira-Carvalho, R C; Souza, E S C; Dianese, J C. A new Dothidasteroma species on leaves of Psidium laruotteanum from the Brazilian Cerrado. Mycotaxon, v. 116, n. 1, p. 27-32, 2011.

Inácio, C A; Pereira-Carvalho, R C; Souza, E S C; Sales, H B; Dianese, J C. A new Hysterostomella species from the Cerrado in Brasília National Park. Mycotaxon, v. 119, n. 1, p. 307-313, 2012.

Index Fungorum. 2017. Disponível em: www.indexfungorum.org. Acesso em: 18 Fev 2017.

Katumoto, K. Notes on some plant-inhabiting ascomycotina from western Japan, 5. Transactions of the Mycological Society of Japan (Japan), 1986.

Kirk, P M; Cannon, P F; Minter, D W; Stalpers, J A. Dictionary of the Fungi. 10. UK: Wallingford, 2008. ISBN 0-85199-826-7.

Klink, C A; Machado, R B. A conservação do Cerrado brasileiro. Megadiversidade, v. 1, n. 1, p. 147-155, 2005.

Léveillé, J H. Description des champignons de l'herbier du Museum de Paris. Annales des sciences naturelles. Botanique et biologie végétale, v. 3, n. 5, p. 286, 1846.

Lumbsch, H T; Huhndorf, S M. Outline of Ascomycota-2007. Myconet, v. 13, p. 1-58, 2007.

Luttrell, E S. The genus Stomiopeltis (Hemisphaeriaceae). Mycologia, v. 38, n. 5, p. 565-586, 1946.

Luz, W C. Micologia avançada: Taxonomia de Ascomicetos. Passo Fundo: Revisão Anual de Patologia de Plantas, 2009.

Medeiros, R B; Dianese, J C. Passalora eitenii sp. nov. on Syagrus comosa in Brazil and a key to Passalora species. Mycotaxon, v. 51, p. 509-513, 1994.

Mendonça, R C; Felfili, J M; Walter, B M T; Silva Júnior, M C; Rezende, A V; Filgueiras, T S; Nogueira, P E; Sano, S M; Almeida, S P. Flora vascular do cerrado. In: (Ed.). Cerrado: ambiente e flora. Planaltina-DF: Embrapa Cerrados, 1998. p.289-556.

Mostert, L; Crous, P W; Kang, J; Phillips, A J L. Species of Phomopsis and a Libertella sp. occurring on grapevines with specific reference to South Africa: morphological, cultural, molecular and pathological characterization. Mycologia, v. 93, n. 1, p. 146-167, 2001. 
Müller, E. Ein neue Discomycet ans Java: Johansonia pandani. Sydowia, v. 8, n. 1-6, p. 54$56,1954$.

Müller, E; Von Arx, J A. Die gattungen der didymosporen Pyrenomyceten. Büchler, 1962.

Myers, N; Mittermeier, R A; Mittermeier, C G; Da Fonseca, G a B; Kent, J. Biodiversity hotspots for conservation priorities. Nature, v. 403, n. 6772, p. 853-858, 2000.

Nag Raj, T R. Coelomycetous anamorphs with appendage-bearing conidia. Waterloo, Ontario: Mycologue Publications, 1993. ISBN 0969223722.

Osorio Romero, J A. Inventario taxonómico de especies pertenecientes al género Phyllachora (Fungi Ascomycota) asociadas a la vegetación de sabana neotropical (Cerrado Brasilero) con énfasis en el Parque Nacional de Brasilia DF. 2008. Dissertação de mestrado. Universidad Tecnológica de Pereira, Risaralda, Colômbia.

Oxford. A dictionary of ecology. Oxford University Press, 2004. ISBN 0199567662.

Parron, L M; Sousa-Silva, J C; Camargo, A J a D. Reservas ecológicas da Embrapa Cerrados: caracterização e zoneamento. Empresa Brasileira de Pesquisa Agropecuária, Centro de Pesquisa Agropecuária dos Cerrados, 1998.

Pereira-Carvalho, R C. Micobiota foliícola associada a espécies de Myrtaceae dos gêneros Blepharocalyx, Eugenia, Gomidesia e Psidium no Cerrado. 2004. 186 Departamento de Fitopatologia, Universidade de Brasília, Dissertação de Mestrado. Brasília, Brasil.

Pereira-Carvalho, R C; Inácio, C A; Dianese, J C. Plurispermiopsis: a new capnodiaceous genus from the Brazilian Cerrado. Mycologia, v. 102, n. 5, p. 1163-1166, 2010.

Pereira-Carvalho, R C; Sepulveda-Chavera, G; Armando, E A; Inacio, C A; Dianese, J C. An overlooked source of fungal diversity: novel hyphomycete genera on trichomes of cerrado plants. Mycological research, v. 113, n. 2, p. 261-74, 2009.

Pereira, O L; Barreto, R W. Pseudocercospora palicoureae sp. nov. associated with the toxic rubiaceous weed Palicourea marcgravii in Brazil, with observations on its mycobiota. Fungal Diversity, v. 23, p. 243-253, 2006.

Petrak, F. Mycologische Notizen V. Annales mycologici, v. 21, p. 16, 1923. Mykologische Notizen. Annales Mycologici, v. 27, n. 5-6, p. 324-410, 1929. . Mykologische Notizen. XI. Annales Mycologici, v. 29, n. 5-6, p. 339-397, 1931. . Mykologische Notizen. XII. Annales Mycologici, v. 32, n. 5-6, p. 317-447, 1934. . Über die Gattungen Phaeochorella Theiss. et Syd. und Phomachorella n. gen. Sydowia, v. 1, n. 1-3, p. 120-126, 1947. 
. Bimeris nov.gen., eine neue Gattung der Sphaeropsideen aus Ekuador. Sydowia, v. 3, n. 1-6, p. 251-255, 1949.

. Beiträge zur Pilzflora von Ekuador. Sydowia, v. 4, n. 1-6, p. 450-587, 1950.

. Beiträge zur Pilzflora von Florida. Sydowia, v. 6, n. 5-6, p. 399-406, 1952.

$555,1955$.

Beiträge zur Pilzflora von Zentral- und Südamerika. Sydowia, v. 9, n. 1-6, p. 550-

Beiträge zur Kenntnis einiger Asterineen der Philippinen. Hedwigia, v. 12, n. 1-6, p. 472-486, 1959.

Petrak, F; Ahmad, S. Beiträge zur pilzflora Pakistans. Sydowia, v. 8, n. 1-6, p. 162-185, 1954.

Petrak, F; Ciferri, R. Fungi Dominicani. Annales Mycologici, v. 28, n. 5-6, p. 377-420, 1930.

Petrak, F; Sydow, H. Sphaeropisidae. Beih. Rep. spec. nov. regn. veg., v. 42, p. 301-313, 1927.

Phengsintham, P; Hyde, K D; Braun, U. Cercospora and allied genera from Laos-1: Notes on Zasmidium (Stenella s. lat.). Cryptogamie, Mycologie, v. 30, n. 3, p. 243-262, 2009.

Phillips, W; Harkness, H W. Fungi of California. Bulletin of the California Academy of Sciences, v. 1, n. 1, p. 23, 1884.

Piepenbring, M. Introducción a la micología en los trópicos. APS Press, 2015. ISBN 0890544565.

Rehm, H. Beiträge zur Pilzflora von Südamerika. XI Dothideaceae. Hedwigia, v. 39, p. 231234, 1900.

Rehner, S A; Uecker, F A. Nuclear ribosomal internal transcribed spacer phylogeny and host diversity in the coelomycete Phomopsis. Canadian Journal of Botany, v. 72, n. 11, p. 16661674, 1994.

Rezende, D V; Dianese, J C. New Ravenelia species on leguminous hosts from the Brazilian Cerrado. Fitopatologia Brasileira, v. 26, n. 3, p. 627-634, 2001.

Aspectos taxonômicos de Uredinales infetando Leguminosas utilizadas na arborização urbana do Distrito Federal. Fitopatologia Brasileira, v. 27, p. 361-371, 2002.

Revisão taxonômica de algumas espécies de ravenelia em leguminosas do cerrado brasileiro. Fitopatologia Brasileira, v. 28, n. 1, p. 27-36, 2003 a.

. Uromyces species on leguminous hosts from the Cerrado with description of U. galactiae sp. nov. Fitopatologia Brasileira, v. 28, n. 5, p. 495-501, 2003 b.

Roskov, Y; Kunze, T; Paglinawan, L; Orrell, T; Nicolson, D; Culham, A; Bailly, N; Kirk, P; Bourgoin, T; Baillargeon, G. Species 2000 \& ITIS Catalogue of Life. 2016 Annual 
Checklist, Leiden, the Netherlands, 2017. Disponível em: www.catalogueoflife.org/annualchecklist/2016. Acesso em: 15 fev 2017.

Rossman, A Y. The Tubeufiaceae and similar loculoascomycetes. Mycological Papers, v. 157, p. 1-71, 1987.

Rossman, A Y; Mouchacca, J; Samuels, G J. Phillipsiella crescentiae comb. nov. and a redescription of $P$. atra, type of the genus Phillipsiella. Sydowia, v. 46, p. 66-74, 1994.

Ryan, R W. The Microthyriaceae of Porto Rico. Mycologia, v. 16, n. 4, p. 177-196, 1924.

Saccardo, P A. Sylloge Fungorum VIII: 785 p. 1889.

. Syllogfe fungorum. 1906.

. Sylloge Fungorum XXII. Padova: 413 p. 1913.

Notae mycologicae. Series XIX. Annales Mycologici v. 13, n. 1, p. 115-138, 1915.

Saccardo, P A; Sydow, P. Sylloge fungorum XIV: Padova 1899.

Sankaran, K V; Sutton, B C; Minter, D. A checklist of fungi recorded on Eucalyptus. CAB INTERNATIONAL, 1995. ISBN 085198990X.

Sano, S M; Almeida, S P; Ribeiro, J F. Cerrado: Ecologia e Flora. Vol 2. EmbrapaCerrados: Brasilia, Brazil, 2008.

Santos, J M; Phillips, A J L. Resolving the complex of Diaporthe (Phomopsis) species occurring on Foeniculum vulgare in Portugal. Fungal Diversity, v. 34, p. 11-125, 2009.

Santos, L T P. Micobiota foliícola de Salacia crassifolia. 2011. 121, Universidade de Brasília, Brasília, Brasil.

Santos, M D; Fonseca-Boiteux, M E; Boiteux, L S; Câmara, P E; Dianese, J C. ITSphylogeny and taxonomy of Phyllachora species on native Myrtacae from the Brazilian Cerrado. Mycologia, v. 108, n. 6, p. 1141-1164, 2016.

Scariot, A; Sousa-Silva, J C; Felfili, J M. Cerrado: ecologia, biodiversidade e conservação. Brasília-DF: Ministério do Meio Ambiente, 2005.

Schroers, H J; Gräfenhan, T; Nirenberg, H I; Seifert, K A. A revision of Cyanonectria and Geejayessia gen. nov., and related species with Fusarium-like anamorphs. Studies in Mycology, v. 68, p. 115-138, 2011.

Seifert, K; Morgan-Jones, G; Gams, W; Kendrick, B. The genera of Hyphomycetes. Utrecht: CBS-KNAW Fungal Biodiversity Centre, 2011. ISBN 9070351854.

Silva-Hanlin, D M W; Halin, R T. The order Phyllachorales: taxonomic review. Mycoscience, v. 39, n. 1, p. 97-104, 1998. 
Silva, M D; Pereira, O L. A new species of Pseudocercospora on Palicourea rigida (Rubiaceae) from Minas Gerais, Brazil. Mycotaxon, v. 102, p. 261-266, 2007.

Silva, M D; Pereira, O L. Black mildew disease of the neotropical orchid Epidendrum secundum caused by Lembosia epidendri sp. nov. from Minas Gerais, Brazil. Mycotaxon, v. 104, p. 385-390, 2008.

Silva, M D; Pinho, D B; Pereira, O L; Fernandes, F M; Barreto, R W. Naming Potentially Endangered Parasites: Foliicolous Mycobiota of Dimorphandra wilsonii, a Highly Threatened Brazilian Tree Species. PloS one, v. 11, n. 2, p. e0147895, 2016.

Sivanesan, A. The bitunicate ascomycetes and their anamorphs. J. Cramer, 1984. ISBN 3768213293.

Souza Armando, E A; Chaves, Z M; Dianese, J C. Phaeostilbelloides and Velloziomycesnew dematiaceous genera from the Brazilian Cerrado. Mycotaxon, v. 130, n. 3, p. 757-767, 2015 .

Souza, C a P; Vitoria, N S; Bezerra, J L; Martins Newman Luz, E D; Inacio, C A; Dianese, J C. Camarotella brasiliensis sp. nov.(Phyllachoraceae) on Syagrus schizophylla (Arecaceae) from Brazil. Mycotaxon, v. 103, p. 313-318, 2008.

Souza, E S C. Alguns fungos presentes em plantas nativas e exóticas do Cerrado. 2011. Universidade de Brasília, Brasília, Brasil.

Souza, E S C; Chaves, Z M; Soares, W R O; Pinho, D B; Dianese, J C. Uromyces hawksworthii nom. nov. for Aecidium goyazense, on Phthirusa stelis (Loranthaceae) from the Brazilian Cerrado. IMA fungus, v. 6, n. 1, p. 155-162, 2015.

Spegazzini, C L. Fungi Guaranitici. Pugillus II. Anales de la Sociedad Científica Argentina, v. 26, n. 1, p. $5-74,1888$.

Speggazini, C L. Fungi Guaranitici. Pugillis I. Anales de la Sociedad Científica Argentina, v. 19 , p. 241-266, 1885.

Sutton, B C. Typification of Dendrophoma and a reassessment of D. obscurans. Transactions of the British Mycological Society, v. 48, n. 1-4, p. 611-616, 1965.

The Coelomycetes: Fungi Imperfecti with Pycnidia Acervuli and Stromata. Commonwealth Mycological Institute Kew, 1980.

Swart, H J. Australian leaf-inhabiting fungi. XXX. Two interesting Parmulariaceae. Transactions of the British Mycological Society, v. 91, n. 4, p. 581-585, 1988.

Sydow, H; Sydow, P. Zweiter Beitrag zur Kenntnis der parasitischen Pilzflora des nördlichen Japans. Annales Mycologici, v. 12, n. 2, p. 158-165, 1914.

Beitrag zur Kenntnis der pilzflora der philippinen-Inseln. Annales Mycologici, v. 15, n. 3-4, p. 165-268, 1917. 
Sydow, H; Sydow, P; Butler, E J. Fungi Indiae Orientalis. Part V. Annales Mycologici, v. 14, n. 3-4, p. 177-220, 1916.

Sydow, H V. Novae fungorum species. Annales Mycologici, v. 30, n. 1-2, p. 91-117, 1932.

Theissen, F. Hemisphaeriales. Annales Mycologici, v. 11, n. 5, p. 468-469, 1913.

. Die Hemisphaerialibus notae supplendae. Broteria, v. 12, p. 73-96, 1914.

Theissen, F; Sydow, H. Die Dothideales. Annales Mycologici, v. 13, n. 3-4, p. 149-430, 1915 a.

Die Dothideales (continuatio). Annales Mycologici, v. 13, n. 5-6, p. 431-746, 1915 b.

. Synoptische Tafeln. Annales Mycologici, v. 15, n. 6, p. 389-491, 1917.

1918.

Vorentwürfe zu den Pseudosphaeriales. Annales Mycologici, v. 16, n. 1-2, p. 1-34,

Toro, R A. Mixomicetos de Santo Domingo colleccionados: por FD Kern y RA Toro. Toro Estacion Agronomica deHaina, Serie B, Botanica 6: 1926.

Traverso, J B; Spessa, D C. Spohaeropsidales. Boletim da Sociedade Broteriana, v. 25, n. 1, 1910.

Udayanga, D; Liu, X; Mckenzie, E H C; Chukeatirote, E; Bahkali, A H A; Hyde, K D. The genus Phomopsis: biology, applications, species concepts and names of common phytopathogens. Fungal Diversity, v. 50, n. 1, p. 189-225, 2011.

Vélez Zambrano, S M. Taxonomia de fungos associados a plantas do cerrado do Distrito Federal e Mato Grosso. 2016. Universidade de Brasília, Brasília, Brasil.

Viégas, A P. Alguns fungos do cerrado. Bragantia, v. 3, n. 4, p. 49-72, 1943.

Alguns fungos do Brasil: II. ascomicetos. Bragantia, v. 4, n. 1-6, p. 5-392, 1944.

Von Arx, J A. Ein Beitrag zur Kenntinis der Pilzflora von Brasilien. Universidade do Recife, 1960.

Von Arx, J A; Müller, E. A re-evaluation of the bitunicate ascomycetes with keys to families and genera. CBS Studies in Mycology. Centraalbureau voor Schimmelcultures, Baarn and Institute of Special Botany, Swiss Federal Institute of Technology, Zurich 1975.

Von Höhnel, F. Fragmente zur Mykologie VI. No. 244. Revision der Myriangiaceen und der Gattung Saccardia. Sitzb. Akad. Wiss. Wien, v. 118, p. 349-376, 1909. 
